\title{
Nearly mode I fracture toughness and fatigue delamination propagation in a multidirectional laminate fabricated by a wet-layup
}

\author{
T. Chocron and L. Banks-Sills
}

\begin{abstract}
The Dreszer Fracture Mechanics Laboratory, School of Mechanical Engineering, Tel Aviv University, Ramat Aviv, 6997801, Israel
\end{abstract}
Five double cantilever beam specimens were tested quasi-statically to obtain a $G_{\mathrm{IR}}$ resistance curve. In addition, nine double cantilever beam specimens were tested in fatigue to obtain a Paris-type relation to describe the delamination propagation rate $\mathrm{d} a / \mathrm{d} N$ where $a$ is delamination length and $N$ is the cycle number. Displacement ratios of $R_{\mathrm{d}}=0.10$ and 0.48 were used for five and four specimens, respectively. The specimens were fabricated by means of a wet-layup process from carbon fiber reinforced polymer plies. The interface containing the delamination was between a unidirectional fabric and a woven ply. The fracture toughness and fatigue delamination propagation protocols are outlined. The mechanical and thermal residual stress intensity factors were obtained by means of finite element analyses and the conservative $M$-integral along the delamination front. They were superposed to determine the total stress intensity factors. It was found that the total mode I stress intensity factor dominates the other two stress intensity factors. Thus, nearly mode I deformation was achieved. Interpolation expressions for the mechanical and thermal residual stress intensity factors were determined using three and two-dimensional fittings, respectively. Results are presented with an expression for $G_{\mathrm{IR}}$ determined. Moreover, the fatigue data is described including threshold values and master-curves. These results shed light on the behavior of delamination propagation in multidirectional laminate composites.

Keywords: constant amplitude, fatigue delamination growth rate, fiber reinforced composites, fracture toughness, resistance curve, $R$-ratio

DOI $10.24411 / 1683-805 X-2018-16014$

\section{Вязкость разрушения типа I и усталостное расслоение слоистого пластика с различной ориентацией волокон, полученного методом мокрого формования}

\author{
T. Chocron, L. Banks-Sills
}

Тель-Авивский университет, Рамат-Авив, 6997801, Израиль

В ходе квазистатических испытаний пяти двухконсольных образцов получена кривая сопротивления $G_{\mathrm{IR}}$. Также проведены испытания девяти двухконсольных образцов на усталость и получено уравнение типа Пэриса для описания скорости распространения расслоения $\mathrm{d} a / \mathrm{d} N$, где $a$ - длина расслоения, $N$ - число циклов. При этом использовали коэффициенты смещения $R_{\mathrm{d}}=$ $=0.10$ и 0.48 для пяти и четырех образцов соответственно. Образцы изготавливали методом мокрого формования из полимерных слоев, армированных углеродным волокном. На границе раздела между однонаправленной тканью и плетеным полотном задавали расслоение. Представлены данные по распространению усталостного расслоения и вязкости разрушения. С использованием анализа методом конечных элементов и $M$-интеграла найдены коэффициенты интенсивности механических и термических остаточных напряжений вдоль фронта расслоения. Путем их наложения определены суммарные коэффициенты интенсивности напряжений. Показано, что коэффициент интенсивности напряжений нормального отрыва доминирует над двумя другими коэффициентами интенсивности напряжений, за счет чего деформация протекает нормальным отрывом. С помощью трехмерного и двумерного сглаживания получены интерполированные выражения для коэффициентов интенсивности механических и термических остаточных напряжений соответственно. Результаты представлены с использованием кривой $G_{\mathrm{IR}}$. Описаны усталостные характеристики, включая пороговые значения и обобщенные кривые. Полученные результаты дают представление о поведении расслоения в слоистых композитах с различной ориентацией волокон.

Ключевые слова: постоянная амплитуда, скорость распространения усталостного расслоения, волокнистые композиты, вязкость разрушения, кривая сопротивления 


\section{Introduction}

Composite materials, in general, and carbon fiber reinforced polymers (CFRP), in particular, have evolved greatly since the 1960s. Currently, composite materials are used in industries, such as automotive manufacturing, air, marine and space structures, civil construction, medical equipment and more. These significant developments, especially in the aerospace industries, stemmed from the fact that polymer composites have low specific weight, with respect to metals. These composites are characterized by high ratios of toughness to weight and strength to weight, which allow them to tolerate defects. These features enable such structures to have longer life cycles and lower fuel consumption, which reduces economic costs [1].

Composite laminates may develop delaminations between plies, as a result of stress raisers, such as corners, free surfaces, an interface between different materials, and more [2]. Quasi-static and cyclic nearly mode I deformation that may cause structural failure are the main focus of this study. For the first, a $G_{\mathrm{IR}}$ resistance curve is determined to characterize the mode I energy release rate $G_{\text {I }}$ which leads to catastrophic delamination propagation for a given delamination length $a$. For the second, a Paris relation between delamination propagation length per cycle $\mathrm{d} a / \mathrm{d} N$ and a function of $G_{\mathrm{I}}, f\left(G_{\mathrm{I}}\right)$, is obtained as

$$
\frac{\mathrm{d} a}{\mathrm{~d} N}=D\left[f\left(G_{\mathrm{I}}\right)\right]^{m}
$$

In Eq. (1), $D$ and $m$ are power law fitting constants. A number of investigations [3-10] made use of Eq. (1) with various functions for $f\left(G_{\mathrm{I}}\right)$.

In Sect. 2, the material and specimen used in this study are presented. In addition, the test protocol for each test type is discussed, including a description of the test setup. Obtaining the integrated averaged mode I energy release rate is discussed in Sect. 3 for determining $G_{\mathrm{IR}}, G_{\mathrm{Imax}}$ and $G_{\text {Imin }}$. For fatigue, the method of calculating $a$ and $\mathrm{d} a / \mathrm{d} N$ for each cycle is described in Sect. 3, as well. In Sect. 4, the results from fracture toughness and fatigue delamination propagation tests are presented. In addition, a technique for determining $G_{\mathrm{I}}$ threshold values and achieving master curves will be described. Finally, a discussion and

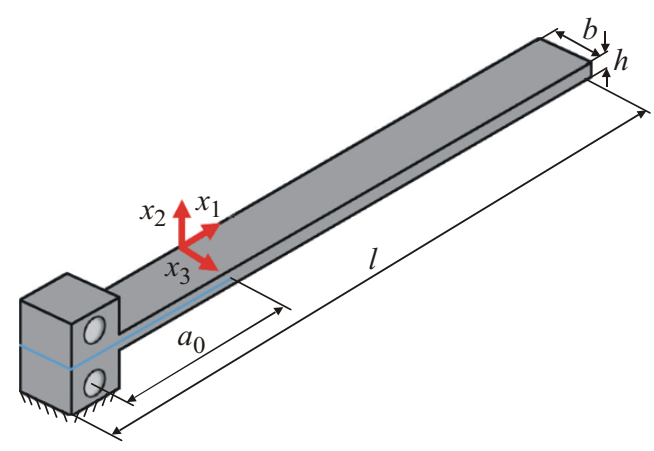

Fig. 1. DCB specimen with load blocks (color online) conclusions of this investigation is presented in Sect. 5. It may be noted that there is a separate section entitled: Supplementary material, where all sections, figures and tables are enumerated with a prefix $\mathrm{S}$.

\section{Material and methods}

\subsection{Specimen and material}

The specimen used in this study is the double cantilever beam (DCB) as presented in Fig. 1. Load blocks were used to apply opening displacements. The specimen length, width and thickness are $l, b$ and $h$, respectively. The initial delamination length $a_{0}$ was measured from the center of a load block hole to the delamination front. All specimens were fabricated by a water jet process from the same plate. The width and thickness ranges, for all specimens, were between 19.74 and $20.08 \mathrm{~mm}$ and between 4.75 and $5.01 \mathrm{~mm}$, respectively. The length of all specimens was about $200 \mathrm{~mm}$ and $a_{0}$ was about $54 \mathrm{~mm}$. The measurements were carried out guided by the standards in $[11,12]$ with some differences as described in Sect. S1 of the Supplementary material. The specimen measurements for the fracture toughness test specimens are presented in Table S1; those for fatigue delamination propagation test specimens may be found in Tables S2 to S4. It should be noted that the standards are for unidirectional (UD) material; whereas, the specimens considered here consist of a multidirectional (MD) laminate.

The composite laminate was fabricated from carbon fibers in an epoxy matrix with a small amount of glass fibers in the UD ply. The mechanical properties and coefficients of thermal expansion (CTEs) of those three constituents are presented in Table S5. The laminate consisted of 19 plies of three different types as illustrated in Fig. 2. The first type is a UD-fabric with carbon fibers in the $0^{\circ}$-direction (along the $x_{1}$-axis) which included a small percentage of glass fibers transverse to the carbon fibers. The two other ply types are plain, balanced weaves with tows in the $0^{\circ} \%$ $90^{\circ}$ and the $+45^{\circ} /-45^{\circ}$-directions, respectively. The upper ply of the interface is the UD-fabric and the lower ply is the weave with tows in the $+45^{\circ} /-45^{\circ}$-directions as shown in Fig. 2. The laminate was manufactured by means of a wetlayup and cured in an oven at $85^{\circ} \mathrm{C}$.

The weight fraction of each component (carbon and glass fibers, epoxy and voids) in each ply were found by dissolving the matrix in an acid bath. For the UD fabric, the carbon was burned off to measure the weight fraction of the glass fibers. The equivalent volume fractions are presented in Table S6. The material properties of the constituents, as well as their volume fractions were used as input to the high-fidelity generalized method of cells (HFGMC) micromechanical model [13] to obtain the effective mechanical and thermal properties of the UD-fabric and the weave. These properties are presented in Tables S7 and S9, respectively. The UD-fabric is modeled to be transversely 

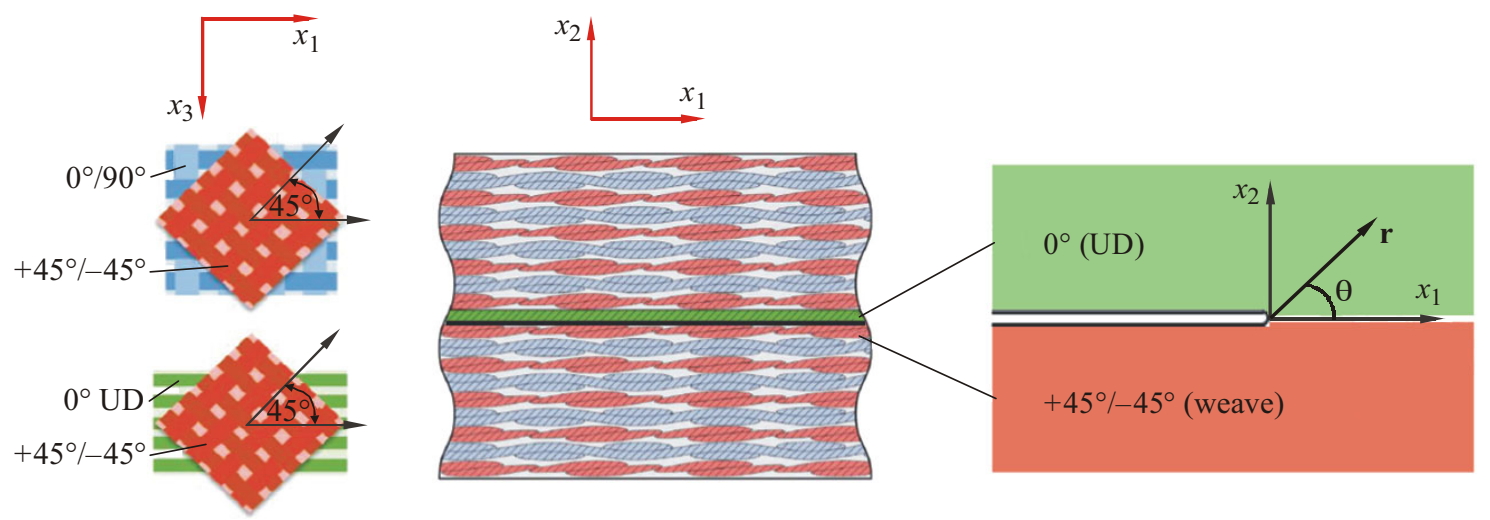

Fig. 2. Laminate plies and interface (color online)

isotropic [14] with five independent effective mechanical properties and two CTEs. The glass fibers were accounted for by increasing the Young's modulus of the matrix by means of the rule of mixtures. The weave is tetragonal [14] and described by six independent effective mechanical properties and two CTEs.

\subsection{Fracture toughness test protocol}

The fracture toughness standards $[11,12]$ make use of a DCB specimen to measure the mode I delamination toughness of UD laminates. These standards were used as guidance in testing the MD laminate composed of a UD-fabric and woven plies. It is emphasized that the delamination is between two plies with fibers in different directions making it an interface crack between two effectively anisotropic (homogeneous) materials. Moveover, the delamination plane is not a symmetry plane. Thus, there are three deformation modes: 1, 2 and III. The contribution of the shear modes will be discussed in the sequel.

The test protocol used here followed the two standards and that developed in [10]. Fracture toughness tests were performed on five DCB specimens denoted as FT-wet-1-0 $j$ $(j=4, \ldots, 8)$; FT represents fracture toughness; wet indicates that the specimens were fabricated by means of a wetlayup; the first numeral represents the batch number; the second numeral represents the specimen location in the plate, with respect to the other specimens.

The system used in the test is described in Sect. S3 and presented in Fig. S5 in the Supplementary material. As prescribed in the standards, the tests were conducted under displacement control. Automatic test instructions were written using Instron WaveMatrix computer software [15] which interacts with the Instron servohydraulic loading machine (model number 8872; High Wycombe, England) used in the tests. An Instron $250 \mathrm{~N}$ Dynacell load cell was used with an accuracy of about $\pm 0.25 \%$ of the measured load greater than $2.5 \mathrm{~N}$. In the first test stage, the displacement rate was set to increase at $1 \mathrm{~mm} / \mathrm{min}$, until a load drop of at least $2 \mathrm{~N}$ occurred or the delamination propagated between
3 and $5 \mathrm{~mm}$, as prescribed in the standards. Then, the specimen was unloaded with a displacement rate of $4 \mathrm{~mm} / \mathrm{min}$ until the value of the load acting on the specimen was $3 \mathrm{~N}$. A small positive load was chosen so as not to induce compression in the specimen. The standards recommend a displacement rate of between 0.5 and $5 \mathrm{~mm} / \mathrm{min}$ for loading; for unloading, the displacement rate should be less than $25 \mathrm{~mm} / \mathrm{min}$. The rates used in this protocol were in keeping with the standards. In the next step, the displacement rate was again set to $1 \mathrm{~mm} / \mathrm{min}$. This displacement rate was used until the delamination propagated by at least $60 \mathrm{~mm}$. Finally, in the last step of the test, unloading was performed to $3 \mathrm{~N}$ with a displacement rate of $8 \mathrm{~mm} / \mathrm{min}$. Every $0.5 \mathrm{~s}$ during a test, an image was taken using a LaVision digital camera (model Imager Pro SX, Göttingen, Germany). From the images and after the test, it was possible to measure the delamination length $a$ as it propagated. Concurrently, values of the load and displacement were also recorded. It may be noted that there was full synchronization between the load, displacement and images. Each test took approximately $60 \mathrm{~min}$. The specimens were stored in an environmental conditioning chamber (M.R.C. BTH80/-20, Holon, Israel) at least one week before a test was performed with a temperature of $23 \pm 1^{\circ} \mathrm{C}$ and a relative humidity (RH) of $50 \pm 3 \%$. The ASTM standard requires a temperature of $23 \pm 3^{\circ} \mathrm{C}$ and relative humidity of $50 \pm 10 \%$. During each test, the room temperature and $\mathrm{RH}$ were measured every five minutes.

\subsection{Fatigue test protocol}

Tests were performed on five specimens, FTG-wet-1-0j $(j=9, \ldots, 13)$ with a cyclic displacement ratio $R_{\mathrm{d}}=0.10$, and on four, FTG-wet- $1-0 j(j=14, \ldots, 17)$ with $R_{\mathrm{d}}=0.48$; FTG represents fatigue and $R_{\mathrm{d}}$ is given by

$$
R_{\mathrm{d}}=d_{\text {min }} / d_{\text {max }} \text {. }
$$

In Eq. (2), $d_{\min }$ and $d_{\max }$ are the minimum and maximum actuator displacements, respectively, during a constant amplitude fatigue test. In theory, $R_{\mathrm{d}}$ should be equal to the cyclic load ratio $R_{\mathrm{p}}$ which is given by 

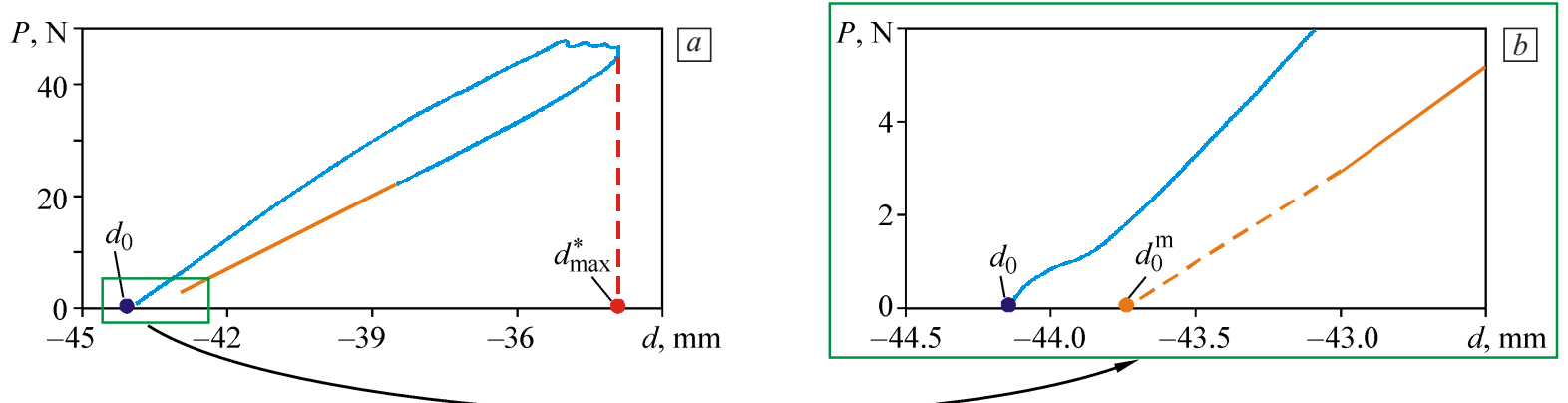

Fig. 3. Actuator displacement values: $d_{0}$ and $d_{\max }^{*}(a)$ and $d_{0}^{\mathrm{m}}(b)$ (color online)

$$
R_{\mathrm{p}}=P_{\min } / P_{\max },
$$

where $P_{\min }$ and $P_{\max }$ are the minimum and maximum loads, respectively, acting during a fatigue cycle. In practice, $R_{\mathrm{d}}$ and $R_{\mathrm{p}}$ are not equal. The only standard dealing with mode I fatigue deformation is Ref. [16]. This standard focuses on determining the number of cycles $N$ leading to delamination propagation initiation as a function of the mode I maximum energy release rate $G_{\text {Imax }}$ in a cycle for a DCB UD laminate specimen. Currently, there is no standard for delamination propagation of MD laminates, and in particular, for woven plies. Since the present study focuses on delamination propagation, the test protocol is different from that described in the standard; rather, it follows that presented in [10]. However, this study is consistent with the spirit of the standard in preparation of the specimens, use of suitable equipment, maintenance of environmental conditions, etc.

The system used for the fatigue tests is the same as that used for the fracture toughness tests. Again, displacement control was applied. Every 10 or 15 min during the tests, measurements of temperature and $\mathrm{RH}$ were recorded. These tests lasted up to 9 days running continuously.

Correctly determining the actuator position is an important aspect in the test procedure. The position of the actuator, once connected to the specimen, was recorded as $d_{0}$ as shown in Fig. 3. First, a quasi-static opening displacement at a rate of $1 \mathrm{~mm} / \mathrm{min}$ was applied in order to propagate the delamination between 3 and $5 \mathrm{~mm}$, as indicated in the standard. The procedure was carried out as described in Sect. 2.2 for the fracture toughness tests. The maximum actuator displacement $d_{\max }^{*}$ was recorded as shown in Fig. 3, $a$. It is used as the maximum displacement in the fatigue tests. Next, unloading was performed at a rate of $8 \mathrm{~mm} / \mathrm{min}$ until the load $P=3 \mathrm{~N}$ was reached. There are two difficulties associated with the test system. The first problem relates to the uncertainty in a load less than $2.5 \mathrm{~N}$ as explained in Sect. 2.2. This is especially problematic for $R_{\mathrm{d}}=0.10$. The second problem results from some freedom in the test system which may be a result of the connections between the specimen and the test machine. It may be observed in Fig. 3, $b$ in the load-displacement $(P-d)$ curve that the minimum displacement does not return to its initial position $d_{0}$. The unloading curve was extrapolated linearly as shown by the dotted orange line in Fig. 3, $b$ to obtain the expected position $d_{0}^{m}$ for $P=0$. The maximum actuator displacement in a fatigue cycle relative to its position at $d_{0}^{m}$ is defined as $d_{\max }$ and given as

$$
d_{\max }=d_{\max }^{*}-d_{0}^{m} \text {. }
$$

For a given value of $R_{\mathrm{d}}$, it is possible to determine the minimum displacement $d_{\min }$ of the actuator in a fatigue cycle relative to its position at $d_{0}^{m}$ as

$$
d_{\text {min }}=d_{\text {max }} R_{\mathrm{d}} \text {. }
$$

With the values of $d_{\max }$ and $d_{\min }$, the cyclic amplitude $A$ is found as

$$
A=\left(d_{\text {max }}-d_{\text {min }}\right) / 2 \text {. }
$$

An algorithm was written using the WaveMatrix software to control the test machine. The data entered into the algorithm includes $d_{\max }^{*}, A$, the test frequency $f$, and the maximum number of cycles $N$. The values of $R_{\mathrm{d}}, N$ and $f$ for each specimen are presented in Table 1 . The data which is inserted into the algorithm is sufficient to define a fatigue test. Also, the measurement frequency $\Delta t$ of temperature and RH, during each test, is also given in Table 1. For each cycle, the values of $P_{\max }$ and $P_{\min }$, as well as $d_{\max }$

Table 1

Displacement ratio, number of cycles, frequency and measurement frequency of temperature and $\mathrm{RH}$ in fatigue tests

\begin{tabular}{c|c|c|c|c}
\hline Specimen & $R_{\mathrm{d}}$ & $N$ & $f, \mathrm{~Hz}$ & $\Delta t, \mathrm{~min}$ \\
\hline FTG-wet-1-09 & 0.10 & $1.35 \times 10^{6}$ & 5 & 10 \\
\hline FTG-wet-1-10 & 0.10 & $2.70 \times 10^{6}$ & 4 & 10 \\
\hline FTG-wet-1-11 & 0.10 & $3.00 \times 10^{6}$ & 4 & 10 \\
\hline FTG-wet-1-12 & 0.10 & $3.00 \times 10^{6}$ & 4 & 15 \\
\hline FTG-wet-1-13 & 0.10 & $3.00 \times 10^{6}$ & 4 & 15 \\
\hline FTG-wet-1-14 & 0.48 & $0.47 \times 10^{6}$ & 5 & 15 \\
\hline FTG-wet-1-15 & 0.48 & $3.00 \times 10^{6}$ & 5 & 15 \\
\hline FTG-wet-1-16 & 0.48 & $3.00 \times 10^{6}$ & 5 & 15 \\
\hline FTG-wet-1-17 & 0.48 & $3.00 \times 10^{6}$ & 5 & 15 \\
\hline
\end{tabular}




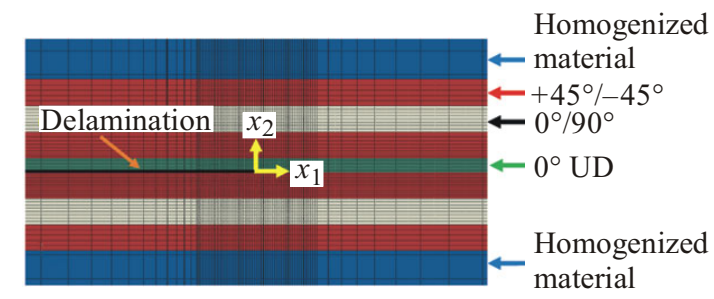

Fig. 4. Distribution of plies in the DCB finite element model (color online)

and $d_{\min }$ were recorded. The number of cycles desired for each specimen was $3 \times 10^{6}$. In Table 1, it is possible to observe that not all specimens experienced the full number of cycles. An explanation is detailed in Sect. 4.

\section{Theory and calculations}

In this section, the process for obtaining various required quantities will be described. In Sect. 3.1, details about the finite element analyses (FEAs) used in this study are discussed. In addition, the integrated average of the mode I energy release rate along the delamination front is presented so that $G_{\text {IR }}, G_{\text {Imax }}$ and $G_{\text {Imin }}$ may be determined. In Sects. 3.2 and 3.3, respectively, the methods for obtaining the delamination length $a$ in each fatigue cycle and the delamination length per cycle $\mathrm{d} a / \mathrm{d} N$ are described. Several choices for $f\left(G_{\mathrm{I}}\right)$ in Eq. (1) are presented in Sect. 3.4.

\subsection{Finite element analyses to obtain $\bar{G}_{\mathrm{I}}$}

Finite element analyses of the DCB specimens were carried out using the program ABAQUS [17]. Four plies directly above the interface and three plies directly below it were modeled using the effective material properties found for each ply. In order to reduce computation time and computer memory required, the six outer upper and outer lower plies were modeled as one effective homogenous, anisotropic material (see Fig. 2). These plies are relatively far from the delamination/interface. The material properties of all plies are presented in Sect. S2. There were four types of materials used in the FEAs including the UD-fabric, the $+45^{\circ} /-45^{\circ}$ weave, the $0^{\circ} / 90^{\circ}$ weave and the outer homogenized, anisotropic material. The effective mechanical properties of the latter are presented in Table S10; whereas, the thermal properties are the same as those for the woven plies given in Table S9. In Fig. 4, the distribution of the plies in the finite element model is illustrated. Since the homogenized outer material is truncated in Fig. 4, its thickness is not to scale relative to the other plies. In Sect. S4, a convergence study to determine an optimal mesh is described.

Next, the stress intensity factors resulting from the mechanical loading $K_{m}^{(\mathrm{f})}(m=1,2$, III), as well as the thermal residual curing stresses $K_{m}^{(\mathrm{r})}(m=1,2, \mathrm{III})$, arising from the autoclave process, are considered. For each specimen, seven FEAs were performed to determine the displacement field in the specimen including six mechanical analyses and one thermal analysis. All seven analyses were carried out in the same manner as described in Sect. S4 with a mesh similar to that shown in Fig. S8. The refined region of the mesh remains the same as that shown in Fig. S8. Since it is placed surrounding the delamination front, a change in the delamination length translates the location of the refined region.

For mechanical analyses, the applied load was taken to be $1 \mathrm{~N}$. Six delamination lengths were used in the fracture toughness and fatigue models. For fracture toughness: $a_{1}=50 \mathrm{~mm}, a_{2}=65 \mathrm{~mm}, a_{3}=80 \mathrm{~mm}, a_{4}=95 \mathrm{~mm}, a_{5}=$ $=110 \mathrm{~mm}$, and $a_{6}=120 \mathrm{~mm}$; for fatigue: $a_{1}=50 \mathrm{~mm}$, $a_{2}=55 \mathrm{~mm}, a_{3}=60 \mathrm{~mm}, a_{4}=65 \mathrm{~mm}, a_{5}=70 \mathrm{~mm}$, and $a_{6}=80 \mathrm{~mm}$. These delamination length ranges span the lengths achieved during the tests. Using the conservative mechanical $M$-integral, which was extended in [18] for the interface shown in Fig. 2, six sets of mechanical stress intensity factors, $K_{m}^{(\mathrm{f})}(m=1,2$, III) were obtained for each specimen, along the delamination front, for each delamination length $a_{n}(n=1,2, \ldots, 6)$. Of the six sets obtained from the mechanical analyses, it is possible to assemble the data in a three-dimensional space. The data included points $\left[K_{m}^{(\mathrm{f})}, a, x_{3}\right]$ for each of the three stress intensity factors ( $m=1,2$, III). A three-dimensional surface was fit through the points for each mechanical stress intensity factor as shown in Fig. 5. In addition, a functional relation was obtained relating $K_{m}^{(\mathrm{f})}$ to $a$ and $x_{3}$ which is given by

$$
K_{m}^{(\mathrm{f})}=\sum_{i=0}^{5} p_{i 0}\left(\frac{x_{3}}{b}\right)^{i}+\sum_{i=0}^{4} p_{j 1}\left(\frac{x_{3}}{b}\right)^{j} \frac{a}{a_{0}}
$$

In Eq. (7), $p_{i 0}$ and $p_{j 1}$ are surface fitting parameters, $b$ and $a_{0}$ are, respectively, the width and initial delamination length of the specimen as shown in Fig. 1. Using any value of $a, K_{m}^{(\mathrm{f})}$ may be expressed as a function of $x_{3}$, namely $K_{m}^{(\mathrm{f})}\left(x_{3}\right)$. The fitting parameters for the fracture toughness specimens may be found in Tables S13 to S17 and for the fatigue specimens in Tables S23 to S31.

For the thermal analysis, a constant temperature change was applied given by

$$
\Delta \vartheta=\vartheta_{i}-90^{\circ} \text {. }
$$

In Eq. (8), $\vartheta_{i}$ was selected as the value of the temperature at the beginning of the test for each specimen. These values are presented in Tables S41 and S45, for fracture toughness and fatigue delamination propagation tests, respectively. In Eq. (8), the value of $90^{\circ} \mathrm{C}$ is the maximum temperature measured during the curing process at five thermocouples placed within the composite plate. There was an exothermic reaction. For the thermal analyses, a delamination length of $a=85 \mathrm{~mm}$ for the fracture toughness tests and $a=65 \mathrm{~mm}$ for fatigue tests were selected. One analysis, instead of six, was sufficient for each specimen; it was found that the delamination length has a negligible effect on the residual curing stress intensity factors $K_{m}^{(\mathrm{r})}$. Using 

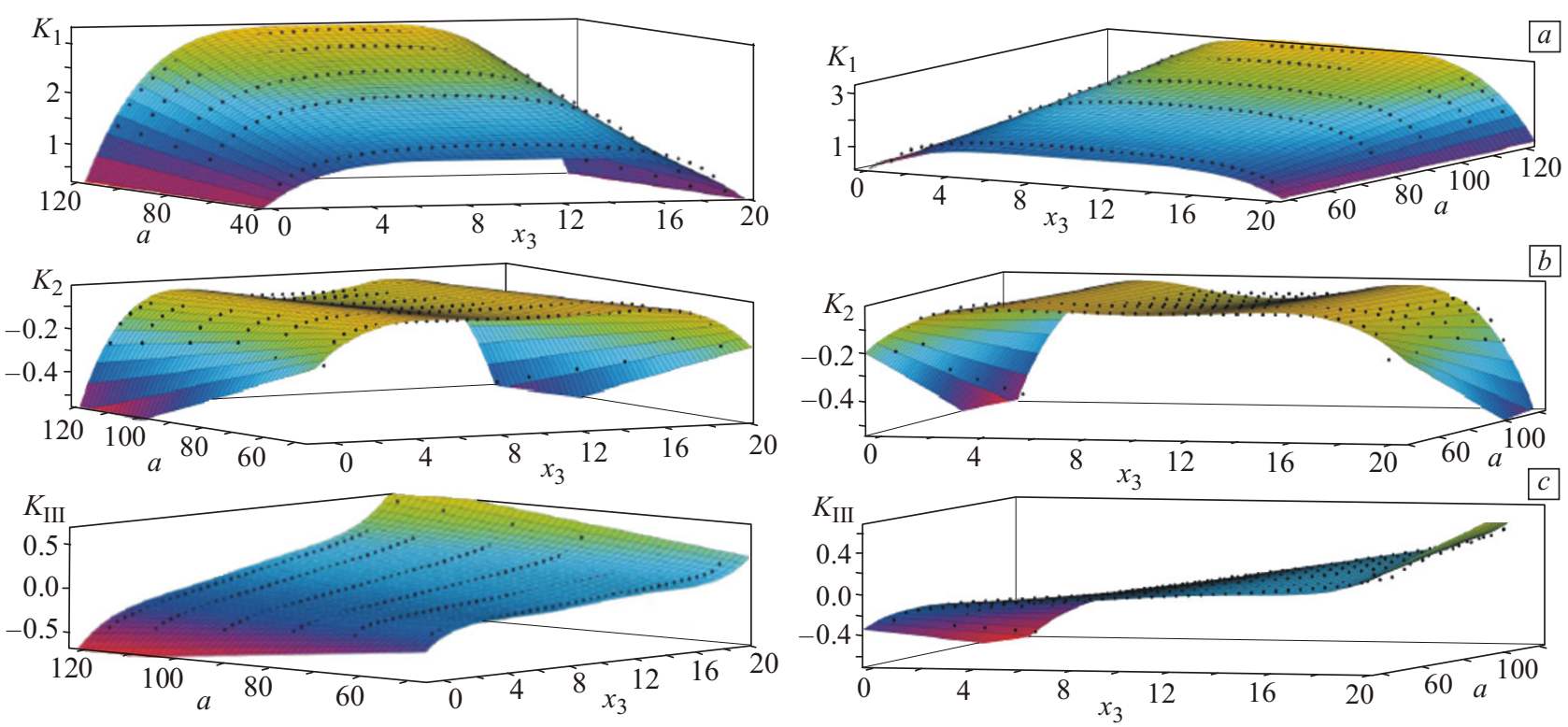

Fig. 5. Surface fitting examples of $K_{m}^{(\mathrm{f})}$ as a function of $a$ and $x_{3}$; two views of $K_{1}^{(\mathrm{f})}(a), K_{2}^{(\mathrm{f})}(b)$, and $K_{\mathrm{III}}^{(\mathrm{f})}(c)$ (color online)

the thermal $M$-integral [18], a single set of $K_{m}^{(\mathrm{r})}$ was obtained for each specimen, along the delamination front. From the set obtained from the thermal analyses, a mathematical relation between $K_{m}^{(\mathrm{r})}$ and $x_{3}$ was found using a 14th-order polynomial defined as

$$
K_{m}^{(\mathrm{r})}=\sum_{i=0}^{14} d_{i}\left(\frac{x_{3}}{b}\right)^{i},
$$

where $d_{i}$ are fitting constants. For the fracture toughness specimens, $d_{i}$ may be found in Tables S18 to S22; for the fatigue specimens, see Tables S32 to S40.

The total stress intensity factors $K_{m}^{(\mathrm{t})}$ may be calculated as a function of $x_{3}$ for each cycle in the test as

$$
K_{m}^{(\mathrm{t})}\left(x_{3}\right)=P K_{m}^{(\mathrm{f})}\left(x_{3}\right)+K_{m}^{(\mathrm{r})}\left(x_{3}\right) .
$$

The parameter $P$ in Eq. (10) is the load leading to delamination propagation in a fracture toughness test or $P_{\max }$ or $P_{\min }$ from the fatigue tests. Through the images, the given load $P$ is associated with the delamination length $a$ and used in Eq. (7). With $K_{m}^{(\mathrm{t})}$ a function of $x_{3}$, for a given value of $a$ and $P$, it is possible to obtain the interface energy release rate as a function of $x_{3}$ as

$$
G_{i}=\frac{1}{H_{1}}\left[K_{1}^{(\mathrm{t}) 2}+K_{2}^{(\mathrm{t}) 2}\right]+\frac{1}{H_{2}} K_{\mathrm{III}}^{(\mathrm{t}) 2} .
$$

By calculating the phase angles in Eqs. (S7) and (S8) [19], it is shown in Sect. S4 that they are less than $0.2 \mathrm{rad}$ along the delamination front for a wide range of examples. Thus, $G_{i}$ in Eq. (11) is replaced by $G_{\mathrm{I}}$ in this study. In Eq. (11), $H_{1}$ and $H_{2}$ which are related to the mechanical properties of the plies on either side of the interface were found to be 7.87 and $10.49 \mathrm{GPa}$, respectively.

An integrated average for $G_{\mathrm{I}}\left(x_{3}\right)$, along the delamination front, leads to

$$
\bar{G}_{\mathrm{I}}=\frac{1}{b} \int_{0}^{b} G_{\mathrm{I}}\left(x_{3}\right) \mathrm{d} x_{3},
$$

where $b$ is the specimen width. If $P$ in Eq. (10) is the load for delamination propagation in a fracture toughness test, then $\bar{G}_{\mathrm{I}}$ in Eq. (12) is identified as $\bar{G}_{\mathrm{IR}}$ for the corresponding delamination length $a$. On the other hand, if $P$ in Eq. (10) is chosen as $P_{\max }$ or $P_{\min }, \bar{G}_{\mathrm{I}}$ in Eq. (12) would be $\bar{G}_{\text {Imax }}$ and $\bar{G}_{\text {Imin }}$, respectively, for the appropriate delamination length $a$. In the sequel, the overbar is omitted and the energy release rates are understood to be averaged through the specimen width.

\subsection{Delamination length in each fatigue cycle}

In this section, the method for determining the delamination length during a particular fatigue cycle is presented. For each cycle in a fatigue test, the values of the maximum and minimum loads and displacements, $P_{\max }, P_{\min }, d_{\max }$ and $d_{\text {min }}$, respectively, were recorded. From these values, the compliance $C$ was calculated in each cycle as

$$
C=\frac{d_{\max }-d_{\min }}{P_{\max }-P_{\min }} .
$$

To proceed, the delamination lengths from the specimen images, taken during the test, were measured using ImageJ software [20]. The corresponding compliance values from Eq. (13) were known as a result of the synchronization between load, displacement and image number. Points of compliance versus delamination length were plotted as shown as red $\times$ in Fig. 6 for specimen FTG-wet-1-09. For these points, an expression was found as

$$
a=g C^{n},
$$

where the parameters $g$ and $n$ are power law fitting parameters. For specimen FTG-wet-1-09, the values of $g, n$ and 


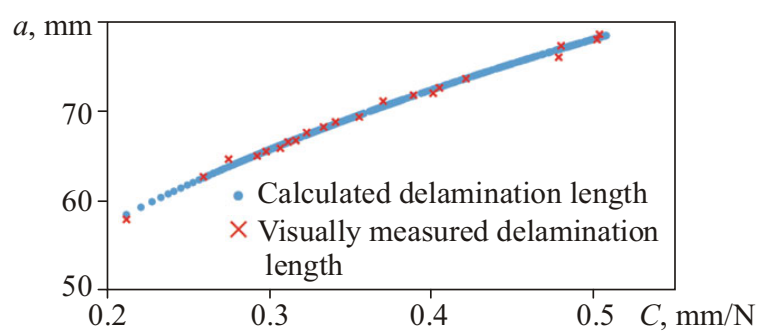

Fig. 6. Delamination length versus compliance in a fatigue test for specimen FTG-wet-1-09 (color online)

the coefficient of determination $R^{2}$ were found as 98.97 , 0.3386 , and 0.9949 , respectively. Values for all other specimens may be found in Table S43. Using the relationship from Eq. (14) and knowledge of the compliance values in each cycle, it was possible to calculate the approximate delamination length in each cycle which is shown as blue dots in Fig. 6. It may be observed that there is good agreement between the measured and calculated values of $a$.

\subsection{Delamination propagation rate $\mathrm{d} a / \mathrm{d} N$ in each cycle}

A method is presented for determining delamination length $a$ as a function of the cycle number $N$, in each cycle of the test. Differentiating this function with respect to $N$ leads to the relation between $\mathrm{d} a / \mathrm{d} N$ and $N$, in each cycle. In many studies, a seven (or another number) point incremental fit was used to obtain a relation between $a$ and $N$, in each cycle of the test. This method is described in [21]. In [10], it was shown that the seven point incremental fit leads to much scatter in the relationship between $a$ and $N$. Instead, the relation [10]

$$
a=A_{1}\left(N+B_{1}\right)^{B_{2}}+A_{2}
$$

was proposed, where $B_{1}$ and $B_{2}$ are arbitrary nondimensional parameters. Using these parameters, together with $N$, a value of $\left(N+B_{1}\right)^{B_{2}}$ was defined for each cycle so that points $\left[a,\left(N+B_{1}\right)^{B_{2}}\right]$ were plotted, where $a$ was obtained from Eq. (14). The parameters $A_{1}$ and $A_{2}$ with units of $\mathrm{mm}$ were determined from a linear fit of these points, together with the coefficient of determination $R^{2}$.

Using the "solver" function of [22], the value of $R^{2}$ for Eq. (15) was calculated with $B_{1}$ and $B_{2}$ varying between -10000 and 10000 , until the best value of $R^{2}$ was obtained. The solver function uses a nonlinear generalized reduced gradient (GRG). The solver increments the values of $B_{1}$ and $B_{2}$ so that the value of $R^{2}$ increases. When the value of $R^{2}$ ceases to increase, the solver stops and produces the relevant values of $A_{1}, A_{2}, B_{1}, B_{2}$ and $R^{2}$. This method produces a local maximum for $R^{2}$ in a range of $B_{1}$ and $B_{2}$ and not necessarily the global maximum. Therefore, it is necessary to run the solver multiple times with different initial values for $B_{1}$ and $B_{2}$. Moreover, existence of a high value for $R^{2}$ was not the final step taken to verify
Eq. (15). Equation (15) was compared to the visually obtained measurements of $a$ from the images taken during the test. For specimen FTG-wet-1-09, the values of $A_{1}, A_{2}$, $B_{1}, B_{2}$, and $R^{2}$ of Eq. (15) were found to be $5.74 \mathrm{~mm}$, $50.42 \mathrm{~mm},-62.36,0.114$, and 0.9975 , respectively. For all specimens, see Table S44. In Fig. 7, a plot of delamination length as a function of the cycle number for specimen FTGwet-1-09 is presented. Points marked with a red $\times$ are visually obtained measurements of delamination lengths using the images taken during the test. In addition, the green curve describes Eq. (15). Note that the visual measurements from the test and Eq. (15) are well correlated. Differentiating Eq. (15) by the cycle number $N$ leads to

$$
\frac{\mathrm{d} a}{\mathrm{~d} N}=A_{1} B_{1}\left(N+B_{1}\right)^{B_{2}-1}
$$

\subsection{Relation between $\mathrm{d} a / \mathrm{d} N$ and $G_{\mathrm{I}}$}

In [10], normalized functions for $f\left(G_{\mathrm{I}}\right)$ in Eq. (1) were considered such as

$$
f\left(G_{\mathrm{I}}\right)=\hat{G}_{\mathrm{Imax}}=\frac{G_{\mathrm{Imax}}}{G_{\mathrm{IR}}}
$$

and

$$
f\left(G_{\mathrm{I}}\right)=\Delta \hat{G}_{\text {Ieff }}=\left(\sqrt{\hat{G}_{\text {Imax }}}-\sqrt{\hat{G}_{\text {Imin }}}\right)^{2},
$$

where $\hat{G}_{I \min }$ is defined similarly to $\hat{G}_{\text {Imax }}$ in Eq. (17). The parameter $G_{\mathrm{IR}}$ in Eq. (17) is taken from the $G_{\mathrm{IR}}$-curve for a specific delamination length; that is, during a fatigue test as $a$ increases, $G_{\mathrm{IR}}$ increases until it reaches its steady state value. By substituting Eq. (17) into Eq. (1), it is possible to plot $\mathrm{d} a / \mathrm{d} N$ versus $\hat{G}_{\text {Imax }}$ on a log-log scale for various values of the cycle ratio $R$ as shown schematically in Fig. 8a. For each $R$-ratio, the same asymptotic value (at high values of $\mathrm{d} a / \mathrm{d} N$ ) giving the cycle fracture toughness are found for all curves. For low values of $\mathrm{d} a / \mathrm{d} N$, each curve approaches a different threshold value which increases with $R$. Next consider substituting Eq. (18) into Eq. (1); one may obtain the plot shown in Fig. 8, $b$. It may be observed that the same threshold value is obtained for each curve, independent of $R$. Moreover, each curve approaches a different value (at high values of $\mathrm{d} a / \mathrm{d} N$ ), increasing as $R$ decreases. It may be observed that the slopes of the linear part of the curves are high. In [10], the values of $m$ in Eq. (1)

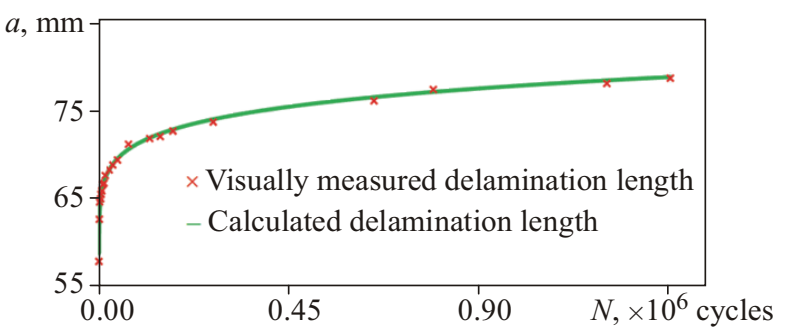

Fig. 7. Delamination propagation in fatigue test for specimen FTGwet-1-09 (color online) 

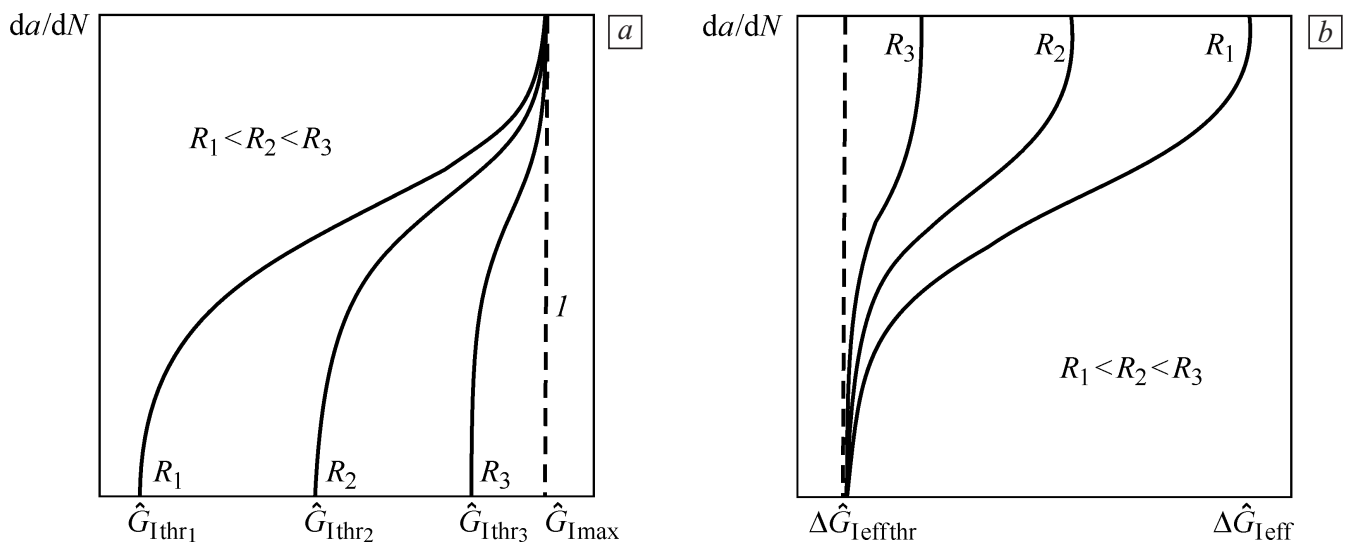

Fig. 8. Schematic description of fatigue test data for different cycle ratios on a $\log -\log$ scale: $\mathrm{d} a / \mathrm{d} N$ versus $\hat{G}_{\text {Imax }}(a)$ and $\Delta \hat{G}_{\text {Ieff }}(b)$ (courtesy of [10])

were between 7 and 27 for $0.10 \leq R_{\mathrm{d}} \leq 0.75$. When comparing slopes obtained for metals using stress intensity factors in a Paris relation, the powers for $f\left(G_{\mathrm{I}}\right)$ must be multiplied by a factor of 2 . Thus, for a small change or error in the applied load, the delamination growth rate is very high making this approach difficult for use in a damage tolerance paradigm.

Hence, a function used originally for metals [23] was adapted in [4] by defining the function

$$
f\left(G_{\mathrm{I}}\right)=\Delta K_{1}=\frac{\sqrt{G_{\text {Imax }}}-\sqrt{G_{\text {Ithr }}}}{\sqrt{1-\sqrt{G_{\text {Imax }} / A}}}
$$

and used in $[8,9]$. In Eq. (19), $G_{\text {Ithr }}$ is the threshold value of $G_{\text {Imax }}$ from which there will be no delamination propagation and $A$ is a constant which may be thought of as the cyclic fracture toughness. In [4], the value of $m$ in Eq. (1) was fixed at 2 and various material sets for modes I and II, and mixed mode I/II were examined for UD material. For each material, a value of $D$ in Eq. (1) was fixed and $G_{\text {Ithr }}$ and $A$ were varied. In [8], values of $m$ varied between 2.4 and 7.5. In [9], a master curve was achieved using Eq. (19) for a large data set, by taking $A$ to be the value of $G_{\text {Ic }}$, varying $G_{\mathrm{Ithr}}$ and determining $m=2.65$. With a master curve, all the data collapses about one straight line.

Equation (19) was normalized in [10] resulting in

$$
f\left(G_{\mathrm{I}}\right)=\Delta \bar{K}_{2}=\frac{\sqrt{\hat{G}_{\text {Imax }}}-\sqrt{\hat{G}_{\text {Ithr }}}}{\sqrt{1-\sqrt{\hat{G}_{\text {Imax }}}}},
$$

where the hat quantities are as in Eq. (17). In [10], Eq. (20) was substituted into Eq. (1) yielding a master curve which is independent of the cyclic load or displacement ratio for the material system described there. A value for $\hat{G}_{\text {Ithr }}$ was obtained by examining the test data. By fitting Eq. (1) to the test data, a slope of $m=5.2$ was found. It would appear that with these lower slopes for both Eqs. (19) and (20) as compared to the functions in Eqs. (17) and (18), the delami- nation would propagate more slowly. It was shown in [10], that for a small change in $\hat{G}_{\text {Imax }}$, there is a large change in $\mathrm{d} a / \mathrm{d} N$, as well as $\Delta \bar{K}_{2}$. Hence, a small slope for the latter function does not ameliorate the large change in $\mathrm{d} a / \mathrm{d} N$. Moreover, using Eq. (20), the full $\mathrm{d} a / \mathrm{d} N$ curves were recalculated as functions of $\hat{G}_{\text {Imax }}$ and $\Delta \hat{G}_{\text {Ieff }}$ as shown schematically in Fig. 8.

\section{Results}

In Sects. 4.1 and 4.2, respectively, the fracture toughness and fatigue delamination propagation test results are presented. The fatigue thresholds for the two models considered here are determined in Sect. 4.3. In Sect. 4.4, two master curves making use of Eqs. (19) and (20) are obtained. Using the master curve found with Eq. (20), a full set of data is back-calculated in Sect. 4.5.

\subsection{Fracture toughness test results}

Fracture toughness tests were carried out on a set of 5 DCB specimens. Additional information about the tests is presented in Sect. S5 in the Supplementary material.

The specimens were analyzed by means of the finite element method to determine the stress intensity factors as described in Sect. 3.1. The values of $p_{i 0}$ and $p_{j 1}(i=0$, $1, \ldots, 5$ and $j=0,1, \ldots, 4)$ from Eq. (7), and $d_{i}(i=0,1, \ldots$, 14) from Eq. (9), are presented for each specimen in Tables S13 through S22. Values of load and displacement were recorded during the test producing load-displacement $(P-d)$ curves which are presented in Fig. S9. Since the system compliance was $0.5 \%$ less than the compliance of the specimen, the actuator displacement $d$ was used in place of the load-line displacement. Using the appropriate loads and delamination lengths, the total stress intensity factors in Eq. (10) were obtained. It was found that the value of $K_{1}^{(\mathrm{t})}$ was much greater than the other two stress intensity factors. Further details are given in Sect. S4. Thus, it may be concluded that the tests produce nearly mode I deforma- 


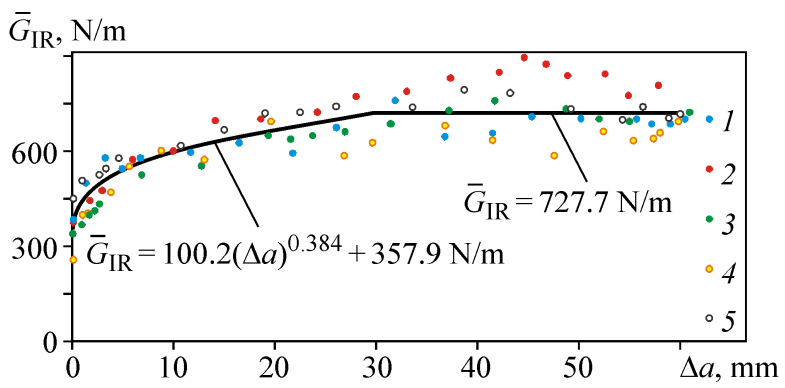

Fig. 9. Resistance curve $G_{\mathrm{IR}}$ versus $\Delta a=a-a_{0}$ : FT-wet-1-04 (1), FT-wet-1-05 (2), FT-wet-1-06 (3), FT-wet-1-07 (4), FT-wet-1-08 (5) (color online)

tion. Furthermore, from the FEAs, numerically obtained $P-d$ curves for each specimen were determined. Comparison between the tests and the numerical analyses in the linear region of the curves showed good agreement. By this comparison, the effective mechanical and thermal properties found for the plies are validated.

As mentioned previously, the specimens were measured before the tests (see Table S1). After the tests were carried out, the delamination lengths were measured on both sides of each specimen with the optical mode of an Olympus Confocal Microscope (model no. OLS4100, Tokyo, Japan) and given in Table S42. The difference between these measurements was less than $2 \mathrm{~mm}$ conforming to the standards $[11,12]$ for UD material. In addition, during the tests, values of temperature and $\mathrm{RH}$ were recorded and may be found in Table S41. The tests conform to the standards.

Using Eqs. (11) and (12), values of $G_{\text {I }}$ were calculated for each load and delamination length. Note that $G_{i}$ in Eq. (11) is identified as $G_{I}$ and the overbar is omitted. These values are averaged over the thickness. This data is plotted as points in Fig. 9. An initiation fracture toughness is shown for $\Delta a=0$ as $G_{\mathrm{Ic}}=357.9 \mathrm{~N} / \mathrm{m}$. As $\Delta a$ increases, the values of $G_{\mathrm{IR}}$ increase, as well, reaching a steady state value of $G_{\mathrm{ss}}=727.7 \mathrm{~N} / \mathrm{m}$ for $\Delta a=30 \mathrm{~mm}$. Fitting the points between $0 \leq \Delta a \leq 30 \mathrm{~mm}$ leads to the power law given by

$$
G_{\mathrm{IR}}=100.2(\Delta a)^{0.384}+357.9 \text {. }
$$

This curve and the extreme points are plotted in Fig. 9. A coefficient of determination $R^{2}$ of the power law in Eq. (21) was found as 0.82 .

\subsection{Fatigue tests results}

In this section, the fatigue tests carried out as described in Sect. 2.3 are presented. Results and additional explanations are given in Sect. S.6. Recall that two cyclic displacement ratios were used: $R_{\mathrm{d}}=0.10$ and 0.48 . The aim was for each specimen to undergo $3 \times 10^{6}$ cycles. In Table 1 , the number of cycles experienced by each specimen is presented. During the tests on specimens FTG-wet-1-09 and FTG-wet-1-10, there was a power failure. If a test is interrupted, it is not possible to remount the specimen in the same position that it had been before the interruption. Hence, the number of cycles experienced by each of these specimens is less than $3 \times 10^{6}$. Although specimen FTG-wet-1-14 was subjected to all planned cycles, it appears that there was a temperature change which affected the measured compliance values as shown in Fig. 10. It is possible to note that the room temperature for $N \approx 475000$ cycles is about $23.5^{\circ} \mathrm{C}$; after that, it decreased suddenly to less than $21.0^{\circ} \mathrm{C}$. In addition, the compliance value increased significantly for $N=475000$ cycles. As a result, data from this cycle forwards was not taken into account in calculating the delamination propagation rate. It was found that the specimens tested in this investigation were very sensitive to temperature changes. Another illustration is described in the sequel for specimen FTG-wet-1-15. As a result, data from the first 30000 cycles of this test was omitted. For all specimens, the compliance values calculated as a function of $N$ are illustrated in Fig. S10.

As described in Sect. 3.2, the delamination length may be obtained using Eq. (14) with the value of the compliance in each cycle. In Table S43, the fitting constants $g$ and $n$, together with the coefficient of determination $R^{2}$ of Eq. (14) are presented for each specimen with $R^{2}>0.97$. Moreover, in Sect. 3.3, a method for determining a relation between the delamination length $a$ and the cycle number $N$ in Eq. (15) was described. In Table S44, the fitting constants, $A_{1}, A_{2}, B_{1}$ and $B_{2}$, and the coefficient of determination $R^{2}$ are presented for all specimens with $R^{2}>0.97$.

Next, in a manner similar to that described in Sect. 4.1 for the fracture toughness tests, the stress intensity factors and the maximum and minimum values of the energy release rates $G_{\text {Imax }}$ and $G_{\text {Imin }}$ were determined. The coefficients $p_{i 0}$ and $p_{j 1}(i=0,1, \ldots, 5$ and $j=0,1, \ldots, 4)$ from Eq. (7), and $d_{i}(i=0,1, \ldots, 14)$ from Eq. (9), are presented for each specimen in Tables S23 through S40. Values of $\hat{G}_{\text {Imax }}$ and $\Delta \hat{G}_{\text {Ieff }}$, from Eqs. (17) and (18), respectively, were also determined in each cycle.

As mentioned earlier, a change in the room temperature affected the behavior of specimen FTG-wet-1-15 during the test. All obtained data for this specimen was used to plot a curve for $\mathrm{d} a / \mathrm{d} N$ as a function of $\hat{G}_{\text {Imax }}$ on a log-log scale. This curve, together with that for specimen FTG-

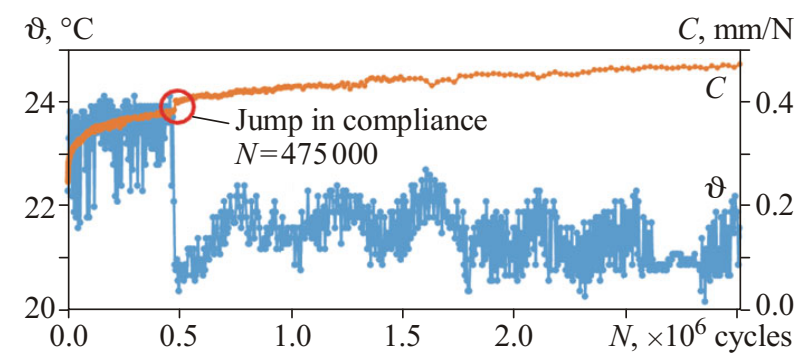

Fig. 10. Compliance $C$ values calculated by Eq. (13) and temperature $\vartheta$ values measured during fatigue test of specimen FTG-wet1-14 (color online) 
$\mathrm{d} a / \mathrm{d} N, \mathrm{~mm} /$ cycle

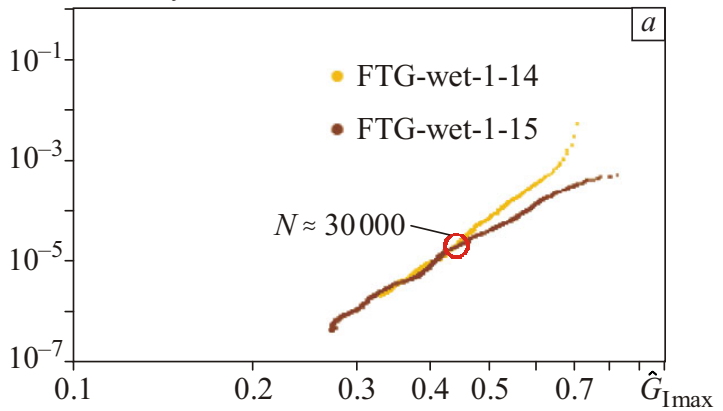

$\vartheta,{ }^{\circ} \mathrm{C}$

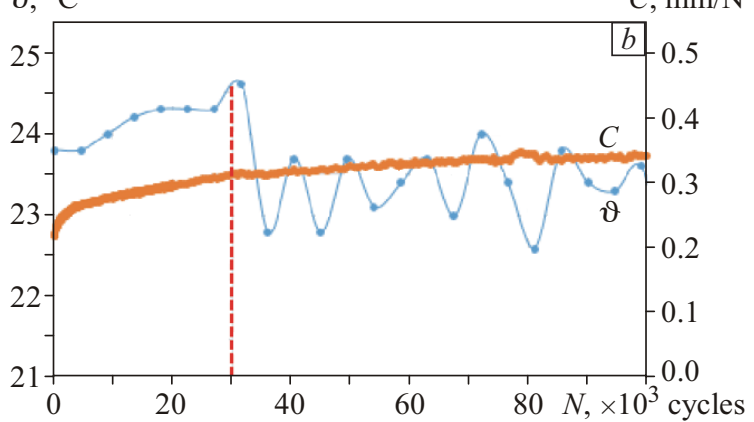

Fig. 11. Temperature effect on results. Plot of $\mathrm{d} a / \mathrm{d} N$ versus $\hat{G}_{\text {Imax }}$ for specimens FTG-wet-1-14 and FTG-wet-1-15 (a). Compliance $C$ values calculated using Eq. (13) and measured temperature $\vartheta$ values during the fatigue test of specimen FTG-wet-1-15 during the first 100000 cycles $(b)$ (color online)

wet-1-14, are shown in Fig. 11, a. It may be observed that for low values of $\mathrm{d} a / \mathrm{d} N$ the curves approach one another; whereas, for high values of $\mathrm{d} a / \mathrm{d} N$, they diverge. It should be noted that for specimen FTG-wet-1-14, data is shown only for $N \leq 475000$. Since the tests of these two specimens were performed with $R_{\mathrm{d}}=0.48$, it was expected that they would show similar behavior. Next, for specimen FTGwet-1-15, the temperature is examined in Fig. 11, $b$ during the first 100000 cycles. For $N<30000$ cycles, the temperature increased from $23.75^{\circ} \mathrm{C}$ to above $24.5^{\circ} \mathrm{C}$. For $N>$ $>30000$ cycles, the temperature decreased to about an average value of $23.3^{\circ} \mathrm{C}$ until the end of the test. This small change in temperature apparently created a reduction in the delamination propagation rate. There is no discontinuity in the compliance values as in specimen FTG-wet-1-14. But the compliance values differ from those of specimen FTG-wet-1-14 during the first 30000 cycles of the test. As a result of Fig. 11, going forward, the analysis of specimen FTG-wet-1-15 was performed without the data from the first 30000 cycles. It may be noted that the ASTM standards recommend temperatures of $23 \pm 3^{\circ} \mathrm{C}$. Clearly, the temperatures for this specimen conform to the standards.

Possible explanations for this behavior are presented next. The plate from which the specimens were taken was manufactured by means of a wet-layup. During the curing stage, the maximum imposed temperature was about $85^{\circ} \mathrm{C}$ with an exothermic reaction bringing the temperature to $90^{\circ} \mathrm{C}$ within the composite plate. The data sheet for the epoxy used in these specimens specifies that the maximum curing temperature should be $130^{\circ} \mathrm{C}$ in order to obtain a glass transition temperature $T_{\mathrm{g}}=130^{\circ} \mathrm{C}$ [24]. Dynamic mechanical analysis (DMA) tests were performed where it was found that $T_{\mathrm{g}}=104^{\circ} \mathrm{C}$. This lower value of $T_{\mathrm{g}}$ may explain the sensitivity of these specimens to small temperature changes.

Recall that for specimen FTG-wet-1-14 in Fig. 10, a temperature decrease of about $3^{\circ} \mathrm{C}$ significantly affected the compliance value. In practice, this change affected the minimum load $P_{\min }$ measured in the corresponding cycle which decreased by about $0.4 \mathrm{~N}$. As a result the compliance value increased, as may be seen in Eq. (13).

Moreover, the temperature sensitivity may be related to the load cell sensitivity of the Instron testing machine. To this end, a test was carried out by hanging a mass of $1 \mathrm{~kg}$ on the load cell and heating and cooling the room between 25 and $21.5^{\circ} \mathrm{C}$. It was seen that the load varied between $9.81 \mathrm{~N}$, at the higher temperature, and $9.56 \mathrm{~N}$, at the lower one. These small changes in the load affect, in particular, $P_{\text {min }}$ and hence, the compliance. It is speculated that both the low glass transition temperature, as well as the load cell sensitivity affected the compliance and, hence, the final results.

Some additional data is given in the Supplementary material. In Table $\mathrm{S} 45$, the average cyclic load ratio $R_{\mathrm{p}}$, for each specimen in the first 10000 cycles, is shown. It is somewhat lower than $R_{\mathrm{d}}$. For specimen FTG-wet-1-15, $R_{\mathrm{p}}$ is an average for the first 30000 to 40000 cycles. In addition, the delamination lengths at the end of the tests for each specimen, on both sides, and their differences $\Delta_{f}$, are given, as well. It was seen that $\Delta_{f}<2 \mathrm{~mm}$, in keeping with the fracture toughness test standards. Initial test temperatures are also shown.

Next, values of $\mathrm{d} a / \mathrm{d} N$ versus $\hat{G}_{\text {Imax }}$ and $\Delta \hat{G}_{\text {Ieff }}$, from Eqs. (17) and (18), were plotted on a log-log scale as shown in Figs. 12, $a$ and 12, b, respectively. Generally, linear behavior is observed. Such curves may be used to predict delamination propagation when $\hat{G}_{\text {Imax }}$ or $\Delta \hat{G}_{\text {Ieff }}$ is known for a structure containing the interface studied here. In Fig. 12, the plots include data for all fatigue specimens. It may be observed that the data for high values of $\mathrm{d} a / \mathrm{d} N$ appear to approach an asymptote as also shown in Fig. 8. Similar to Fig. 8, $a$, in Fig. 12, $a, \hat{G}_{\text {Imax }} \rightarrow 1$; in Figs. 8, $b$ and $12, b$ for $\Delta \hat{G}_{\text {Ieff }}$, different asymptotic values for large $\mathrm{d} a / \mathrm{d} N$ are approached for each value of $R$.

Ignoring the data for large values of $\mathrm{d} a / \mathrm{d} N$ (up to 500 cycles), a mathematical expression in the linear range of the curves on a log-log scale, in Figs. 12, $a$ and 12, $b$, are given by 
$\mathrm{d} a / \mathrm{d} N, \mathrm{~mm} /$ cycle

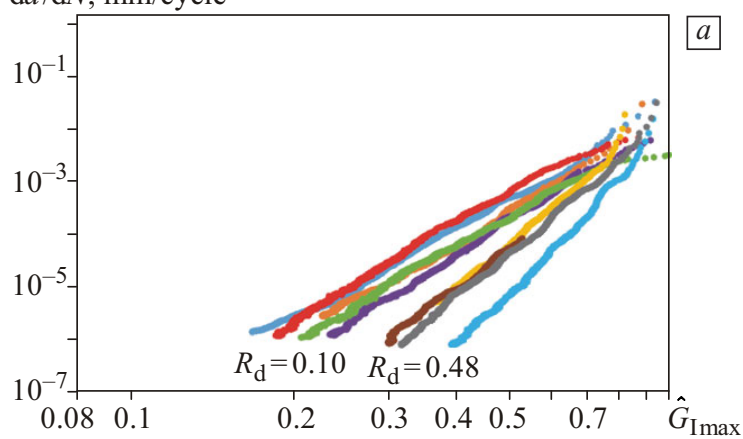

$\mathrm{d} a / \mathrm{d} N, \mathrm{~mm} /$ cycle

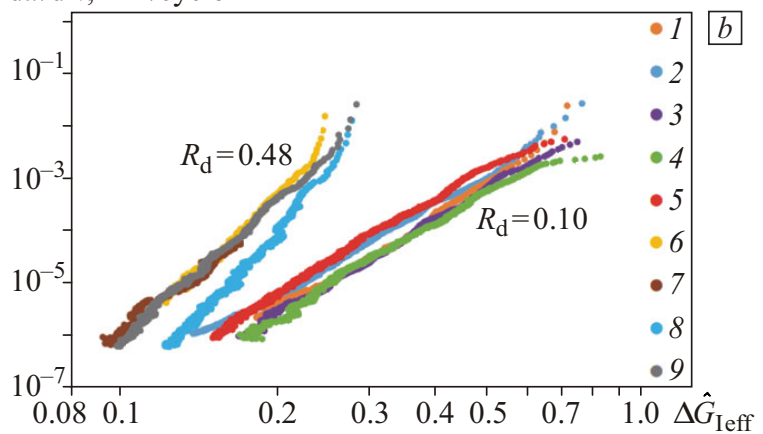

Fig. 12. Plots of $\mathrm{d} a / \mathrm{d} N$ versus $\hat{G}_{\text {Imax }}(a)$ and $\Delta \hat{G}_{\text {Ieff }}(b)$ : FTG-wet-1-09 (1), FTG-wet-1-10 (2), FTG-wet-1-11 (3), FTG-wet-1-12 (4), FTG-wet-1-13 (5), FTG-wet-1-14 (6), FTG-wet-1-15 (7), FTG-wet-1-16 (8), FTG-wet-1-17 (9) (color online)

$$
\frac{\mathrm{d} a}{\mathrm{~d} N}=D_{1} \hat{G}_{\mathrm{Imax}}^{m_{1}}
$$

and

$$
\frac{\mathrm{d} a}{\mathrm{~d} N}=D_{2} \Delta \hat{G}_{\text {Ieff }}^{m_{2}}
$$

where the parameters $D_{i}$ and $m_{i}(i=1,2)$ are power law fitting constants. These parameters for each specimen are presented in Table 2, together with $R^{2}$ and the number of sampling points. It may be seen that $R^{2}>0.9877$ for all specimen, which is excellent.

In Figs. 12, $a$ and 12, $b$, it may be observed that the specimens separate into two groups according to the cyclic displacement ratio $R_{\mathrm{d}}$. Ideally, the curves for each $R_{\mathrm{d}}$ should coincide. In practice, this is not the case, and there is variability between the curves, as reflected by that of the slopes, $m_{1}$ and $m_{2}$. In Fig. 12, it may be observed that the data from specimen FTG-wet-1-16 deviates from the rest of the specimens in its group. In Table 2, a slope significantly higher than that of the other specimens with the same value of $R_{\mathrm{d}}$ is noted. We have no explanation for this behavior except that it is normal scatter in fatigue data. Fur- thermore, it may be seen in Table 2 that the slopes of the curves for $R_{\mathrm{d}}=0.10$ are smaller than those for $R_{\mathrm{d}}=0.48$, as illustrated in Fig. 8. Averages of the slopes, for each set of specimens, are $\bar{m}_{1}^{(0.1)}=6.10, \bar{m}_{2}^{(0.1)}=5.86$ for $R_{\mathrm{d}}=0.10$; $\bar{m}_{1}^{(0.48)}=8.77, \bar{m}_{2}^{(0.48)}=8.92$ for $R_{\mathrm{d}}=0.48$. The value of the coefficient of variation $(\mathrm{CV})$ of the slopes may be calculated as

$$
\mathrm{CV}=\frac{\mathrm{SDV}}{\bar{X}},
$$

where SDV is the standard deviation and $\bar{X}$ is the average value. The values of CV for $R_{\mathrm{d}}=0.10$ are 0.06 for $m_{1}$ and 0.03 for $m_{2}$; for $R_{\mathrm{d}}=0.48$, they are 0.13 for $m_{1}$ and 0.16 for $m_{2}$. An increase in the slopes, as $R_{\mathrm{d}}$ increases was expected and also seen in [10] and Fig. 8. Furthermore, in Fig. 12, $a$, it is possible to observe that for a given value of $\hat{G}_{\text {Imax }}$, a higher value of $\mathrm{d} a / \mathrm{d} N$ is obtained for specimens with $R_{\mathrm{d}}=0.10$ as compared to those with $R_{\mathrm{d}}=0.48$. On the other hand, it may be seen in Fig. 12, $b$ that for a given value of $\Delta \hat{G}_{\text {Ieff }}$, a higher value of $\mathrm{d} a / \mathrm{d} N$ is obtained for specimens with $R_{\mathrm{d}}=0.48$ as compared to those with $R_{\mathrm{d}}=$ $=0.10$.

Displacement ratio, fitting constants, $R^{2}$ and number of sample points for Eqs. (22) and (23) for each specimen

\begin{tabular}{c|c|c|c|c|c|c|c|c}
\hline \multirow{2}{*}{ Specimen } & \multirow{2}{*}{$R_{\mathrm{d}}$} & \multicolumn{3}{|c|}{ Eq. (22) } & \multicolumn{3}{c|}{ Eq. (23) } & $\begin{array}{c}\text { Number of } \\
\text { sample points }\end{array}$ \\
\cline { 3 - 8 } & & $D_{1}$ & $m_{1}$ & $R^{2}$ & $D_{2}$ & $m_{2}$ & $R^{2}$ & 734 \\
\hline FTG-wet-1-09 & 0.10 & 0.0121 & 5.90 & 0.9937 & 0.0414 & 5.75 & 0.9929 & 794 \\
\hline FTG-wet-1-10 & 0.10 & 0.0181 & 5.68 & 0.9950 & 0.0602 & 5.62 & 0.9958 & 806 \\
\hline FTG-wet-1-11 & 0.10 & 0.0144 & 6.65 & 0.9972 & 0.0431 & 5.93 & 0.9967 & 806 \\
\hline FTG-wet-1-12 & 0.10 & 0.0109 & 5.97 & 0.9957 & 0.0376 & 5.91 & 0.9938 & 806 \\
\hline FTG-wet-1-13 & 0.10 & 0.0427 & 6.29 & 0.9971 & 0.1347 & 6.09 & 0.9973 & 601 \\
\hline FTG-wet-1-14 & 0.48 & 0.0202 & 8.68 & 0.9969 & 1165.6 & 9.08 & 0.9896 & 541 \\
\hline FTG-wet-1-15 & 0.48 & 0.0071 & 7.52 & 0.9902 & 22.048 & 7.14 & 0.9915 & 806 \\
\hline FTG-wet-1-16 & 0.48 & 0.0070 & 10.31 & 0.9953 & 3487.9 & 10.67 & 0.9878 & 806 \\
\hline FTG-wet-1-17 & 0.48 & 0.0123 & 8.56 & 0.9975 & 629.80 & 8.79 & 0.9950 & \\
\hline
\end{tabular}




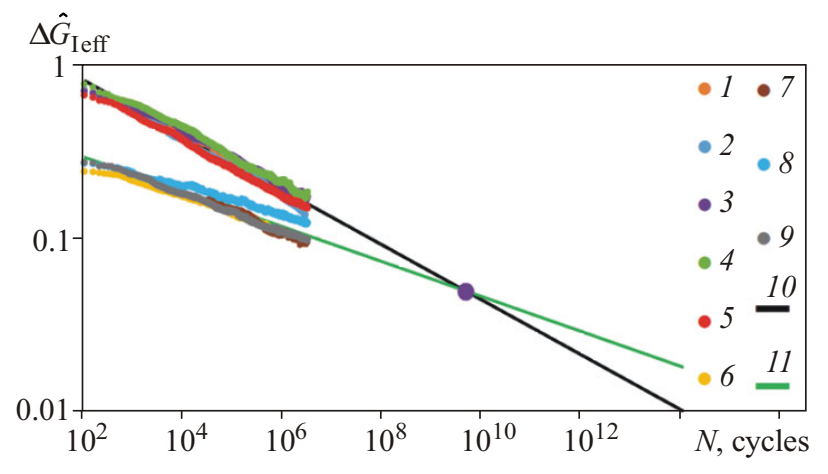

Fig. 13. Plot of $\Delta \hat{G}_{\text {Ieff }}$ from Eq. (18) versus the cycle number $N$, for all fatigue specimens: FTG-wet-1-09 (1); FTG-wet-1-10 (2); FTG-wet-1-11 (3); FTG-wet-1-12 (4); FTG-wet-1-13 (5); FTGwet-1-14 (6); FTG-wet-1-15 (7); FTG-wet-1-16 (8); FTG-wet-117 (9); fit, $R_{\mathrm{d}}=0.10(10)$; fit, $R_{\mathrm{d}}=0.48$ (11) (color online)

\subsection{Energy release rate threshold values}

In this section, values of $G_{\text {Ithr }}$ and $\hat{G}_{\text {Ithr }}$ from Eqs. (19) and (20), respectively, are determined. It is difficult to experimentally obtain threshold values. However, it is possible to determine approximate values as outlined here and presented in [10].

It may be shown that [10]

$$
G_{\text {Ithr }}=\frac{\Delta G_{\text {Ieff thr }}}{\left(1-R_{\mathrm{p}}\right)^{2}} .
$$

Thus, knowledge of $\Delta G_{\text {Ieff thr }}$ and $R_{\mathrm{p}}$ is sufficient for obtaining $G_{\text {Ithr }}$. Moreover, normalized values of $G_{\text {Ithr }}$ and $\Delta G_{\text {Ieff thr }}$, respectively, may be used in Eq. (25), so that

$$
\hat{G}_{\text {Ithr }}=\frac{\Delta \hat{G}_{\text {Ieff thr }}}{\left(1-R_{\mathrm{p}}\right)^{2}} .
$$

Thus, the threshold values $G_{\text {Ithr }}$ and $\hat{G}_{\text {Ithr }}$ may be found once $\Delta G_{\text {Ieff thr }}$ and $\Delta \hat{G}_{\text {Ieff thr }}$ are known.

As presented in Fig. $8, b$, the values of $\Delta G_{\text {Ieff thr }}$ or $\Delta \hat{G}_{\text {Ieff thr }}$ are each the same for any value of $R_{\mathrm{d}}$ for a particular material system. To determine $\Delta \hat{G}_{\text {Ieff thr }}$, all of the

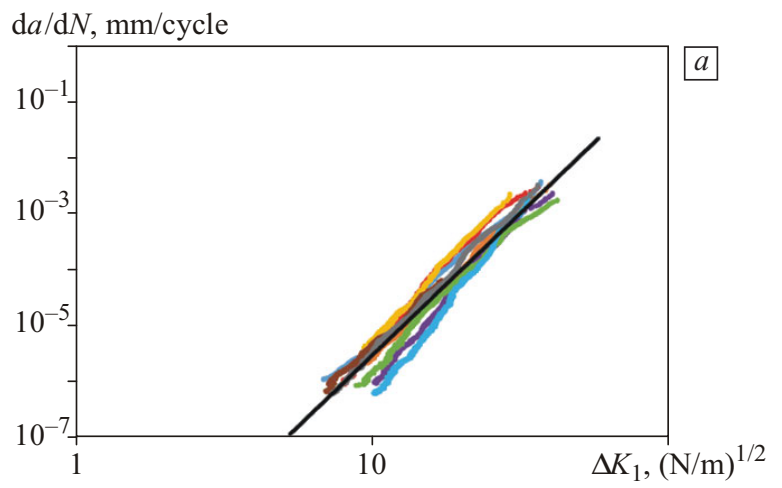

test results are plotted versus the cycle number $N$ on a log$\log$ scale as illustrated in Fig. 13. For each value of $R_{\mathrm{d}}$, a straight line was fit through each group of results. The intersection of the lines yields an initial value $\Delta \hat{G}_{\text {Ieff thr }}^{(\mathrm{i})}$. This value of $\Delta \hat{G}_{\text {Ieff }}$ is the initial value used to determine a final value $\Delta \hat{G}_{\text {Ieff thr }}^{(\mathrm{f})}$ when determining a master curve. For each displacement ratio, the expressions for the straight lines are given in Eqs. (S9) and (S10). The parameter $R^{2}$ for each equation is presented in Table S46. In Fig. 13, the intersection point of the two lines was obtained for values of $N=4.7 \times 10^{9}$ and $\Delta \hat{G}_{\text {Ieff thr }}^{(\mathrm{i})}=0.0492$. In the same manner, with a plot of $\Delta G_{\text {Ieff }}$ versus $N$ as shown in Fig. S11, a value of $\Delta G_{\text {Ieff thr }}^{(\mathrm{i})}=33.98 \mathrm{~N} / \mathrm{m}$ was found. This value of $\Delta G_{\text {Ieff }}$ was used as an initial value for determining a final value $\Delta G_{\text {Ieff thr }}^{(\mathrm{f})}$.

\subsection{Master curves}

One major objective of this study is to obtain a master curve to describe the fatigue data which is independent of $R_{\mathrm{d}}$. This curve may be found by using the fatigue test results presented in Sect. 4.2, together with the initial threshold values given in Sect. 4.3. The method used here follows that described in [10] for $\Delta \bar{K}_{2}$ in Eq. (20).

In Fig. $14, \mathrm{~d} a / \mathrm{d} N$ is plotted versus $\Delta K_{1}$ and $\Delta \bar{K}_{2}$, from Eqs. (19) and (20), respectively. Initially, the graphs were obtained using the values $\Delta G_{\text {Ieff thr }}^{(\mathrm{i})}, \Delta \hat{G}_{\text {Ieff thr }}^{(\mathrm{i})}$ and the initial value of $A$ in Eq. (19). Recall that the value of $A$ is a constant representing the critical cyclic energy release rate. For an initial value of $A, G_{\mathrm{IR}}$ in Eq. (21) was chosen for $3 \mathrm{~mm} \leq \Delta a \leq 5 \mathrm{~mm}$ as $500 \mathrm{~N} / \mathrm{m}$. The value of $G_{\mathrm{IR}}$ to be used in Eqs. (17) and (20) is $G_{\mathrm{IR}}$ for the given value of $\Delta a$. Note that $A$ is a free parameter and used in the fitting; whereas, $G_{\mathrm{IR}}$ changes as the delamination length increases.

Equation (1) is used with $f\left(G_{\mathrm{I}}\right)=\Delta K_{1}$ or $\Delta \bar{K}_{2}$. The parameters $D$ and $m$ are found by fitting the fatigue data to a straight line on a log-log scale with $A$ and $\Delta G_{\text {Ieff thr }}$ as free parameters for $\Delta K_{1}$, and $\Delta \hat{G}_{\text {Ieff thr }}$ as a free parameter for $\Delta \bar{K}_{2}$. The values of $\Delta G_{\text {Ieff thr }}, \Delta \hat{G}_{\text {Ieff thr }}$ and $A$ were

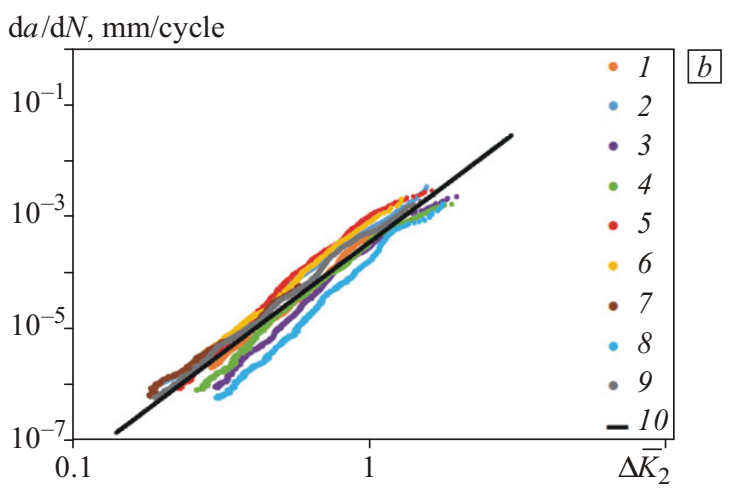

Fig. 14. Master curves for $\Delta K_{1}$ in Eq. (19) (a) and $\Delta \bar{K}_{2}$ in Eq. (20) (b): FTG-wet-1-09 (1), FTG-wet-1-10 (2), FTG-wet-1-11 (3), FTGwet-1-12 (4), FTG-wet-1-13 (5), FTG-wet-1-14 (6), FTG-wet-1-15 (7), FTG-wet-1-16 (8), FTG-wet-1-17 (9), master curve (10) (color online) 
Table 3

Fitting constants, coefficient of determination, initial and final threshold values $\Delta \hat{G}_{\text {Ieff thr }}$ and $\Delta G_{\text {Ieff thr }}$ for Eq. (1) using $\Delta K_{1}$ and $\Delta \bar{K}_{2}$ as $f\left(G_{\mathrm{I}}\right)$, respectively

\begin{tabular}{|c|c|c|c|c|c|}
\hline \multicolumn{6}{|c|}{ Eq. (1) with $\Delta K_{1}$ as $f\left(G_{\mathrm{I}}\right)$} \\
\hline$D$ & $m$ & $R^{2}$ & $\begin{array}{c}\Delta G_{\text {Ieff thr }}^{(\mathrm{i})} \\
\quad \mathrm{N} / \mathrm{m}\end{array}$ & $\begin{array}{c}\Delta G_{\text {Ieff thr }}^{(\mathrm{f})}, \\
\mathrm{N} / \mathrm{m}\end{array}$ & $\Delta \hat{G}_{\text {Ieff thr }}^{(\mathrm{f})}$ \\
\hline $3.14 \times 10^{-11}$ & 5.1 & 0.8796 & 33.98 & 32.70 & 0.0449 \\
\hline \multicolumn{6}{|c|}{ Eq. (1) with $\Delta \bar{K}_{2}$ as $f\left(G_{\mathrm{I}}\right)$} \\
\hline$D$ & $m$ & $R^{2}$ & $\Delta \hat{G}_{\text {Ieff thr }}^{(\mathrm{i})}$ & $\begin{array}{c}\Delta G_{\text {Ieff thr }}^{(\mathrm{f})}, \\
\mathrm{N} / \mathrm{m}\end{array}$ & $\Delta \hat{G}_{\text {Ieff thr }}^{(\mathrm{f})}$ \\
\hline $4.09 \times 10^{-4}$ & 4.0 & 0.8765 & 0.0492 & 42.64 & 0.0586 \\
\hline
\end{tabular}

incremented from their initial values, until the highest value of $R^{2}$ was achieved. The values of $D, m$ and $R^{2}$ for Eq. (1), using $\Delta K_{1}$ or $\Delta \bar{K}_{2}$ are presented in Table 3. The initial and final values of $\Delta G_{\text {Ieff thr }}$ and $\Delta \hat{G}_{\text {Ieff thr }}$, respectively, are given in Table 3, as well. The final value of $A$ was $619 \mathrm{~N} / \mathrm{m}$.

In Figs. 14, $a$ and 14, $b$, using $\Delta K_{1}$ or $\Delta \bar{K}_{2}$ as $f\left(G_{\mathrm{I}}\right)$, respectively, the data was plotted and the best fit for the master curve is shown as a continuous black line. The lines are independent of $R_{\mathrm{d}}$. However, it may be seen that there is some scatter in the test results, as reflected in the coefficient of determination. Recall that the results obtained from each test do not include the first 500 cycles. The value of the slope $m$ for Eq. (1) using $\Delta \bar{K}_{2}$ is lower than the slopes presented in Table 2 for the curves presented in Fig. 12, $a$ for $\hat{G}_{\text {Imax }}$. Recall that for purposes of comparison, the slopes in Eq. (22) require multiplication by a factor of 2. Nevertheless, in [10] for another material system, it was shown that use of $\Delta \bar{K}_{2}$ does not result in a smaller increase in $\mathrm{d} a / \mathrm{d} N$ as the delamination propagates. The value of the slope in Eq. (1) using $\Delta K_{1}$, is higher than the slope for Eq. (1) using $\Delta \bar{K}_{2}$ with values of $R^{2}$ almost identical.

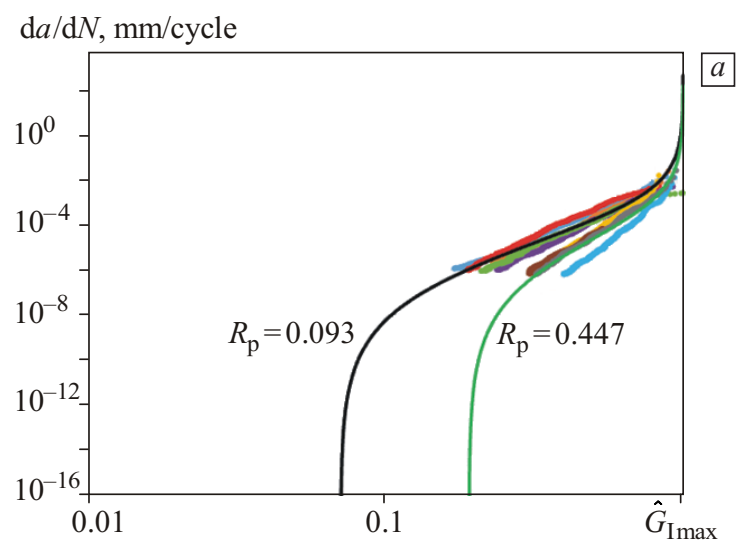

In Table 3, it may be observed that the value of $\Delta G_{\text {Ieff thr }}^{(\mathrm{f})}$ is rather close to that of $\Delta G_{\text {Ieff thr }}^{(\mathrm{i})}$. There is a greater percent difference between $\Delta \hat{G}_{\text {Ieff thr }}^{(\mathrm{f})}$ and $\Delta \hat{G}_{\text {Ieff thr }}^{(\mathrm{i})}$. It may be noted that $\Delta G_{\text {Ieff thr }}^{(\mathrm{f})}$ when using $\Delta K_{1}$ is not identical to $\Delta G_{\text {Ieff thr }}^{(\mathrm{f})}$ for $\Delta \bar{K}_{2}$. This difference results from the independent fitting processes. In Table S47, the final values of $G_{\text {Ithr }}$ and $\hat{G}_{\text {Ithr }}$, for Eq. (1) using $\Delta K_{1}$ or $\Delta \bar{K}_{2}$ as $f\left(G_{\mathrm{I}}\right)$, respectively, are presented for all specimens. When using $\Delta \bar{K}_{2}$ and for $R_{\mathrm{d}}=0.10$, the average value of $G_{\text {Ieff thr }}^{(\mathrm{f})}=$ $=51.8 \mathrm{~N} / \mathrm{m}$; for $R_{\mathrm{d}}=0.48$, the average value of $G_{\text {Ieff thr }}^{(\mathrm{f})}=$ $=139.5 \mathrm{~N} / \mathrm{m}$. These values appear reasonable.

\subsection{Back-calculation of full $\mathrm{d} a / \mathrm{d} N$ curves}

In this section, the values of $\mathrm{d} a / \mathrm{d} N$ are calculated using $\Delta \bar{K}_{2}$ of Eq. (20) in Eq. (1) for each of the two displacement ratios. They are then plotted versus $\hat{G}_{\text {Imax }}$ and $\Delta \hat{G}_{\text {Ieff }}$ for an extended range of $\mathrm{d} a / \mathrm{d} N$. For the calculation, the average values of the cyclic load ratios $R_{\mathrm{p}}$ presented in Table S45 were used for each set of specimens with the same $R_{\mathrm{d}}$ ratio. The average values are $R_{\mathrm{p}}=0.093$ and $R_{\mathrm{p}}=0.447$, for $R_{\mathrm{d}}=0.10$ and $R_{\mathrm{d}}=0.48$, respectively. The former values were used to determine the threshold values from Eqs. (25) and (26). In addition, the value of $\Delta \hat{G}_{\text {Ieff thr }}^{(\mathrm{f})}$ for $\Delta \bar{K}_{2}$ from Table 3 was used. In Fig. 15, two plots are presented: a plot in Fig. 15, $a$ of $\mathrm{d} a / \mathrm{d} N$ versus $\hat{G}_{\text {Imax }}$ and a plot in Fig. $15, b$ of $\mathrm{d} a / \mathrm{d} N$ versus $\Delta \hat{G}_{\text {Ieff }}$. The data obtained from the tests shown in Figs. 12, $a$ and $12, b$, are also presented in Figs. 15, $a$ and 15, $b$, respectively. In addition, two continuous curves (black and green) are exhibited which were obtained using Eq. (20) in Eq. (1) for displacement ratios of $R_{\mathrm{d}}=0.10$ and $R_{\mathrm{d}}=0.48$, respectively. It may be observed that the theory presented in [10] which also appears in Fig. 8 is validated for this material system. In the same manner, using Eq. (19) in Eq. (1), values of $\mathrm{d} a / \mathrm{d} N$ may be recalculated versus $G_{\text {Imax }}$ and

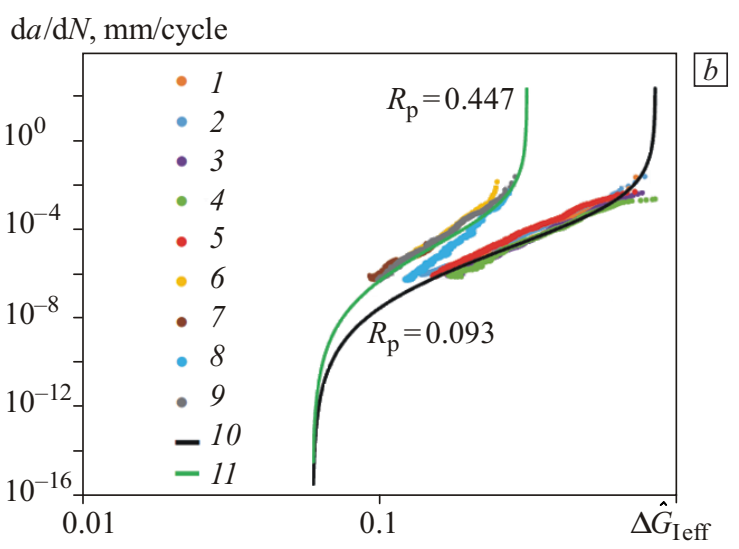

Fig. 15. Recalculation of $\mathrm{d} a / \mathrm{d} N$ using Eq. (20) in Eq. (1), with values of $D$ and $m$ presented in Table 3 for $\Delta \bar{K}_{2}$. Black curves for $R_{\mathrm{p}}=$ $=0.093$ and green curves for $R_{\mathrm{p}}=0.447$. Plot of $\mathrm{d} a / \mathrm{d} N$ versus $\hat{G}_{\text {Imax }}(a)$ and $\Delta \hat{G}_{\text {Ieff }}(b)$ : FTG-wet-1-09 (1); FTG-wet-1-10 (2); FTGwet-1-11 (3); FTG-wet-1-12 (4); FTG-wet-1-13 (5); FTG-wet-1-14 (6); FTG-wet-1-15 (7); FTG-wet-1-16 (8); FTG-wet-1-17 (9); fit, $R_{\mathrm{p}}=0.09(10) ;$ fit, $R_{\mathrm{p}}=0.45(11)$ (color online) 
$\Delta G_{\text {Ieff }}$, for each of the two displacement ratios. These results suggest that use of Eqs. (19) and (20) in Eq. (1) allows a full approximate prediction of the results without conducting tests of extended length.

\section{Discussion and conclusions}

In this section, a discussion and conclusions are presented. This study focused on nearly mode I fracture toughness and fatigue delamination propagation tests carried out with DCB specimens illustrated in Fig. 1. The specimen plies were composed of carbon fibers in an epoxy matrix. The laminate consisted of 18 multidirectional, plain, woven plies and one UD-fabric ply as shown in Fig. 2 which was fabricated by means of a wet-layup process. The woven plies alternated between those with tows in the $0^{\circ} / 90^{\circ}$ directions and $+45^{\circ} /-45^{\circ}$-directions. The delamination was between a UD-fabric (upper) ply and a woven (lower) ply with tows in the $+45^{\circ} /-45^{\circ}$-directions.

Fracture toughness tests on five DCB specimens led to a $G_{\mathrm{IR}}$-curve as shown in Fig. 9. This resistance curve or $R$-curve is characterized by two values of $G$. The curve initiates from its fracture toughness value of $G_{\text {Ic }}=357.9 \mathrm{~N} / \mathrm{m}$ at $\Delta a=0$. From this value, an increase may be observed until a steady state value $G_{\mathrm{ss}}=727.7 \mathrm{~N} / \mathrm{m}$ is reached at $\Delta a=30 \mathrm{~mm}$. For the material system discussed in [10], which included only MD woven plies, the values were $G_{\mathrm{Ic}}=$ $=508.0 \mathrm{~N} / \mathrm{m}$ and $G_{\mathrm{ss}}=711.0 \mathrm{~N} / \mathrm{m}$. Moreover, a steady state was reached at $\Delta a=10 \mathrm{~mm}$.

Fatigue delamination propagation tests on nine DCB specimens for two cyclic displacement ratios $R_{\mathrm{d}}=0.10$ and 0.48 provided $\mathrm{d} a / \mathrm{d} N$ data. The compliance $C$ in each cycle was obtained using Eq. (13). Measured values of delamination length $a$ were plotted versus matching compliance values as presented as red $\times$ in Fig. 6 . A relation between $a$ and $C$ was obtained by fitting Eq. (14) to the measured delamination lengths. In this way, values of $a$ in each cycle could be found without additional measurements. These values of $a$, calculated with Eq. (14), were plotted versus the corresponding values of $\left(N+B_{1}\right)^{B_{2}}$ where $B_{1}$ and $B_{2}$ are non-dimensional parameters to be determined in the fitting of Eq. (15). The methods for determining $a$ in each cycle of a test and obtaining a relation between $a$ and $N$ were found to be effective. In Fig. 6, it may be observed that there is good agreement between the measured and calculated values of $a$. Moreover, in Fig. 7 it is possible to observe that the visual measurements of $a$ from a test and Eq. (15) are well correlated. A relation between $\mathrm{d} a / \mathrm{d} N$ and $N$ in each cycle was determined by differentiating Eq. (15) to obtain Eq. (16).

The curing process may have a significant effect on the results. In this study, the glass transition temperature $T_{\mathrm{g}}$ was found to be $104^{\circ} \mathrm{C}$ which is lower than that specified in the data sheet $\left(130^{\circ} \mathrm{C}\right)$ for this epoxy. This lower value of $T_{\mathrm{g}}$ may partially explain the sensitivity of the speci- mens to small temperature changes. Recall that for specimen FTG-wet-1-14 in Fig. 10, a temperature decrease of about $3{ }^{\circ} \mathrm{C}$ significantly affected the compliance value. Moreover, the temperature sensitivity may be also related to the load cell sensitivity of the Instron testing machine, as described in Sect. 4.2. Hence, it appears that the specimens tested in this study are sensitive to small temperature changes.

Values of $\mathrm{d} a / \mathrm{d} N$ versus $\hat{G}_{\text {Imax }}$ and $\Delta \hat{G}_{\text {Ieff }}$, from Eqs. (17) and (18), were plotted on a log-log scale as shown in Figs. 12, $a$ and 12, $b$, respectively. The data for high values of $\mathrm{d} a / \mathrm{d} N$ appear to approach an asymptote as also shown schematically in Fig. 8. Similar to Fig. 8, $a$, for large values of $\mathrm{d} a / \mathrm{d} N, \hat{G}_{\text {Imax }} \rightarrow 1$; as for $\Delta \hat{G}_{\text {Ieff }}$, different asymptotic values are approached for each value of the cycle ratio $R$, as described in Fig. 8, $b$. In Figs. 12, $a$ and 12, $b$, ideally the curves for each $R_{\mathrm{d}}$ should coincide. In practice, this is not the case, and there is variability between the curves. The data from specimen FTG-wet-1-16 for $R_{\mathrm{d}}=$ $=0.48$ deviates from the rest of the specimens in its group. No explanation was found for this behavior except that it is normal scatter in fatigue data. Furthermore, the slopes of the curves for $R_{\mathrm{d}}=0.10$ are smaller than those for $R_{\mathrm{d}}=$ $=0.48$, as illustrated in Fig. 8. An increase in the slopes, as $R_{\mathrm{d}}$ increases was expected and also seen in [10] for a different material system.

Master curves were obtained using $\Delta K_{1}$ and $\Delta \bar{K}_{2}$ in Eqs. (19) and (20), respectively, as $f\left(G_{\mathrm{I}}\right)$ in Eq. (1). These curves, presented in Figs. 14, $a$ and 14, $b$, respectively, eliminate the dependence of $\mathrm{d} a / \mathrm{d} N$ on the cyclic ratio $R_{\mathrm{d}}$. To compare the slopes of the curves, for example in Fig. 12, $a$ and Table 2 for $\hat{G}_{\text {Imax }}$ to that for $\Delta \bar{K}_{2}$ in Fig. 14, $b$, the former is multiplied by two making the difference even greater. Nevertheless, in [10] for another material system, it was shown that use of $\Delta \bar{K}_{2}$ does not result in a smaller increase in $\mathrm{d} a / \mathrm{d} N$ for a given change in $\hat{G}_{\text {Imax }}$. Thus, the master-curves do not overcome the problem of accelerated delamination propagation in laminates. In addition, the value of the slope in Eq. (1) using $\Delta K_{1}$, is higher than the slope for Eq. (1) using $\Delta \bar{K}_{2}$ with values of the coefficient of determination $R^{2}$ almost identical. For $\Delta \bar{K}_{2}$ and for $R_{\mathrm{d}}=$ $=0.10$, the average value of $G_{\text {Ieff thr }}^{(\mathrm{f})}=51.8 \mathrm{~N} / \mathrm{m}$; for $R_{\mathrm{d}}=$ $=0.48$, the average value of $G_{\text {Ieff thr }}^{(\mathrm{f})}=139.5 \mathrm{~N} / \mathrm{m}$. These values appear reasonable. It may be pointed out that using these results in a damage tolerance paradigm may not be particularly useful. Perhaps the threshold values found here for this material combination may be used in predictions of safety factors.

Finally, using the master curve of, for example, $\Delta \bar{K}_{2}$ of Eq. (20) in Eq. (1), back calculation of $\mathrm{d} a / \mathrm{d} N$ as a function of $\hat{G}_{\text {Imax }}$ or $\Delta \hat{G}_{\text {Ieff }}$ for two cyclic displacement ratios was carried out leading to a range of values beyond that of the tests. The behavior shown in Fig. 8 was validated for this material system in Fig. 15. The back calculation pro- 
vides a full range of $\mathrm{d} a / \mathrm{d} N$ values (from high asymptotic values approaching the fracture toughness, to low asymptotic values approaching the thresholds) without the need to conduct extended fatigue tests. Future studies should include tests on the same material system for nearly mode II deformation or mixed modes 1 and 2.

\section{Acknowledgments}

We would like to express our appreciation to Mor Mega, Ido Simon, Victor Fourman and Rami Eliasy for their invaluable help during this investigation.

\section{References}

1. Karbhari V., Zhao L. Use of composites for 21 st century civil infrastructure // Comput. Meth. Appl. M. - 2000. - V. 185. - P. 433-454.

2. Raju I.S., O'Brien T.K. Fracture Mechanics Concepts, Stress Fields, Strain Energy Release Rates, Delamination Initiation and Growth Criteria // Delamination Behaviour of Composites / Ed. by S. Sridharan. Cambridge, England: Woodhead Publishing Ltd., 2008. - P. 3-27.

3. Jones R., Pitt S., Brunner A.J., Hui D. Application of the HartmanSchijve equation to represent mode I and mode II fatigue delamination growth in composites // Compos. Struct. - 2012. - V. 94. P. $1343-1351$.

4. Jones R., Stelzer S., Brunner A.J. Mode I, II and mixed mode I/II delamination growth in composites // Compos. Struct. - 2014. V. 110. - P. 317-324.

5. Jones R., Hu W., Kinloch A.J. A convenient way to represent fatigue crack growth in structural adhesives // Fatigue Fract. Eng. Mater. Struct. - 2015. - V. 38. - P. 379-391.

6. Jones R., Kinloch A.J., Hu W. Cyclic-fatigue crack growth in composite and adhesively-bonded structures: The FAA slow crack growth approach to certification and the problem of similitude // Int. J. Fatigue. - 2016. - V. 88. - P. 10-18.

7. Ishbir C., Banks-Sills L., Fourman V., Eliasi R. Delamination propagation in a multidirectional woven composite DCB specimen subjected to fatigue loading // Compos. B. Eng. - 2014. - V. 66. - P. 180-189.

8. Brunner A.J., Stelzer S., Mujtaba A., Jones R. Examining the application of the Hartman-Schijve equation to the analysis of cyclic fatigue fracture of polymer-matrix composites // Theor. Appl. Fract. Mech. 2017. - V. 92. - P. 420-425.

9. Mujtaba A., Stelzer S., Brunner A., Jones R. Thoughts on the scatter seen in cyclic mode I fatigue delamination growth in DCB tests // Compos. Struct. - 2017. - V. 160. - P. 1329-1338.

10. Simon I., Banks-Sills L., Fourman V. Mode I delamination propagation and $R$-ratio effects in woven composite DCB specimens for a multi-directional layup // Int. J. Fatigue. - 2017. - V. 96. - P. 237251 .

11. ASTM D5528-13. Standard Test Method for Mode I Interlaminar Fracture Toughness of Unidirectional Fiber-Reinforced Polymer Matrix Composites. - West Conshohocken, PA: ASTM International, 2013.

12. ISO 15024. Fiber Reinforced Plastic Composites-Determination of Mode I Interlaminar Fracture Toughness, $G_{\mathrm{I}}$, for Unidirectional Reinforced Materials. - Switzerland: ISO, 2001.

13. Aboudi J. The generalized method of cells and high-fidelity generalized method of cells micromechanical models - A review // Mech. Adv. Mater. Struct. - 2004. - V. 11. - P. 329-366.

14. Ting T. Anisotropic Elasticity: Theory and Applications. - New York: Oxford University Press, 1996.

15. WaveMatrix Software. Version 1.8.383.0. - High Wycombe, UK: Instron.

16. ASTM D6115-97. Standard Test Method for Mode I Fatigue Delamination Growth Onset of Unidirectional Fiber-Reinforced polymer matrix composites. - West Conshohocken, PA: ASTM International, 2011.

17. ABAQUS. Version 6.17. - Providence, RI: Dassault Systemes Simulia Corp., 2017.
18. Mega M., Banks-Sills L. Mixed Mode Interface Fracture Toughness of a Multi-Directional Composite-UD/woven pair (in preparation).

19. Banks-Sills L. Interface Fracture and Delaminations in Composite Materials. - Cham, Switzerland: Springer, 2018.

20. Rasband W.S. Image J. - Bethesda, Maryland: U.S. National Institutes of Health, 1997-2014. - http://imagej.nih.gov/ij/ (Accessed January, 2015).

21. ASTM E647-13. Standard Test Method for Measurement of Fatigue Crack Growth Rates. - West Conshohocken, PA: ASTM International, 2013

22. Microsoft Excel Software. Version 16.0.4266.1001. - Microsoft Corporation, 2016.

23. Hartman A., Schijve J. The effects of environment and load frequency on the crack propagation law for macro fatigue crack growth in aluminium alloys // Eng. Fract. Mech. - 1970. - V. 1. - P. 615-631.

24. Swiss-Composite: Material Property Data. - https://www.swiss-composite.ch/pdf/tepikote-1-20-epikure-960-e.pdf (Accessed 26.05.2018).

\section{SUPPLEMENTARY MATERIAL}

Section, figure, table and equation numbers are preceded with an $\mathrm{S}$; those without an $\mathrm{S}$ are in the body of the paper. In Sect. S1, measurements of the fracture toughness and fatigue delamination propagation specimens are given. The mechanical and thermal properties of the plies are described in Sect. S2. In Sect. S3, the test setup is discussed. Details about the finite element analysis and a convergence study are presented in Sect. S4. In Sects. S5 and S6, elaboration of the fracture toughness and fatigue delamination propagation tests, respectively, is discussed.

\section{S1. Measurements of DCB specimens}

Fracture toughness tests were performed on five DCB specimens denoted as FT-wet- $1-0 j(j=4,5,6,7,8)$; FT represents fracture toughness; wet indicates that the specimens were fabricated by means of a wet-layup; the numeral 1 denotes batch 1 ; the next number represents the location in the row of the plate from which it was fabricated. For each specimen, the length, width and thickness were measured; these measurements are presented in Table S1. The width and thickness were measured at five locations along the specimen length as shown in Fig. S1. Average values and standard deviations (SDVs) of these five measurements were calculated and are also presented. Note that the width of the specimen was measured by means of a caliper with a resolution of $0.01 \mathrm{~mm}$ and the thickness of the specimen was measured by means of a micrometer with a resolution of $0.001 \mathrm{~mm}$. For each specimen, the delamination length $a_{0}$ was measured from the center of the loading holes to the end of the delamination front on both sides of the specimen: front and back, and marked with a superscript (f) and (b), respectively. These measurements were made with the optical mode of an Olympus confocal microscope (model number OLS4100; Tokyo, Japan) and given in Table S1; its resolution is $0.001 \mathrm{~mm}$. The difference between them $\Delta_{0}$ is also presented. It may be seen that the differences are less than $2 \mathrm{~mm}$ which complies with the fracture toughness standards $[1,2]$. The parameter $a$ in 
Table S1

Fracture toughness specimen measurements

\begin{tabular}{c|c|c|c|c|c|c|c}
\hline Specimen & $h_{1}, \mathrm{~mm}$ & $h_{2}, \mathrm{~mm}$ & $h_{3}, \mathrm{~mm}$ & $h_{4}, \mathrm{~mm}$ & $h_{5}, \mathrm{~mm}$ & $\bar{h}, \mathrm{~mm}$ & SDV, mm \\
\hline FT-wet-1-04 & 5.01 & 5.07 & 5.00 & 5.01 & 4.96 & 5.01 & 0.04 \\
\hline FT-wet-1-05 & 4.98 & 5.02 & 5.08 & 5.01 & 4.90 & 5.00 & 0.06 \\
\hline FT-wet-1-06 & 4.94 & 5.03 & 4.97 & 4.88 & 4.97 & 4.96 & 0.05 \\
\hline FT-wet-1-07 & 4.94 & 4.88 & 4.94 & 4.86 & 4.85 & 4.89 & 0.04 \\
\hline FT-wet-1-08 & 4.94 & 4.87 & 4.94 & 4.84 & 4.88 & 4.89 & 0.04 \\
\hline & $b_{1}, \mathrm{~mm}$ & $b_{2}, \mathrm{~mm}$ & $b_{3}, \mathrm{~mm}$ & $b_{4}, \mathrm{~mm}$ & $b_{5}, \mathrm{~mm}$ & $\bar{b}, \mathrm{~mm}$ & SDV, mm \\
\hline FT-wet-1-04 & 19.74 & 19.96 & 19.64 & 19.71 & 19.72 & 19.75 & 0.12 \\
\hline FT-wet-1-05 & 20.01 & 19.94 & 20.13 & 20.31 & 20.00 & 20.08 & 0.13 \\
\hline FT-wet-1-06 & 19.89 & 19.96 & 19.64 & 19.65 & 19.97 & 19.82 & 0.15 \\
\hline FT-wet-1-07 & 19.90 & 20.00 & 20.10 & 19.95 & 20.31 & 20.05 & 0.16 \\
\hline FT-wet-1-08 & 19.90 & 19.95 & 19.99 & 19.72 & 19.62 & 19.80 & 0.16 \\
\hline & $a_{0}^{(f)}, \mathrm{mm}$ & $a_{0}^{(b)}, \mathrm{mm}$ & $\Delta_{0}, \mathrm{~mm}$ & $a^{(\mathrm{f})}, \mathrm{mm}$ & $a^{(\mathrm{b})}, \mathrm{mm}$ & $\Delta, \mathrm{mm}$ & $l, \mathrm{~mm}$ \\
\hline FT-wet-1-04 & 53.92 & 54.57 & 0.65 & 63.92 & 64.26 & 0.34 & 202 \\
\hline FT-wet-1-05 & 53.72 & 54.01 & 0.29 & 63.60 & 64.12 & 0.52 & 201 \\
\hline FT-wet-1-06 & 54.22 & 53.94 & 0.28 & 64.10 & 63.56 & 0.54 & 200 \\
\hline FT-wet-1-07 & 53.92 & 53.64 & 0.28 & 63.87 & 63.59 & 0.28 & 200 \\
\hline FT-wet-1-08 & 53.81 & 53.34 & 0.47 & 63.79 & 63.49 & 0.30 & 200 \\
\hline
\end{tabular}

Table S1 is the delamination length from the edge of the specimen to the delamination front. This parameter was also measured on both sides (front and back) of the specimen. The difference between these two measurements is denoted as $\Delta$. In addition, the length of the specimens $l$ was measured with a ruler and complies with the requirement that $l$ be at least $125 \mathrm{~mm}$.

Fatigue delamination propagation tests were carried out on nine DCB specimens: five with the cyclic displacement ratio $R_{\mathrm{d}}=0.1$ and four with $R_{\mathrm{d}}=0.48$ (see Eq. (2) for a definition of $R_{\mathrm{d}}$ ). Specimen width measurements are pre-

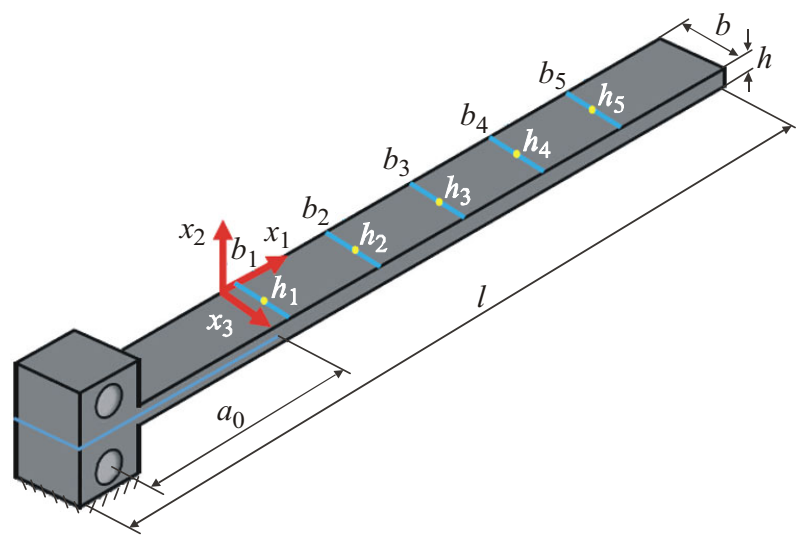

Fig. S1. Measurement locations of DCB specimens for fracture toughness tests (color online) sented in Table S2 and thickness measurements in Table S3. Each specimen is denoted with FTG indicating that it is a specimen tested in fatigue; wet denotes that it is fabricated by means of a wet-layup; the number 1 indicates that this is batch 1; the next number represents the location in the row of the plate from which the specimen was fabricated. It may be noted that all of the specimens tested here, both fracture and fatigue, were fabricated from the same plate. Specimen FT-wet-1-08, from the fracture toughness set, was next to specimen FTG-wet-1-09, from the fatigue delamination propagation set, in the plate.

The locations at which measurements were carried out of the width $b$ and thickness $h$ are presented in Fig. S2. The coordinate system in Fig. S2 is positioned at the location where $b_{2}$ is indicated with the origin on the edge of the specimen next to $h_{23}$. It is not located there in the figure so that it will be clearly visible. Two width measurements shown as $b_{1}$ and $b_{4}$ were made $25 \mathrm{~mm}$ from each edge of the specimen (along the $x_{1}$-axis). These two measurements were made as indicated in the ASTM fracture toughness standard [1], while the fatigue standard [3] suggests measurement of $b_{2}$ along the delamination front. The last width measurement $b_{3}$ was made nearly half-way between $b_{2}$ and $b_{4}$. The ASTM standard [1] recommends making only one measurement between $b_{1}$ and $b_{4}$. In addition, this standard recommends making only one thickness measurement, along the specimen width, in each location at which a width measurement is made and along the centerline of the speci- 
Width measurements and averages as presented in Fig. S2 (mm)

\begin{tabular}{c|c|c|c|c|c|c}
\hline Specimen & $b_{1}$ & $b_{2}$ & $b_{3}$ & $b_{4}$ & $\bar{b}$ & SDV \\
\hline FTG-wet-1-09 & 19.86 & 19.84 & 19.84 & 20.25 & 19.95 & 0.20 \\
\hline FTG-wet-1-10 & 19.93 & 19.92 & 19.68 & 19.66 & 19.80 & 0.15 \\
\hline FTG-wet-1-11 & 19.85 & 19.38 & 19.61 & 20.13 & 19.74 & 0.32 \\
\hline FTG-wet-1-12 & 19.87 & 19.89 & 19.94 & 19.70 & 19.85 & 0.10 \\
\hline FTG-wet-1-13 & 19.86 & 19.91 & 19.85 & 20.09 & 19.93 & 0.11 \\
\hline FTG-wet-1-14 & 19.56 & 19.77 & 19.84 & 19.78 & 19.74 & 0.12 \\
\hline FTG-wet-1-15 & 19.98 & 19.91 & 20.01 & 20.12 & 20.01 & 0.09 \\
\hline FTG-wet-1-16 & 19.98 & 19.98 & 19.94 & 19.83 & 19.93 & 0.07 \\
\hline FTG-wet-1-17 & 20.03 & 20.05 & 19.99 & 20.03 & 20.03 & 0.03 \\
\hline
\end{tabular}

men. Since the polytetrafluoroethylene (PTFE) film $(13 \mu \mathrm{m}$ thick) forming the delamination may have an effect on the thickness measurement, at the location where $b_{1}$ was measured, a thickness measurement was not made there. At each of the locations at which $b_{2}, b_{3}$ and $b_{4}$ were measured, three thickness measurements were made along the specimen width and not only at the one prescribed in [1]. The purpose of making three measurements was to account for the change of thickness along the $x_{3}$-axis, which may vary as a result of the wet-layup manufacturing process. In the ISO fracture toughness standard [2], three width measurements at equal distances along the specimen length are recommended. At the location of the middle one, of these three, performance of three thickness measurements is recommended, similar to those shown in Fig. S2. At the locations of the other width measurements, only one thickness measurement is prescribed. In this investigation, a combination of that recommended in both fracture toughness standards was carried out on the fatigue delamination propagation specimen set so that the measurements are ideal for obtaining the width and thickness of the specimen. These measurements were performed using the same instruments,

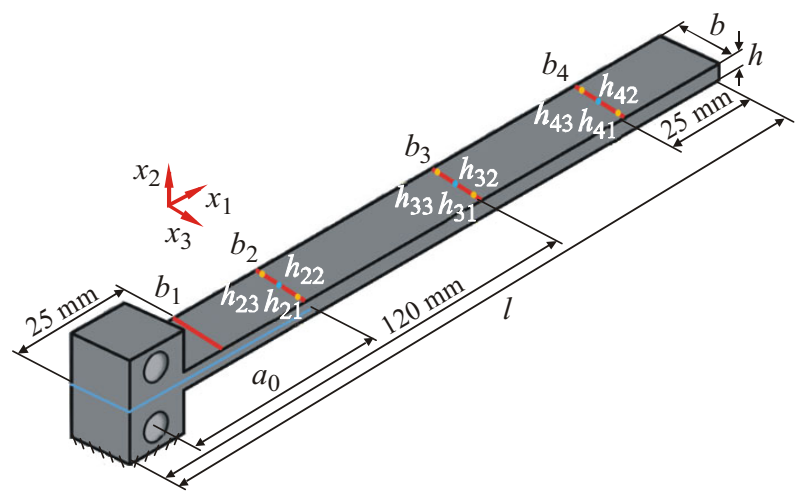

Fig. S2. Measurement locations of DCB specimens for fatigue delamination propagation tests (color online)
Thickness measurements and averages as presented in Fig. S2 (mm)

\begin{tabular}{|c|c|c|c|c|c|}
\hline Specimen & $h_{21}$ & $h_{22}$ & $h_{23}$ & $\bar{h}_{2}$ & SDV \\
\hline FTG-wet-1-09 & 4.89 & 4.89 & 4.95 & 4.91 & 0.03 \\
\hline FTG-wet-1-10 & 4.88 & 4.86 & 4.86 & 4.87 & 0.01 \\
\hline FTG-wet-1-11 & 4.81 & 4.79 & 4.89 & 4.83 & 0.05 \\
\hline FTG-wet-1-12 & 4.83 & 4.83 & 4.85 & 4.84 & 0.01 \\
\hline FTG-wet-1-13 & 4.88 & 4.85 & 4.85 & 4.86 & 0.02 \\
\hline FTG-wet-1-14 & 4.74 & 4.76 & 4.70 & 4.73 & 0.03 \\
\hline FTG-wet-1-15 & 4.83 & 4.79 & 4.88 & 4.83 & 0.05 \\
\hline FTG-wet-1-16 & 4.91 & 4.93 & 4.81 & 4.88 & 0.06 \\
\hline \multirow[t]{2}{*}{ FTG-wet-1-17 } & 4.86 & 4.85 & 4.84 & 4.85 & 0.01 \\
\hline & $h_{31}$ & $h_{32}$ & $h_{33}$ & $\bar{h}_{3}$ & SDV \\
\hline FTG-wet-1-09 & 4.91 & 4.94 & 4.95 & 4.93 & 0.02 \\
\hline FTG-wet-1-10 & 4.79 & 4.83 & 4.89 & 4.84 & 0.05 \\
\hline FTG-wet-1-11 & 4.78 & 4.77 & 4.75 & 4.77 & 0.02 \\
\hline FTG-wet-1-12 & 4.58 & 4.68 & 4.74 & 4.67 & 0.08 \\
\hline FTG-wet-1-13 & 4.76 & 4.72 & 4.72 & 4.73 & 0.02 \\
\hline FTG-wet-1-14 & 4.84 & 4.77 & 4.75 & 4.79 & 0.05 \\
\hline FTG-wet-1-15 & 4.91 & 4.89 & 4.94 & 4.91 & 0.03 \\
\hline FTG-wet-1-16 & 4.85 & 4.79 & 4.91 & 4.85 & 0.06 \\
\hline \multirow[t]{2}{*}{ FTG-wet-1-17 } & 4.72 & 4.87 & 4.82 & 4.80 & 0.08 \\
\hline & $h_{41}$ & $h_{42}$ & $h_{43}$ & $\overline{h_{4}}$ & SDV \\
\hline FTG-wet-1-09 & 4.85 & 4.89 & 4.82 & 4.85 & 0.03 \\
\hline FTG-wet-1-10 & 4.88 & 4.97 & 4.90 & 4.92 & 0.05 \\
\hline FTG-wet-1-11 & 4.78 & 4.81 & 4.77 & 4.79 & 0.02 \\
\hline FTG-wet-1-12 & 4.77 & 4.72 & 4.77 & 4.75 & 0.03 \\
\hline FTG-wet-1-13 & 4.87 & 4.88 & 4.86 & 4.87 & 0.01 \\
\hline FTG-wet-1-14 & 4.94 & 4.80 & 4.83 & 4.86 & 0.07 \\
\hline FTG-wet-1-15 & 4.92 & 4.89 & 4.87 & 4.89 & 0.03 \\
\hline FTG-wet-1-16 & 4.90 & 4.89 & 4.98 & 4.92 & 0.05 \\
\hline FTG-wet-1-17 & 4.83 & 4.90 & 4.91 & 4.88 & 0.04 \\
\hline
\end{tabular}

caliper and micrometer, respectively, for the width and thickness, which were used for measurements of fracture toughness specimens. In addition, for the measurements presented in Tables $\mathrm{S} 2$ and $\mathrm{S} 3$, the SDV is also given.

For all width and thickness measurements presented in Fig. S2, average values were calculated and are presented in Table S4. The value of the coefficient of variation (CV) given as

$$
\mathrm{CV}=\frac{\mathrm{SDV}}{\bar{X}},
$$

where $\bar{X}$ is the average value of a group of measurements was calculated. The largest value of CV for the width measu- 
Table S4

Fatigue specimen measurements as presented in Fig. S2 (mm)

\begin{tabular}{c|c|c|c|c|c|c}
\hline Specimen & $\bar{b}$ & $\bar{h}$ & $a_{0}^{(\mathrm{f})}$ & $a_{0}^{(\mathrm{b})}$ & $\Delta_{0}$ & $l$ \\
\hline FTG-wet-1-09 & 19.95 & 4.82 & 53.53 & 53.92 & 0.39 & 200 \\
\hline FTG-wet-1-10 & 19.80 & 4.87 & 53.58 & 54.01 & 0.43 & 200 \\
\hline FTG-wet-1-11 & 19.74 & 4.80 & 54.14 & 54.00 & 0.14 & 200 \\
\hline FTG-wet-1-12 & 19.85 & 4.75 & 53.97 & 53.87 & 0.10 & 200 \\
\hline FTG-wet-1-13 & 19.93 & 4.82 & 53.53 & 53.92 & 0.39 & 200 \\
\hline FTG-wet-1-14 & 19.74 & 4.79 & 53.46 & 53.82 & 0.36 & 200 \\
\hline FTG-wet-1-15 & 20.01 & 4.88 & 53.95 & 54.07 & 0.12 & 200 \\
\hline FTG-wet-1-16 & 19.83 & 4.88 & 53.70 & 53.79 & 0.09 & 200 \\
\hline FTG-wet-1-17 & 20.03 & 4.84 & 53.86 & 54.28 & 0.42 & 199 \\
\hline
\end{tabular}

rements was 0.02 . In addition, for each specimen, the SDV value for each group of thickness measurements $h_{i 1}, h_{i 2}$ and $h_{i 3}(i=2,3,4)$ are presented, as well, in Table S3. The largest value of $\mathrm{CV}$ for the thickness measurements is 0.02 , as well.

In addition, the delamination length measurements shown in Fig. S2, at the front and back sides of the specimen, $a_{0}^{(\mathrm{f})}$ and $a_{0}^{(\mathrm{b})}$, respectively, and the difference between them $\Delta_{0}$ are also presented in Table S4. The measurements were made from the center of the loading block hole to the delamination front using the optical mode of the confocal microscope. The values of $\Delta_{0}$ in Table S4 are less than $2 \mathrm{~mm}$ as recommended in both fracture toughness standards. Similarly, after the tests were performed, the delamination length was measured on both sides of the specimen; these measurements will be presented in Sect. S6. The length of each specimen was measured with a ruler and is also presented in Table S4.

\section{S2. Mechanical and thermal properties of plies in the laminate}

This investigation deals with carbon fiber reinforced polymer (CFRP) composite laminates. Figure 2 in the body of the paper may be consulted for the laminate layup. The constituents include carbon fibers in an epoxy matrix with a small amount of glass fibers in the UD-fabric ply. The mechanical properties of the carbon fibers taken from [4]. The coefficients of thermal expansion (CTEs) were taken from $[5,6]$. Typical properties were taken for the epoxy. From [7], the properties of the glass fibers were obtained. The mechanical and thermal properties are presented in Table S5, where $E_{\mathrm{A}}$ and $E_{\mathrm{T}}$ are the Young's moduli, $G_{\mathrm{A}}$ and $G_{\mathrm{T}}$ are the shear moduli, $v_{\mathrm{A}}$ and $\nu_{\mathrm{T}}$ are the Poisson's ratios, $\alpha_{\mathrm{A}}$ and $\alpha_{\mathrm{T}}$ are the CTEs in the axial and transverse directions, respectively. The carbon fibers are transversely isotropic, described by five independent mechanical properties and two independent CTEs. The shear modulus $G_{\mathrm{T}}$ is related to $E_{\mathrm{T}}$ and $v_{\mathrm{T}}$. The epoxy and glass are both isotropic materials, described by two independent mechanical properties and one independent CTE.

The volume fraction of each constituent in the UD-fabric and woven plies are presented in Table S6. Two samples were provided for each ply and an average value was calculated which was used to obtain the effective material properties by means of the micro-mechanical model, the highfidelity generalized method of cells (HFGMC) [8]. For the UD-fabric, these properties are presented in Table S7. It may be noted that the glass fibers which are transverse to the carbon fibers were used to increase the Young's modulus of the epoxy. Thus, the ply is effectively transversely isotropic.

In order to calculate material properties of the woven ply by means of the HFGMC micromechanical model, a repeating unit cell (RUC) was chosen as shown schematically in two dimensions as the red box in Fig. S3, $a$ and in three dimensions in Fig. S3, $b$. The geometric parameters of the RUC are the thickness of the RUC $h$, the length of the tows $a$ in the $x_{1}$ - and $x_{3}$-directions and the length and width of the epoxy pocket $g$ between them. The parameters $a$ and $g$ were measured at 110 random locations of the ply using a Dino Lite digital microscope (model no. AM311ST, AnMo Electronics Corp., Taiwan). The thickness of an entire specimen was measured with a micrometer at 7 locations. The thickness of the UD fabric ply was measured to be $0.145 \mathrm{~mm}$. By simple arithmetic, the ply thickness $h$ was obtained and is presented in Table S8 together with the SDV. An additional geometric parameter, which is dependent on two of the previous ones, is the angle of the yarn $\beta$ with respect to the $x_{1}$-direction as shown schematically in Fig. S4. This angle is given by

$$
\beta=\tan ^{-1}\left(\frac{h}{4 g}\right)
$$

and is also presented in Table S8.

Mechanical properties [4] and CTEs [5, 6] of carbon fibers, epoxy and glass fibers [7]

\begin{tabular}{c|c|c|c|c|c|c|c|c}
\hline Material & $E_{\mathrm{A}}, \mathrm{GPa}$ & $E_{\mathrm{T}}, \mathrm{GPa}$ & $G_{\mathrm{A}}, \mathrm{GPa}$ & $G_{\mathrm{T}}, \mathrm{GPa}$ & $v_{\mathrm{A}}$ & $v_{\mathrm{T}}$ & $\alpha_{\mathrm{A}}, 10^{-6 /{ }^{\circ} \mathrm{C}}$ & $\alpha_{\mathrm{T}}, 10^{-6 /{ }^{\circ} \mathrm{C}}$ \\
\hline Carbon & 230.0 & 8.0 & 27.3 & 3.08 & 0.26 & 0.30 & -0.41 & 10.08 \\
\hline Epoxy & 2.8 & - & - & - & 0.36 & - & 70.0 & - \\
\hline Glass & 69.0 & - & - & - & 0.22 & - & 7.2 & - \\
\hline
\end{tabular}


Volume fractions of constituents in the UD-fabric and woven plies

\begin{tabular}{l|c|c|c|c|c|c}
\hline \multirow{2}{*}{ Component } & \multicolumn{3}{|c|}{ UD-fabric } & \multicolumn{3}{c}{ Weave } \\
\cline { 2 - 7 } & Sample 1 & Sample 2 & Average & Sample 1 & Sample 2 & Average \\
\hline Carbon, \% & 51.90 & 51.60 & $\mathbf{5 1 . 8}$ & 42.67 & 42.76 & $\mathbf{4 2 . 7}$ \\
\hline Epoxy, \% & 39.44 & 40.54 & $\mathbf{4 0 . 0}$ & 53.81 & 53.85 & $\mathbf{5 3 . 8}$ \\
\hline Glass, \% & 4.56 & 4.10 & $\mathbf{4 . 3}$ & - & - & - \\
\hline Voids, \% & 4.10 & 3.76 & $\mathbf{3 . 9}$ & 3.52 & 3.39 & $\mathbf{3 . 5}$ \\
\hline
\end{tabular}

Table S7

Effective mechanical properties and CTEs of UD-fabric ply

\begin{tabular}{c|c|c|c|c|c|c|c}
\hline$E_{\mathrm{A}}, \mathrm{GPa}$ & $E_{\mathrm{T}}, \mathrm{GPa}$ & $G_{\mathrm{A}}, \mathrm{GPa}$ & $G_{\mathrm{T}}, \mathrm{GPa}$ & $v_{\mathrm{A}}$ & $v_{\mathrm{T}}$ & $\alpha_{\mathrm{A}}, 10^{-6 /{ }^{\circ} \mathrm{C}}$ & $\alpha_{\mathrm{T}}, 10^{-6 /{ }^{\circ} \mathrm{C}}$ \\
\hline 104.4 & 8.74 & 6.60 & 3.15 & 0.30 & 0.39 & 2.32 & 49.70 \\
\hline
\end{tabular}
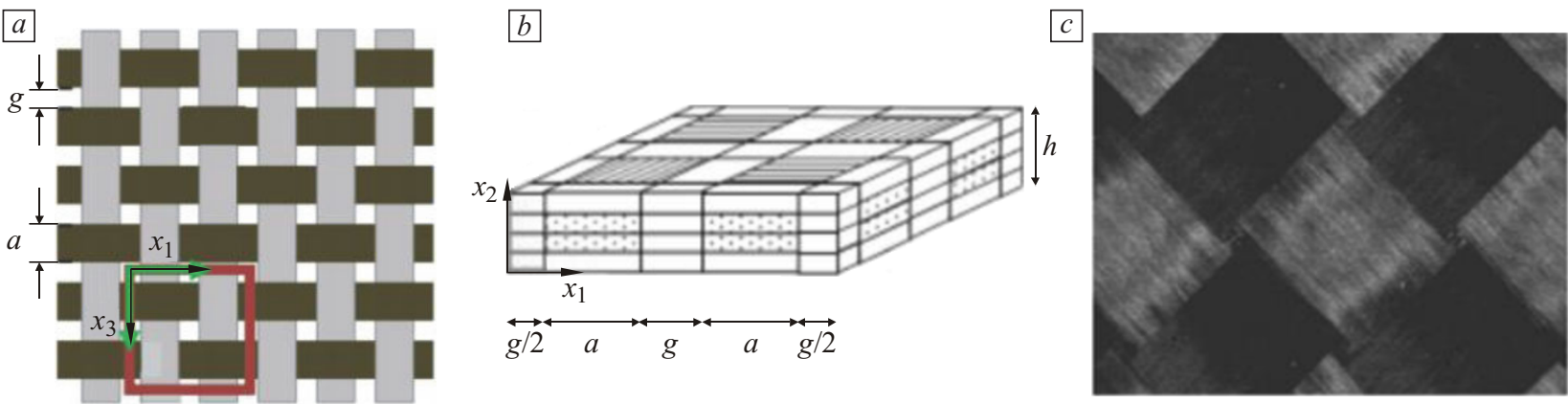

Fig. S3. Two-dimensional schematic view of a plain weave with an RUC shown in red $(a)$; three-dimensional schematic view of the RUC (b); image of $+45^{\circ} /-45^{\circ}$ woven ply (c) (color online)

Using HFGMC with these measurements, together with the constituent properties and volume fractions, the effective mechanical properties and CTEs of the woven ply with tows in the $0^{\circ} / 90^{\circ}$-directions were found; they are presented in Table S9. Further details my be found in [9]. These properties were rotated [10] by $45^{\circ}$ about the $x_{2}$-axis to obtain the effective mechanical properties and CTEs of the ply with tows in the $+45^{\circ} /-45^{\circ}$-direction, which are also presented in Table S9 (see Fig. S3, c).

Rather than modeling each individual ply, six outer, upper and lower plies of the laminate, as presented in Fig. 2, were modeled in the finite element analyses as an effective material with anisotropic, homogenized properties. In this

Table S8

Geometrical measurements of the RUC in the woven ply

\begin{tabular}{c|c|c}
\hline Parameter & Value & SDV \\
\hline$a, \mathrm{~mm}$ & 1.75 & 0.05 \\
\hline$g, \mathrm{~mm}$ & 0.25 & 0.05 \\
\hline$h, \mathrm{~mm}$ & 0.27 & 0.03 \\
\hline$\beta$ & $15.1^{\circ}$ & - \\
\hline
\end{tabular}

way, computer time and memory were reduced. The mechanical properties of the effective material were calculated by means of HFGMC and are presented in Table S10. The effective CTEs are the same as for each woven ply and presented in Table S9. All other plies were modeled individually in the analyses.

\section{S3. Test setup}

The tests (fracture toughness and fatigue) were performed with an Instron hydraulic tensile testing machine (model number 8872; High Wycombe, UK). It includes a fast track 8800 controller as shown in Fig. S5. The load cell has a capacity of $250 \mathrm{~N}$ with an accuracy of $\pm 0.25 \%$ of the load measured for a load greater than $2.5 \mathrm{~N}$. To track the delamination front, a digital camera from LaVision (model Imager pro SX, LaVision GmbH, Göttingen, Ger-

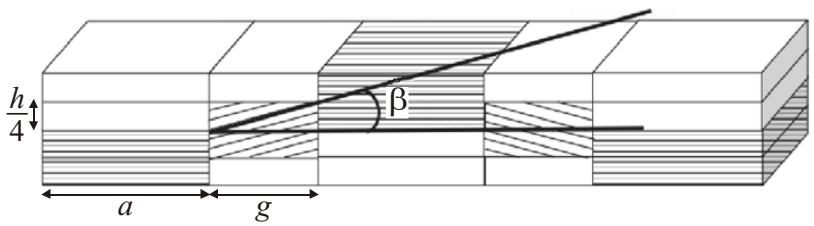

Fig. S4. Schematic view of $\beta$ in the RUC 
Table S9

Weave with tows in the $0^{\circ} / 90^{\circ}$ - and $+45^{\circ} /-45^{\circ}$-directions: effective mechanical properties and CTEs

\begin{tabular}{c|c|c|c|c|c|c}
\hline \multicolumn{7}{c}{ Effective mechanical properties } \\
\hline Orientation & $E_{11}=E_{33}, \mathrm{GPa}$ & $E_{22}, \mathrm{GPa}$ & $G_{13}, \mathrm{GPa}$ & $G_{21}=G_{23}, \mathrm{GPa}$ & $v_{13}$ & $v_{21}=v_{23}$ \\
\hline $0^{\circ} / 90^{\circ}$ & 43.9 & 4.9 & 2.3 & 1.8 & 0.034 & 0.046 \\
\hline$+45^{\circ} /-45^{\circ}$ & 8.4 & 4.9 & 21.2 & 1.8 & 0.816 & 0.046 \\
\hline \multicolumn{7}{c}{ Effective CTEs } \\
\hline Orientation & $\alpha_{11}, 10^{-6} /{ }^{\circ} \mathrm{C}$ & $\alpha_{22}, 10^{-6 /} \mathrm{C}$ & $\alpha_{33}, 10^{-6} /{ }^{\circ} \mathrm{C}$ & $\alpha_{23}, 10^{-6} /{ }^{\circ} \mathrm{C}$ & $\alpha_{13}, 10^{-6 /} /{ }^{\circ} \mathrm{C}$ & $\alpha_{12}, 10^{-6 /{ }^{\circ} \mathrm{C}}$ \\
\hline Both ply types & 4.3 & 72.1 & 4.3 & 0 & 0 & 0 \\
\hline
\end{tabular}

many), was used, with the accompanying computer and software. Using an external PTU (programmable timing unit) controlled by DaVis computer software [11], the images taken with the camera were adjusted to the load and actuator displacement at the moment of capture. An image of the DCB specimen, taken with the camera of the LaVision system, is shown in Fig. S6. All of the LaVision components were synchronized with a LaVision light source shown in Fig. S5. Each time an image was taken, the light source was turned on. In addition, the LaVision system is synchronized with the Instron; the load value appears on the image of the specimen. Attached to the specimen was millimeter paper used for calibration when the delamination length was determined visually. In Fig. S6, it is possible to see tracking marks for the post-test delamination propagation measurements. On both sides of the specimens, white acrylic paint was applied for easier measurement of the delamination length after the test.

\section{S4. Finite element analyses and convergence study}

In this study, DCB specimens were modeled for finite element analyses (FEAs) [12]. Achieving convergence of the results, requires sufficiently fine meshes. For the convergence study, a DCB specimen was modeled with dimensions shown in Fig. 1 of $l=200 \mathrm{~mm}, b=20 \mathrm{~mm}, h=5 \mathrm{~mm}$ and $a_{0}=50 \mathrm{~mm}$. The loading blocks were not modeled. It was found that the difference in the results with and without loading blocks is negligible. Four different meshes were used in the convergence study. Very coarse, coarse, fine and finest meshes with a description of each presented in Table S11. Twenty noded, isoparametric brick elements were used in the analyses. Along the delamination front, quarter-point elements were used to model the dominant

Effective mechanical properties of alternating

Table S10 $+45^{\circ} / 45^{\circ}$ and $0^{\circ} / 90^{\circ}$ plies

\begin{tabular}{c|c|c|c|c|c}
\hline $\begin{array}{c}E_{11}=E_{33}, \\
\mathrm{GPa}\end{array}$ & $\begin{array}{c}E_{22}, \\
\mathrm{GPa}\end{array}$ & $\begin{array}{c}G_{13}, \\
\mathrm{GPa}\end{array}$ & $\begin{array}{c}G_{21}=G_{23}, \\
\mathrm{GPa}\end{array}$ & $v_{13}$ & $v_{21}=v_{23}$ \\
\hline 30.9 & 4.9 & 11.7 & 1.8 & 0.32 & 0.046 \\
\hline
\end{tabular}

square-root singularity. The oscillatory part of the singularity was not modeled.

The laminate layup is presented in Fig. 2. Each of the seven plies, four above and three below the interface, was
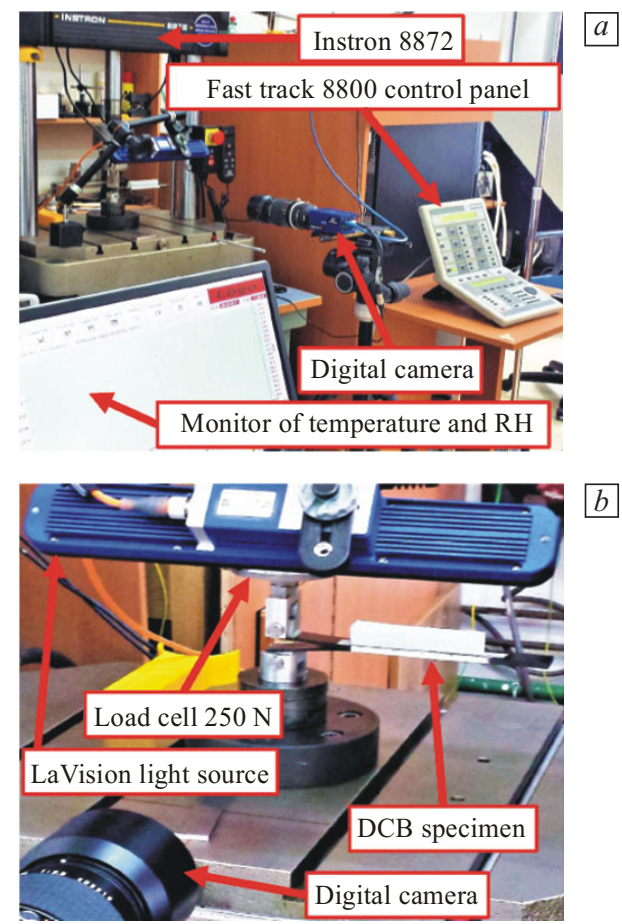

Fig. S5. Test system; zoom out view ( $a$ ) and close-up (b) (color online)

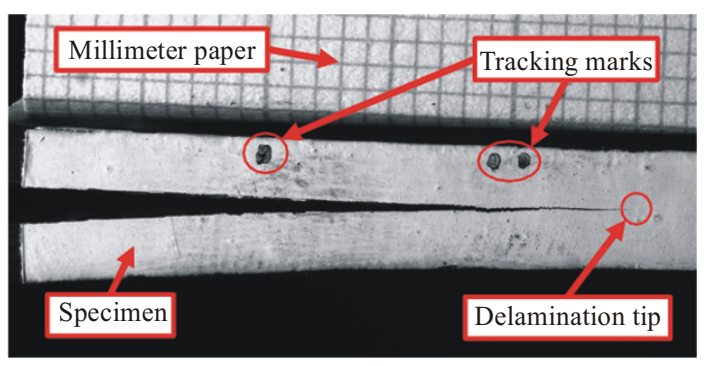

Fig. S6. Image of DCB specimen taken with LaVision digital camera (color online) 
Table S11

Four meshes which were used in a convergence study of the DCB specimen

\begin{tabular}{l|c|c|c}
\hline \multicolumn{1}{c|}{ Mesh } & $\begin{array}{c}\text { No. } \\
\text { of elements }\end{array}$ & $\begin{array}{c}\text { No. of } \\
\text { nodes }\end{array}$ & $\begin{array}{c}\text { Element size near } \\
\text { delamination front, } \mathrm{mm}^{3}\end{array}$ \\
\hline Very coarse & 18720 & 85007 & $0.145 \times 0.145 \times 0.5$ \\
\hline Coarse & 82360 & 352290 & $0.048 \times 0.048 \times 0.5$ \\
\hline Fine & 201600 & 846733 & $0.024 \times 0.024 \times 0.5$ \\
\hline Finest & 310000 & 1293831 & $0.018 \times 0.018 \times 0.5$ \\
\hline
\end{tabular}

modeled individually using their effective homogenous, anisotropic material properties given in Tables S7 and S9. The outer six upper and lower plies were modeled as one effective homogenous, anisotropic material with mechanical properties given in Table S10 and the CTEs in Table S9. These plies are relatively far from the delamination/interface. Therefore, there is no need to model each ply individually. In total, there were four material types used in the finite element analyses: the UD-fabric ply, the $+45^{\circ}$ / $-45^{\circ}$ woven ply, the $0^{\circ} / 90^{\circ}$ woven ply and the group of outer plies. In Fig. 4, the distribution of plies in the finite element model, according to the materials which were used, is presented, with the effective outer material truncated. Thus, the thickness of the outer ply groups are not to scale relative to the other plies.

Two different problems were solved in the convergence study. The first problem examined the DCB specimen with an applied load; in the second, a change in temperature was considered. For the first problem, a line-force perpendicular to the delamination in the $x_{2}$-direction (see Fig. S1) along the specimen width was applied to nodes along the upper surface of the upper arm of the DCB specimen. The force was applied at a distance $a_{0}$ from the delamination front. In addition, the opposite nodes on the lower specimen arm were constrained to be stationary in the $x_{1}$ - and $x_{2}$-directions. The applied load and displacement boundary conditions cause the specimen arms to separate in the $x_{2}$-direction. For all four meshes, there were 40 elements along the width of the specimen which is in the $x_{3}$-direction. As a result of this number and the type of element

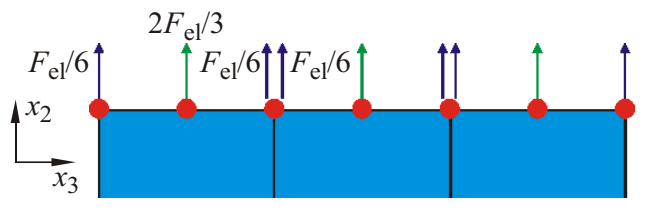

Fig. S7. Example of nodal point forces for three elements along the load line for a DCB specimen (color online)

used, the displacement boundary conditions were applied to 81 nodes on the lower specimen arm. The total force applied in the model was

$$
F_{\mathrm{T}}=20 \mathrm{~N} \text {, }
$$

which occurs at the end of the linear region of the loaddisplacement curves in the tests. This force was divided equally between the 40 elements along the specimen width. The force acting on each element is given by

$$
F_{\mathrm{el}}=\frac{F_{\mathrm{T}}}{n_{\mathrm{el}}}=0.5 \mathrm{~N},
$$

where $n_{\mathrm{el}}$ is the number of elements across the width of a specimen. The force $F_{\text {el }}$ from Eq. (S4) is divided between the three nodes of an element according to finite element theory. In Fig. S7, the load acting on the center node is $2 F_{\text {el }} / 3$, while the force acting on the outer two nodes is $F_{\text {el }} / 6$. As a result, the total force on a shared node from two elements is $F_{\text {el }} / 3$.

In the second problem, a temperature difference was imposed with

$$
\Delta \vartheta=\vartheta_{i}-90^{\circ}
$$

In Eq. (S5), $\vartheta_{i}$ was taken to be a typical room temperature value of $\vartheta_{i}=25^{\circ} \mathrm{C}$. Thus, $\Delta \vartheta=-65^{\circ} \mathrm{C}$. In Eq. (S5), the value of $90^{\circ} \mathrm{C}$ is the maximum temperature which was measured in the laminate during the curing process.

By means of mechanical and thermal $M$-integrals [9], mechanical and thermal residual stress intensity factors were obtained along the delamination front, for the four meshes. For $0.0375 \leq x_{3} / b \leq 0.9625$, the relative difference between the stress intensity factors, for each pair of meshes and for each problem type, was calculated. In Table S12, the largest relative differences (LRD) calculated between the stress intensity factors are presented. One may observe the con-

Table S12

Largest relative difference (LRD) between stress intensity factors along the delamination front with $0.0375 \leq x_{3} / b \leq 0.9625$, for pairs of meshes and for both problems.

The data of the meshes is presented in Table S11

\begin{tabular}{l|c|c|c|c|c|c|c|c|c}
\hline Meshes & \multicolumn{2}{|c|}{ Very coarse and coarse } & \multicolumn{3}{c|}{ Coarse and fine } & \multicolumn{3}{c}{ Fine and finest } \\
\hline & $K_{1}$ & $K_{2}$ & $K_{\mathrm{III}}$ & $K_{1}$ & $K_{2}$ & $K_{\mathrm{III}}$ & $K_{1}$ & $K_{2}$ & $K_{\mathrm{III}}$ \\
\hline \multicolumn{8}{c}{ Mechanical model } \\
\hline LRD, \% & 2.0 & 148.9 & 9.1 & 0.09 & 1.5 & 1.0 & 0.07 & 0.3 & 0.2 \\
\hline \multicolumn{8}{c}{ Thermal model } \\
\hline LRD, \% & 42.7 & 37.4 & 8.0 & 3.7 & 5.2 & 0.8 & 1.5 & 1.0 & 0.2 \\
\hline
\end{tabular}



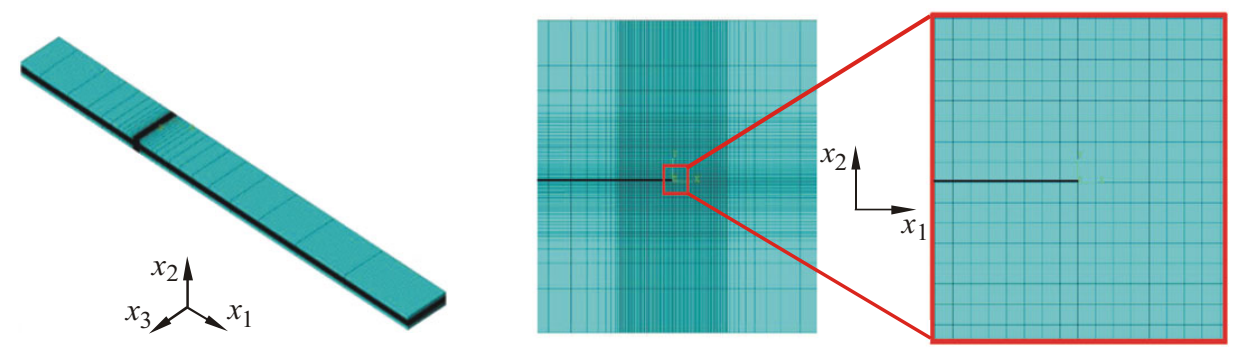

Fig. S8. Finite element mesh for DCB specimen used in this investigation with mesh data presented in Table S11 (color online)

vergence of the stress intensity factors as the meshes become finer. The finest mesh was used in the remainder of this investigation. The data of the mesh is presented in Table S11 and the mesh itself is illustrated in Fig. S8.

Table S13

Constants $p_{i 0}(i=0,1, \ldots, 5)$ and $p_{j 1}(i=0,1, \ldots, 4)$ of Eq. (7) for specimens FT-wet-1-04

\begin{tabular}{c|c|c|c}
\hline Constant & \multicolumn{2}{|c|}{$\begin{array}{c}K_{1}^{(\mathrm{f})}, \\
\mathrm{MPa} \sqrt{\mathrm{mm}}(\mathrm{mm})^{-i \varepsilon}\end{array}$} & $\begin{array}{c}K_{\mathrm{III}}^{(\mathrm{f})}, \\
\mathrm{MPa} \sqrt{\mathrm{mm}}\end{array}$ \\
\hline$p_{00}$ & 0.1676 & 0.0233 & -0.0467 \\
\hline$p_{10}$ & -0.5801 & -0.1628 & 1.6958 \\
\hline$p_{20}$ & 0.8781 & 0.5247 & -11.6128 \\
\hline$p_{30}$ & -0.5945 & -0.7231 & 30.4266 \\
\hline$p_{40}$ & 0.2955 & 0.3603 & -34.0272 \\
\hline$p_{50}$ & 0.0009 & 0.0009 & 13.6109 \\
\hline$p_{01}$ & 0.1654 & -0.2230 & -0.2514 \\
\hline$p_{11}$ & 9.7156 & 2.2110 & 0.9411 \\
\hline$p_{21}$ & -29.1336 & -8.2727 & -1.3149 \\
\hline$p_{31}$ & 38.8350 & 12.1235 & 0.8767 \\
\hline$p_{41}$ & -19.4170 & -6.0617 & -0.0001 \\
\hline
\end{tabular}

Table S15

Constants $p_{i 0}(i=0,1, \ldots, 5)$ and $p_{j 1}(i=0,1, \ldots, 4)$ of Eq. (7) for specimen FT-wet-1-06

\begin{tabular}{c|c|c|c}
\hline \multirow{2}{*}{ Constant } & \multicolumn{2}{|c|}{$\begin{array}{c}K_{1}^{(\mathrm{f})}, \\
\mathrm{MPa} \sqrt{\mathrm{mm}}(\mathrm{mm})^{-i \varepsilon}\end{array}$} & $\begin{array}{c}K_{\mathrm{III}}^{(\mathrm{f})}, \\
\mathrm{MPa} \sqrt{\mathrm{mm}}\end{array}$ \\
\hline$p_{00}$ & 0.1695 & 0.0235 & -0.0463 \\
\hline$p_{10}$ & -0.5892 & -0.1651 & 1.6929 \\
\hline$p_{20}$ & 0.8762 & 0.5333 & -11.5884 \\
\hline$p_{30}$ & -0.5784 & -0.7386 & 30.3502 \\
\hline$p_{40}$ & 0.2969 & 0.3724 & -33.9370 \\
\hline$p_{50}$ & -0.0056 & -0.0020 & 13.5748 \\
\hline$p_{01}$ & 0.1639 & -0.2264 & -0.2560 \\
\hline$p_{11}$ & 9.9238 & 2.2504 & 0.9531 \\
\hline$p_{21}$ & -29.7794 & -8.4313 & -1.3231 \\
\hline$p_{31}$ & 39.7110 & 12.3623 & 0.8821 \\
\hline$p_{41}$ & -19.8555 & -6.1814 & 0.0000 \\
\hline
\end{tabular}

Using the finest mesh determined in the convergence study, mechanical and thermal finite element analyses were performed using specimen FT-wet-1-04 with initial and final delamination lengths from the fracture toughness tests

Table S14

Constants $p_{i 0}(i=0,1, \ldots, 5)$ and $p_{j 1}(i=0,1, \ldots, 4)$ of Eq. (7) for specimen FT-wet-1-05

\begin{tabular}{c|c|c|c}
\hline \multirow{2}{*}{ Constant } & \multicolumn{2}{|c|}{$\begin{array}{c}K_{1}^{(\mathrm{f})}, \\
\mathrm{MPa} \sqrt{\mathrm{mm}}(\mathrm{mm})^{-i \varepsilon}\end{array}$} & $\begin{array}{c}K_{\mathrm{III}}^{(\mathrm{f})}, \\
\mathrm{MPa} \sqrt{\mathrm{mm}}\end{array}$ \\
\hline$p_{00}$ & 0.1674 & 0.0232 & -0.0446 \\
\hline$p_{10}$ & -0.5812 & -0.1640 & 1.6378 \\
\hline$p_{20}$ & 0.8549 & 0.5318 & -11.2065 \\
\hline$p_{30}$ & -0.5527 & -0.7366 & 29.3392 \\
\hline$p_{40}$ & 0.2861 & 0.3704 & -32.8023 \\
\hline$p_{50}$ & -0.0072 & -0.0016 & 13.1209 \\
\hline$p_{01}$ & 0.1562 & -0.2179 & -0.2465 \\
\hline$p_{11}$ & 9.6137 & 2.1701 & 0.9165 \\
\hline$p_{21}$ & -28.8535 & -8.1355 & -1.2706 \\
\hline$p_{31}$ & 38.4794 & 11.9304 & 0.8471 \\
\hline$p_{41}$ & -19.2395 & -5.9650 & 0.0000 \\
\hline
\end{tabular}

Table S16

Constants $p_{i 0}(i=0,1, \ldots, 5)$ and $p_{j 1}(i=0,1, \ldots, 4)$ of Eq. (7) for specimen FT-wet-1-07

\begin{tabular}{c|c|c|c}
\hline Constant & \multicolumn{2}{|c|}{$\begin{array}{c}K_{1}^{(\mathrm{f})}, \\
\mathrm{MPa} \sqrt{\mathrm{mm}}(\mathrm{mm})^{-i \varepsilon}\end{array}$} & $\begin{array}{c}K_{\text {III }}^{(\mathrm{f})}, \\
\mathrm{MPa} \sqrt{\mathrm{mm}}\end{array}$ \\
\hline$p_{00}$ & 0.1734 & 0.0242 & -0.0448 \\
\hline$p_{10}$ & -0.6233 & -0.1746 & 1.6651 \\
\hline$p_{20}$ & 0.9529 & 0.5696 & -11.3866 \\
\hline$p_{30}$ & -0.6525 & -0.7894 & 29.7923 \\
\hline$p_{40}$ & 0.3150 & 0.3936 & -33.3019 \\
\hline$p_{50}$ & 0.0077 & 0.0006 & 13.3208 \\
\hline$p_{01}$ & 0.1552 & -0.2281 & -0.2583 \\
\hline$p_{11}$ & 10.0654 & 2.2643 & 0.9530 \\
\hline$p_{21}$ & -30.2670 & -8.5157 & -1.3092 \\
\hline$p_{31}$ & 40.4029 & 12.5028 & 0.8729 \\
\hline$p_{41}$ & -20.2011 & -6.2513 & -0.0001 \\
\hline
\end{tabular}


Constants $p_{i 0}(i=0,1, \ldots, 5)$ and $p_{j 1}(i=0,1, \ldots, 4)$ of Eq. (7) for specimen FT-wet-1-08

\begin{tabular}{c|c|c|c}
\hline \multirow{2}{*}{ Constant } & \multicolumn{2}{|c|}{$\begin{array}{c}K_{1}^{(\mathrm{f})}, \\
\mathrm{MPa} \sqrt{\mathrm{mm}}(\mathrm{mm})^{-i \varepsilon}\end{array}$} & $\begin{array}{c}K_{\text {III }}^{(\mathrm{f})}, \\
\mathrm{MPa} \sqrt{\mathrm{mm}}\end{array}$ \\
\hline$p_{00}$ & 0.1733 & 0.0241 & -0.0465 \\
\hline$p_{10}$ & -0.6086 & -0.1705 & 1.7119 \\
\hline$p_{20}$ & 0.9002 & 0.5526 & -11.7140 \\
\hline$p_{30}$ & -0.5781 & -0.7633 & 30.6671 \\
\hline$p_{40}$ & 0.2790 & 0.3793 & -34.2868 \\
\hline$p_{50}$ & 0.0076 & 0.0021 & 13.7148 \\
\hline$p_{01}$ & 0.1618 & -0.2312 & -0.2615 \\
\hline$p_{11}$ & 10.1134 & 2.2889 & 0.9687 \\
\hline$p_{21}$ & -30.3733 & -8.5954 & -1.3375 \\
\hline$p_{31}$ & 40.5206 & 12.6136 & 0.8919 \\
\hline$p_{41}$ & -20.2608 & -6.3071 & -0.0002 \\
\hline
\end{tabular}

of $a_{0}=53.9 \mathrm{~mm}$ and $a_{\mathrm{f}}=114.8 \mathrm{~mm}$. The final delamination length was measured from the last image taken during the test. For each of the two delamination lengths, $F_{\mathrm{T}}$ was taken as the value recorded in the test. The thermal analyses were performed as described here, but with the temperature change in Eq. (S5) appropriate for this specimen; namely, $\vartheta_{i}=21.6^{\circ} \mathrm{C}$, the initial temperature in the test. All stress intensity factors were calculated along the delamina-

Table S19

Constants $d_{i}(i=0,1,2, \ldots, 14)$ of Eq. (9) for specimen FT-wet-1-05

\begin{tabular}{|c|c|c|c|}
\hline Constant & $\begin{array}{l}K_{1}^{(\mathrm{r})}, \\
\quad \mathrm{MPa} \sqrt{\mathrm{n}}\end{array}$ & $\begin{array}{r}K_{2}^{(\mathrm{r})}, \\
\overline{\mathrm{m}}(\mathrm{mm})^{-i \varepsilon}\end{array}$ & $\begin{array}{c}K_{\mathrm{III}}^{(\mathrm{r})}, \\
\mathrm{MPa} \sqrt{\mathrm{mm}}\end{array}$ \\
\hline$d_{0}$ & -5.3845 & 0.4263 & 9.0172 \\
\hline$d_{1}$ & 252.25 & -48.738 & -340.26 \\
\hline$d_{2}$ & $-6.0796 \times 10^{3}$ & $1.3662 \times 10^{3}$ & $7.4853 \times 10^{3}$ \\
\hline$d_{3}$ & $8.7606 \times 10^{4}$ & $-2.0252 \times 10^{4}$ & $-9.5652 \times 10^{4}$ \\
\hline$d_{4}$ & $-8.0286 \times 10^{5}$ & $1.8841 \times 10^{5}$ & $7.6952 \times 10^{5}$ \\
\hline$d_{5}$ & $4.9483 \times 10^{6}$ & $-1.1748 \times 10^{6}$ & $-4.1234 \times 10^{6}$ \\
\hline$d_{6}$ & $-2.1297 \times 10^{7}$ & $5.1031 \times 10^{6}$ & $1.5242 \times 10^{7}$ \\
\hline$d_{7}$ & $6.5506 \times 10^{7}$ & $-1.5809 \times 10^{7}$ & $-3.9649 \times 10^{7}$ \\
\hline$d_{8}$ & $-1.4570 \times 10^{8}$ & $3.5357 \times 10^{7}$ & $7.3082 \times 10^{7}$ \\
\hline$d_{9}$ & $2.3464 \times 10^{8}$ & $-5.7169 \times 10^{7}$ & $-9.4860 \times 10^{7}$ \\
\hline$d_{10}$ & $-2.7072 \times 10^{8}$ & $6.6151 \times 10^{7}$ & $8.4732 \times 10^{7}$ \\
\hline$d_{11}$ & $2.1799 \times 10^{8}$ & $-5.3372 \times 10^{7}$ & $-4.9551 \times 10^{7}$ \\
\hline$d_{12}$ & $-1.1627 \times 10^{8}$ & $2.8501 \times 10^{7}$ & $1.7072 \times 10^{7}$ \\
\hline$d_{13}$ & $3.6894 \times 10^{7}$ & $-9.0486 \times 10^{6}$ & $-2.6261 \times 10^{6}$ \\
\hline$d_{14}$ & $-5.2706 \times 10^{6}$ & $1.2927 \times 10^{6}$ & -102.88 \\
\hline
\end{tabular}

Constants $d_{i}(i=0,1,2, \ldots, 14)$ of Eq. (9) for specimen FT-wet-1-04

\begin{tabular}{|c|c|c|c|}
\hline Constant & $\begin{array}{l}K_{1}^{(\mathrm{r})}, \\
\quad \mathrm{MPa} \sqrt{\mathrm{r}}\end{array}$ & $\begin{array}{r}K_{2}^{(\mathrm{r})}, \\
\overline{\mathrm{m}}(\mathrm{mm})^{-i \varepsilon}\end{array}$ & $\begin{array}{c}K_{\mathrm{III}}^{(\mathrm{r})}, \\
\mathrm{MPa} \sqrt{\mathrm{mm}}\end{array}$ \\
\hline$d_{0}$ & -5.4592 & 0.4383 & 9.1482 \\
\hline$d_{1}$ & 257.50 & -49.530 & -345.03 \\
\hline$d_{2}$ & $-6.2176 \times 10^{3}$ & $1.3898 \times 10^{3}$ & $7.5773 \times 10^{3}$ \\
\hline$d_{3}$ & $8.9617 \times 10^{4}$ & $-2.0632 \times 10^{4}$ & $-9.6728 \times 10^{4}$ \\
\hline$d_{4}$ & $-8.2128 \times 10^{5}$ & $1.9215 \times 10^{5}$ & $7.7771 \times 10^{5}$ \\
\hline$d_{5}$ & $5.0617 \times 10^{6}$ & $-1.1990 \times 10^{6}$ & $-4.1656 \times 10^{6}$ \\
\hline$d_{6}$ & $-2.1784 \times 10^{7}$ & $5.2105 \times 10^{6}$ & $1.5394 \times 10^{7}$ \\
\hline$d_{7}$ & $6.7004 \times 10^{7}$ & $-1.6147 \times 10^{7}$ & $-4.0037 \times 10^{7}$ \\
\hline$d_{8}$ & $-1.4904 \times 10^{8}$ & $3.6121 \times 10^{7}$ & $7.3789 \times 10^{7}$ \\
\hline$d_{9}$ & $2.4001 \times 10^{8}$ & $-5.8415 \times 10^{7}$ & $-9.5771 \times 10^{7}$ \\
\hline$d_{10}$ & $-2.7691 \times 10^{8}$ & $6.7600 \times 10^{7}$ & $8.5542 \times 10^{7}$ \\
\hline$d_{11}$ & $2.2298 \times 10^{8}$ & $-5.4545 \times 10^{7}$ & $-5.0024 \times 10^{7}$ \\
\hline$d_{12}$ & $-1.1893 \times 10^{8}$ & $2.9128 \times 10^{7}$ & $1.7235 \times 10^{7}$ \\
\hline$d_{13}$ & $3.7739 \times 10^{7}$ & $-9.2479 \times 10^{6}$ & $-2.6516 \times 10^{6}$ \\
\hline$d_{14}$ & $-5.5913 \times 10^{6}$ & $1.3211 \times 10^{6}$ & -7.5699 \\
\hline
\end{tabular}

tion front by means of the mechanical and thermal $M$-integrals, resulting in $K_{m}^{(\mathrm{f})}(m=1,2, \mathrm{III})$ for the former and $K_{m}^{(\mathrm{r})}$ for the latter. For each of the two delamination lengths,

Table S20

Constants $d_{i}(i=0,1,2, \ldots, 14)$ of Eq. (9) for specimen FT-wet-1-06

\begin{tabular}{|c|c|c|c|}
\hline Constant & \multicolumn{2}{|c|}{$\mathrm{MPa} \sqrt{\mathrm{mm}}(\mathrm{mm})^{-i \varepsilon}$} & $\begin{array}{c}K_{\mathrm{III}}^{(\mathrm{r})}, \\
\mathrm{MPa} \sqrt{\mathrm{mm}}\end{array}$ \\
\hline$d_{0}$ & -5.3928 & 0.4279 & 9.0077 \\
\hline$d_{1}$ & 253.25 & -48.851 & -339.42 \\
\hline$d_{2}$ & $-6.1091 \times 10^{3}$ & $1.3703 \times 10^{3}$ & $7.4583 \times 10^{3}$ \\
\hline$d_{3}$ & $8.8054 \times 10^{4}$ & $-2.0329 \times 10^{4}$ & $-9.5244 \times 10^{4}$ \\
\hline$d_{4}$ & $-8.0706 \times 10^{5}$ & $1.8924 \times 10^{5}$ & $7.6593 \times 10^{5}$ \\
\hline$d_{5}$ & $4.9745 \times 10^{6}$ & $-1.1805 \times 10^{6}$ & $-4.1031 \times 10^{6}$ \\
\hline$d_{6}$ & $-2.1410 \times 10^{7}$ & $5.1292 \times 10^{6}$ & $1.5164 \times 10^{7}$ \\
\hline$d_{7}$ & $6.5858 \times 10^{7}$ & $-1.5894 \times 10^{7}$ & $-3.9441 \times 10^{7}$ \\
\hline$d_{8}$ & $-1.4649 \times 10^{8}$ & $3.5551 \times 10^{7}$ & $7.2693 \times 10^{7}$ \\
\hline$d_{9}$ & $2.3591 \times 10^{8}$ & $-5.7489 \times 10^{7}$ & $-9.4350 \times 10^{7}$ \\
\hline$d_{10}$ & $-2.7219 \times 10^{8}$ & $6.6527 \times 10^{7}$ & $8.4274 \times 10^{7}$ \\
\hline$d_{11}$ & $2.1918 \times 10^{8}$ & $-5.3678 \times 10^{7}$ & $-4.9283 \times 10^{7}$ \\
\hline$d_{12}$ & $-1.1690 \times 10^{8}$ & $2.8665 \times 10^{7}$ & $1.6980 \times 10^{7}$ \\
\hline$d_{13}$ & $3.7095 \times 10^{7}$ & $-9.1010 \times 10^{6}$ & $-2.6121 \times 10^{6}$ \\
\hline$d_{14}$ & $-5.2993 \times 10^{6}$ & $1.3002 \times 10^{6}$ & -41.821 \\
\hline
\end{tabular}


Constants $d_{i}(i=0,1,2, \ldots, 14)$ of Eq. (9) for specimen FT-wet-1-07

\begin{tabular}{c|c|c|c}
\hline \multirow{2}{*}{ Constant } & \multicolumn{2}{|c|}{$K_{1}^{(\mathrm{r})}}$, & $K_{2}^{(\mathrm{r})}$, \\
& \multicolumn{2}{|c|}{$\mathrm{MPa} \sqrt{\mathrm{mm}}(\mathrm{mm})^{-i \varepsilon}$} & $\begin{array}{c}K_{\mathrm{III}}^{(\mathrm{r})}, \\
\mathrm{MPa} \sqrt{\mathrm{mm}}\end{array}$ \\
\hline$d_{0}$ & -5.2189 & 0.4049 & 8.6832 \\
\hline$d_{1}$ & 243.09 & -47.104 & -326.86 \\
\hline$d_{2}$ & $-5.8527 \times 10^{3}$ & $1.3210 \times 10^{3}$ & $7.1927 \times 10^{3}$ \\
\hline$d_{3}$ & $8.4350 \times 10^{4}$ & $-1.9573 \times 10^{4}$ & $-9.1935 \times 10^{4}$ \\
\hline$d_{4}$ & $-7.7322 \times 10^{5}$ & $1.8205 \times 10^{5}$ & $7.3972 \times 10^{5}$ \\
\hline$d_{5}$ & $4.7666 \times 10^{6}$ & $-1.1349 \times 10^{6}$ & $-3.9640 \times 10^{6}$ \\
\hline$d_{6}$ & $-2.0517 \times 10^{7}$ & $4.9287 \times 10^{6}$ & $1.4654 \times 10^{7}$ \\
\hline$d_{7}$ & $6.3113 \times 10^{7}$ & $-1.5268 \times 10^{7}$ & $-3.8118 \times 10^{7}$ \\
\hline$d_{8}$ & $-1.4039 \times 10^{8}$ & $3.4143 \times 10^{7}$ & $7.0263 \times 10^{7}$ \\
\hline$d_{9}$ & $2.2609 \times 10^{8}$ & $-5.5203 \times 10^{7}$ & $-9.1203 \times 10^{7}$ \\
\hline$d_{10}$ & $-2.6086 \times 10^{8}$ & $6.3874 \times 10^{7}$ & $8.1467 \times 10^{7}$ \\
\hline$d_{11}$ & $2.1006 \times 10^{8}$ & $-5.1533 \times 10^{7}$ & $-4.7642 \times 10^{7}$ \\
\hline$d_{12}$ & $-1.1204 \times 10^{8}$ & $2.7518 \times 10^{7}$ & $1.6415 \times 10^{7}$ \\
\hline$d_{13}$ & $3.5552 \times 10^{7}$ & $-8.7366 \times 10^{6}$ & $-2.5252 \times 10^{6}$ \\
\hline$d_{14}$ & $-5.0789 \times 10^{6}$ & $1.2481 \times 10^{6}$ & -34.833 \\
\hline
\end{tabular}

the mechanical and thermal stress intensity factors were summed as

$$
K_{m}^{(\mathrm{t})}=K_{m}^{(\mathrm{f})}+K_{m}^{(\mathrm{r})},
$$

where $K_{m}^{(\mathrm{t})}$ is the total stress intensity factor. Two phase angles, $\psi$ and $\phi$ were calculated along the delamination front as [13]

$$
\psi=\tan ^{-1}\left[\frac{I\left(K^{(\mathrm{t})} \hat{L}^{i \varepsilon}\right)}{R\left(K^{(\mathrm{t})} \hat{L}^{i \varepsilon}\right)}\right],
$$

Table S23

Constants $p_{i 0}(i=0,1, \ldots, 5)$ and $p_{j 1}(i=0,1, \ldots, 4)$ of Eq. (7) for specimen FTG-wet-1-09

\begin{tabular}{c|c|c|c}
\hline Constant & \multicolumn{2}{|c|}{$\begin{array}{c}K_{1}^{(\mathrm{f})}, \\
\mathrm{MPa} \sqrt{\mathrm{mm}}(\mathrm{mm})^{-i \varepsilon}\end{array}$} & $\begin{array}{c}K_{\text {III }}^{(\mathrm{f})}, \\
\mathrm{MPa} \sqrt{\mathrm{mm}}\end{array}$ \\
\hline$p_{00}$ & 0.1728 & 0.0241 & -0.0317 \\
\hline$p_{10}$ & -0.6163 & -0.1723 & 1.2753 \\
\hline$p_{20}$ & 0.9381 & 0.5609 & -8.6704 \\
\hline$p_{30}$ & -0.6404 & -0.7772 & 22.5618 \\
\hline$p_{40}$ & 0.3142 & 0.3885 & -25.1721 \\
\hline$p_{50}$ & 0.0046 & 0.0002 & 10.0687 \\
\hline$p_{01}$ & 0.1581 & -0.2295 & -0.2594 \\
\hline$p_{11}$ & 10.0528 & 2.2669 & 0.9600 \\
\hline$p_{21}$ & -30.2104 & -8.5236 & -1.3234 \\
\hline$p_{31}$ & 40.3157 & 12.5136 & 0.8819 \\
\hline$p_{41}$ & -20.1582 & -6.2569 & 0.0003 \\
\hline
\end{tabular}

Constants $d_{i}(i=0,1,2, \ldots, 14)$ of Eq. (9) for specimen FT-wet-1-08

\begin{tabular}{c|c|c|c}
\hline \multirow{2}{*}{ Constant } & \multicolumn{2}{|c|}{$K_{1}^{(\mathrm{r})}}$, & $K_{2}^{(\mathrm{r})}$, \\
& \multicolumn{2}{|c|}{$\mathrm{MPa} \sqrt{\mathrm{mm}}(\mathrm{mm})^{-i \varepsilon}$} & $\begin{array}{c}K_{\mathrm{II}}^{(\mathrm{r})}, \\
\mathrm{MPa} \sqrt{\mathrm{mm}}\end{array}$ \\
\hline$d_{0}$ & -5.2583 & 0.4119 & 8.7479 \\
\hline$d_{1}$ & 246.07 & -47.536 & -329.12 \\
\hline$d_{2}$ & $-5.9324 \times 10^{3}$ & $1.3339 \times 10^{3}$ & $7.2335 \times 10^{3}$ \\
\hline$d_{3}$ & $8.5516 \times 10^{4}$ & $-1.9783 \times 10^{4}$ & $-9.2387 \times 10^{4}$ \\
\hline$d_{4}$ & $-7.8392 \times 10^{5}$ & $1.8413 \times 10^{5}$ & $7.4301 \times 10^{5}$ \\
\hline$d_{5}$ & $4.8325 \times 10^{6}$ & $-1.1484 \times 10^{6}$ & $-3.9804 \times 10^{6}$ \\
\hline$d_{6}$ & $-2.0801 \times 10^{7}$ & $4.9893 \times 10^{6}$ & $1.4712 \times 10^{7}$ \\
\hline$d_{7}$ & $6.3986 \times 10^{7}$ & $-1.5459 \times 10^{7}$ & $-3.8264 \times 10^{7}$ \\
\hline$d_{8}$ & $-1.4233 \times 10^{8}$ & $3.4576 \times 10^{7}$ & $7.0525 \times 10^{7}$ \\
\hline$d_{9}$ & $2.2922 \times 10^{8}$ & $-5.5910 \times 10^{7}$ & $-9.1537 \times 10^{7}$ \\
\hline$d_{10}$ & $-2.6447 \times 10^{8}$ & $6.4697 \times 10^{7}$ & $8.1762 \times 10^{7}$ \\
\hline$d_{11}$ & $2.2197 \times 10^{8}$ & $-5.2200 \times 10^{7}$ & $-4.7814 \times 10^{7}$ \\
\hline$d_{12}$ & $-1.1359 \times 10^{8}$ & $2.7875 \times 10^{7}$ & $1.6474 \times 10^{7}$ \\
\hline$d_{13}$ & $3.6045 \times 10^{7}$ & $-8.8501 \times 10^{6}$ & $-2.5344 \times 10^{6}$ \\
\hline$d_{14}$ & $-5.1492 \times 10^{6}$ & $1.2643 \times 10^{6}$ & -14.148 \\
\hline & & &
\end{tabular}

$$
\psi=\tan ^{-1}\left[\sqrt{\frac{H_{1}}{H_{2}}} \frac{K_{\mathrm{III}}^{(\mathrm{t})}}{\sqrt{K_{1}^{(\mathrm{t}) 2}+K_{2}^{(\mathrm{t}) 2}}}\right] .
$$

In Eq. (S7), $R$ and $I$ are the real and imaginary parts of the quantities in parentheses, $i=\sqrt{-1}, K^{(\mathrm{t})}=K_{1}^{(\mathrm{t})}+i K_{2}^{(\mathrm{t})}, \hat{L}$ is an arbitrary length parameter which was set to $0.2 \mathrm{~mm}$. The oscillatory parameter $\varepsilon=0.0452, H_{1}=7.87 \mathrm{GPa}, H_{2}=$ $=10.49 \mathrm{GPa}$, all depending on the mechanical properties

Table S24

Constants $p_{i 0}(i=0,1, \ldots, 5)$ and $p_{j 1}(i=0,1, \ldots, 4)$ of Eq. (7) for specimen FTG-wet-1-10

\begin{tabular}{c|c|c|c}
\hline Constant & \multicolumn{2}{|c|}{$\begin{array}{c}K_{1}^{(\mathrm{f})}, \\
\mathrm{MPa} \sqrt{\mathrm{mm}}(\mathrm{mm})^{-i \varepsilon}\end{array}$} & $\begin{array}{c}K_{\mathrm{III}}^{(\mathrm{f})}, \\
\mathrm{MPa} \sqrt{\mathrm{mm}}\end{array}$ \\
\hline$p_{00}$ & 0.1737 & 0.0240 & -0.0324 \\
\hline$p_{10}$ & -0.6092 & -0.1702 & 1.2996 \\
\hline$p_{20}$ & 0.8971 & 0.5533 & -8.8391 \\
\hline$p_{30}$ & -0.5791 & -0.7674 & 23.0079 \\
\hline$p_{40}$ & 0.2905 & 0.3850 & -25.6727 \\
\hline$p_{50}$ & 0.0011 & -0.0006 & 10.2691 \\
\hline$p_{01}$ & 0.1612 & -0.2318 & -0.2625 \\
\hline$p_{11}$ & 10.1401 & 2.2926 & 0.9712 \\
\hline$p_{21}$ & -30.4597 & -8.6162 & -1.3383 \\
\hline$p_{31}$ & 40.6430 & 12.6480 & 0.8921 \\
\hline$p_{41}$ & -20.3238 & -6.3244 & 0.0001 \\
\hline
\end{tabular}


Constants $p_{i 0}(i=0,1, \ldots, 5)$ and $p_{j 1}(i=0,1, \ldots, 4)$ of Eq. (7) for specimen FTG-wet-1-11

\begin{tabular}{c|c|c|c}
\hline Constant & \multicolumn{2}{|c|}{$\begin{array}{c}K_{1}^{(\mathrm{f})}, \\
\mathrm{MPa} \sqrt{\mathrm{mm}}(\mathrm{mm})^{-i \varepsilon}\end{array}$} & $\begin{array}{c}K_{\text {III }}^{(\mathrm{f})}, \\
\mathrm{MPa} \sqrt{\mathrm{mm}}\end{array}$ \\
\hline$p_{00}$ & 0.1780 & 0.0248 & -0.0327 \\
\hline$p_{10}$ & -0.6439 & -0.1798 & 1.3228 \\
\hline$p_{20}$ & 0.9959 & 0.5905 & -8.9937 \\
\hline$p_{30}$ & -0.7048 & -0.8218 & 23.4006 \\
\hline$p_{40}$ & 0.3538 & 0.4118 & -26.1072 \\
\hline$p_{50}$ & -0.0007 & -0.0006 & 10.4428 \\
\hline$p_{01}$ & 0.1625 & -0.2423 & -0.2742 \\
\hline$p_{11}$ & 10.5546 & 2.3841 & 1.0110 \\
\hline$p_{21}$ & -31.7464 & -8.9841 & -1.3876 \\
\hline$p_{31}$ & 42.3839 & 13.2002 & 0.9250 \\
\hline$p_{41}$ & -21.1925 & -6.6003 & 0.0001 \\
\hline
\end{tabular}

of the plies on either side of the interface. The phase angle $\psi$ represents the in-plane mode mixity; whereas, the phase angle $\phi$ represents the out-of-plane to in-plane mode mixity. It was found that both $\psi$ and $\phi$ were less than 0.2 rad along the delamination front, except near the specimen edges. Thus, the shear modes are negligible. As a result, the total energy release rate $G_{\mathrm{T}}$ is considered to be the mode I energy release rate $G_{\mathrm{I}}$. Although $K_{1}^{(\mathrm{t})}$ was dominant, calculations of $G_{\mathrm{I}}$ included all stress intensity factors as given in Eq. (11).

As described in Sect. 3.1, surfaces were fit through the finite element results for each of the five fracture tough-

Table S27

Constants $p_{i 0}(i=0,1, \ldots, 5)$ and $p_{j 1}(i=0,1, \ldots, 4)$ of Eq. (7) for specimen FTG-wet-1-13

\begin{tabular}{c|c|c|c}
\hline Constant & \multicolumn{2}{|c|}{$\begin{array}{c}K_{1}^{(\mathrm{f})}, \\
\mathrm{MPa} \sqrt{\mathrm{mm}}(\mathrm{mm})^{-i \varepsilon}\end{array}$} & $\begin{array}{c}K_{\text {III }}^{(\mathrm{f})}, \\
\mathrm{MPa} \sqrt{\mathrm{mm}}\end{array}$ \\
\hline$p_{00}$ & 0.1768 & 0.0247 & -0.0317 \\
\hline$p_{10}$ & -0.6400 & -0.1799 & 1.2919 \\
\hline$p_{20}$ & 0.9795 & 0.5903 & -8.7797 \\
\hline$p_{30}$ & -0.6772 & -0.8194 & 22.8341 \\
\hline$p_{40}$ & 0.3368 & 0.4076 & -25.4718 \\
\hline$p_{50}$ & 0.0009 & 0.0013 & 10.1889 \\
\hline$p_{01}$ & 0.1561 & -0.2349 & -0.2660 \\
\hline$p_{11}$ & 10.2950 & 2.3173 & 0.9791 \\
\hline$p_{21}$ & -30.9708 & -8.7347 & -1.3414 \\
\hline$p_{31}$ & 41.3507 & 12.8346 & 0.8948 \\
\hline$p_{41}$ & -20.6749 & -6.4171 & -0.0005 \\
\hline
\end{tabular}

Constants $p_{i 0}(i=0,1, \ldots, 5)$ and $p_{j 1}(i=0,1, \ldots, 4)$ of Eq. (7) for specimen FTG-wet-1-12

\begin{tabular}{c|c|c|c}
\hline \multirow{2}{*}{ Constant } & \multicolumn{2}{|c|}{$\begin{array}{c}K_{1}^{(\mathrm{f})}, \\
\mathrm{MPa} \sqrt{\mathrm{mm}}(\mathrm{mm})^{-i \varepsilon}\end{array}$} & $\begin{array}{c}K_{\text {III }}^{(\mathrm{f})}, \\
\mathrm{MPa} \sqrt{\mathrm{mm}}\end{array}$ \\
\hline$p_{00}$ & 0.1805 & 0.0252 & -0.0320 \\
\hline$p_{10}$ & -0.6589 & -0.1827 & 1.3153 \\
\hline$p_{20}$ & 1.0117 & 0.5957 & -8.9373 \\
\hline$p_{30}$ & -0.7039 & -0.8251 & 23.2372 \\
\hline$p_{40}$ & 0.3493 & 0.4119 & -25.9190 \\
\hline$p_{50}$ & 0.0015 & 0.0001 & 10.3679 \\
\hline$p_{01}$ & 0.1582 & -0.2446 & -0.2772 \\
\hline$p_{11}$ & 10.6825 & 2.4003 & 1.0166 \\
\hline$p_{21}$ & -32.1603 & -9.0616 & -1.3872 \\
\hline$p_{31}$ & 42.9550 & 13.3217 & 0.9256 \\
\hline$p_{41}$ & -21.4770 & -6.6603 & -0.0007 \\
\hline
\end{tabular}

ness specimens to obtain a relation between $K_{m}^{(\mathrm{f})}(m=1$, 2 , III), the normalized delamination length $a / a_{0}$ and normalized position along the delamination front $x_{3} / b$ for the mechanical problem (f). The equation for the surfaces is given in Eq. (7). The values of $p_{i 0}$ and $p_{j 1}(i=0,1, \ldots, 5$ and $j=0,1, \ldots, 4)$ in this equation are given in Tables S13 through S17.

For the residual stress intensity factors arising from the curing process, lines were fit through the finite element results to obtain a relation between $K_{m}^{(\mathrm{r})}(m=1,2$, III) and normalized position along the delamination front $x_{3} / b$. The equation for the lines is given in Eq. (9). The values of $d_{i}$

Table S28

Constants $p_{i 0}(i=0,1, \ldots, 5)$ and $p_{j 1}(i=0,1, \ldots, 4)$ of Eq. (7) for specimen FTG-wet-1-14

\begin{tabular}{c|c|c|c}
\hline Constant & \multicolumn{2}{|c|}{$\begin{array}{c}K_{1}^{(\mathrm{f})}, \\
\mathrm{MPa} \sqrt{\mathrm{mm}}(\mathrm{mm})^{-i \varepsilon}\end{array}$} & $\begin{array}{c}K_{\mathrm{III}}^{(\mathrm{f})}, \\
\mathrm{MPa} \sqrt{\mathrm{mm}}\end{array}$ \\
\hline$p_{00}$ & 0.1785 & 0.0249 & -0.0327 \\
\hline$p_{10}$ & -0.6428 & -0.1795 & 1.3253 \\
\hline$p_{20}$ & 0.9820 & 0.5868 & -9.0088 \\
\hline$p_{30}$ & -0.6786 & -0.8154 & 23.4365 \\
\hline$p_{40}$ & 0.3384 & 0.4090 & -26.1460 \\
\hline$p_{50}$ & 0.0011 & -0.0008 & 10.4584 \\
\hline$p_{01}$ & 0.1604 & -0.2406 & -0.2722 \\
\hline$p_{11}$ & 10.4586 & 2.3607 & 1.0032 \\
\hline$p_{21}$ & -31.4559 & -8.8995 & -1.3765 \\
\hline$p_{31}$ & 41.9955 & 13.0778 & 0.9178 \\
\hline$p_{41}$ & -20.9983 & -6.5390 & -0.0002 \\
\hline
\end{tabular}


Constants $p_{i 0}(i=0,1, \ldots, 5)$ and $p_{j 1}(i=0,1, \ldots, 4)$ of Eq. (7) for specimen FTG-wet-1-15

\begin{tabular}{c|c|c|c}
\hline \multirow{2}{*}{ Constant } & \multicolumn{2}{|c|}{$\begin{array}{c}K_{1}^{(\mathrm{f})}, \\
\mathrm{MPa} \sqrt{\mathrm{mm}}(\mathrm{mm})^{-i \varepsilon}\end{array}$} & $\begin{array}{c}K_{\mathrm{III}}^{(\mathrm{f})}, \\
\mathrm{MPa} \sqrt{\mathrm{mm}}\end{array}$ \\
\hline$p_{00}$ & 0.1738 & 0.0244 & -0.0314 \\
\hline$p_{10}$ & -0.6268 & -0.1779 & 1.2710 \\
\hline$p_{20}$ & 0.9701 & 0.5868 & -8.6391 \\
\hline$p_{30}$ & -0.6907 & -0.8195 & 22.4738 \\
\hline$p_{40}$ & 0.3512 & 0.4124 & -25.0718 \\
\hline$p_{50}$ & -0.0039 & -0.0019 & 10.0287 \\
\hline$p_{01}$ & 0.1563 & -0.2307 & -0.2609 \\
\hline$p_{11}$ & 10.1236 & 2.2805 & 0.9636 \\
\hline$p_{21}$ & -30.4432 & -8.5871 & -1.3252 \\
\hline$p_{31}$ & 40.6403 & 12.6135 & 0.8837 \\
\hline$p_{41}$ & -20.3207 & -6.3068 & -0.0001 \\
\hline
\end{tabular}

$(i=0,1, \ldots, 14)$ in this equation are given in Tables S18 through S22.

For the nine fatigue delamination propagation specimens, the values of $p_{i 0}$ and $p_{i 1}(i=0,1, \ldots, 5$ and $j=0$, $1, \ldots, 4)$ from Eq. (7), are given for each specimen in Tables S23 through S31. The value of $d_{i}(i=0,1, \ldots, 14)$ from Eq. (9) are given for each specimen in Tables S32 through S40.

\section{S5. Fracture toughness tests}

Fracture toughness tests were carried out on five DCB specimens guided by the ASTM [1] and ISO [2] standards. These standards were developed for UD laminates. Values

Table S31

Constants $p_{i 0}(i=0,1, \ldots, 5)$ and $p_{j 1}(i=0,1, \ldots, 4)$ of Eq. (7) for specimen FTG-wet-1-17

\begin{tabular}{c|c|c|c}
\hline Constant & \multicolumn{2}{|c|}{$\begin{array}{c}K_{1}^{(\mathrm{f})}, \\
\mathrm{MPa} \sqrt{\mathrm{mm}}(\mathrm{mm})^{-i \varepsilon}\end{array}$} & $\begin{array}{c}K_{\mathrm{III}}^{(\mathrm{f})}, \\
\mathrm{MPa} \sqrt{\mathrm{mm}}\end{array}$ \\
\hline$p_{00}$ & 0.1754 & 0.0244 & -0.0312 \\
\hline$p_{10}$ & -0.6344 & -0.1755 & 1.2743 \\
\hline$p_{20}$ & 0.9716 & 0.5734 & -8.6587 \\
\hline$p_{30}$ & -0.6720 & -0.7962 & 22.5160 \\
\hline$p_{40}$ & 0.3321 & 0.3980 & -25.1153 \\
\hline$p_{50}$ & 0.0030 & 0.0003 & 10.0462 \\
\hline$p_{01}$ & 0.1551 & -0.2329 & -0.2640 \\
\hline$p_{11}$ & 10.2475 & 2.2998 & 0.9713 \\
\hline$p_{21}$ & -30.8342 & -8.6669 & -1.3299 \\
\hline$p_{31}$ & 41.1734 & 12.7345 & 0.8867 \\
\hline$p_{41}$ & -20.5868 & -6.3676 & -0.0001 \\
\hline
\end{tabular}

Constants $p_{i 0}(i=0,1, \ldots, 5)$ and $p_{j 1}(i=0,1, \ldots, 4)$ of Eq. (7) for specimen FTG-wet-1-16

\begin{tabular}{c|c|c|c}
\hline \multirow{2}{*}{ Constant } & \multicolumn{2}{|c|}{$\begin{array}{c}K_{1}^{(\mathrm{f})}, \\
\mathrm{MPa} \sqrt{\mathrm{mm}}(\mathrm{mm})^{-i \varepsilon}\end{array}$} & $\begin{array}{c}K_{\text {III }}^{(\mathrm{f})}, \\
\mathrm{MPa} \sqrt{\mathrm{mm}}\end{array}$ \\
\hline$p_{00}$ & 0.1739 & 0.0243 & -0.0318 \\
\hline$p_{10}$ & -0.6231 & -0.1742 & 1.2820 \\
\hline$p_{20}$ & 0.9545 & 0.5682 & -8.7153 \\
\hline$p_{30}$ & -0.6622 & -0.7887 & 22.6765 \\
\hline$p_{40}$ & 0.3315 & 0.3959 & -25.2991 \\
\hline$p_{50}$ & -0.0008 & -0.0012 & 10.1195 \\
\hline$p_{01}$ & 0.1576 & -0.2308 & -0.2609 \\
\hline$p_{11}$ & 10.1001 & 2.2774 & 0.9645 \\
\hline$p_{21}$ & -30.3596 & -8.5678 & -1.3279 \\
\hline$p_{31}$ & 40.5179 & 12.5806 & 0.8848 \\
\hline$p_{41}$ & -20.2583 & -6.2901 & 0.0004 \\
\hline
\end{tabular}

of load and displacement were recorded during the tests to produce load-displacement curves, as presented in Fig. S9 for each specimen. Each precipitous load drop in the curve indicates unstable delamination propagation. When the load decreased in a continuous fashion, the delamination propagated stably. The first delamination propagation (first load drop) occurred for $42 \mathrm{~N} \leq P \leq 45 \mathrm{~N}$, except for specimen FT-wet-1-04. In that case, the load reached $50 \mathrm{~N}$ before abruptly decreasing. In addition, the initial decrease in the

Table S32

Constants $d_{i}(i=0,1,2, \ldots, 14)$ of Eq. (9) for specimen FTG-wet-1-09

\begin{tabular}{c|c|c|c}
\hline \multirow{2}{*}{ Constant } & \multicolumn{2}{|c|}{$\begin{array}{c}K_{1}^{(\mathrm{r})}, \\
\mathrm{MPa} \sqrt{\mathrm{mm}}(\mathrm{mm})^{-i \varepsilon}\end{array}$} & $\begin{array}{c}K_{\mathrm{III}}^{(\mathrm{r})}, \\
\mathrm{MPa} \sqrt{\mathrm{mm}}\end{array}$ \\
\hline$d_{0}$ & -5.3020 & 0.4139 & 8.8304 \\
\hline$d_{1}$ & 247.6614 & -47.8829 & -332.4229 \\
\hline$d_{2}$ & $-5.9671 \times 10^{3}$ & $1.3434 \times 10^{3}$ & 7.3111 \\
\hline$d_{3}$ & $8.6005 \times 10^{4}$ & $-1.9917 \times 10^{4}$ & $-9.3416 \times 10^{3}$ \\
\hline$d_{4}$ & $-7.8837 \times 10^{5}$ & $1.8532 \times 10^{5}$ & $7.5148 \times 10^{4}$ \\
\hline$d_{5}$ & $4.8598 \times 10^{6}$ & $-1.1556 \times 10^{6}$ & $-4.0265 \times 10^{5}$ \\
\hline$d_{6}$ & $-2.0918 \times 10^{7}$ & $5.0196 \times 10^{6}$ & $1.4883 \times 10^{6}$ \\
\hline$d_{7}$ & $6.4346 \times 10^{7}$ & $-1.5551 \times 10^{7}$ & $-3.8714 \times 10^{7}$ \\
\hline$d_{8}$ & $-1.4313 \times 10^{8}$ & $3.4779 \times 10^{7}$ & $7.1358 \times 10^{7}$ \\
\hline$d_{9}$ & $2.3051 \times 10^{8}$ & $-5.6235 \times 10^{7}$ & $-9.2623 \times 10^{7}$ \\
\hline$d_{10}$ & $-2.6596 \times 10^{8}$ & $6.5070 \times 10^{7}$ & $8.2734 \times 10^{7}$ \\
\hline$d_{11}$ & $2.1416 \times 10^{8}$ & $-5.2500 \times 10^{7}$ & $-4.8383 \times 10^{7}$ \\
\hline$d_{12}$ & $-1.1423 \times 10^{8}$ & $2.8034 \times 10^{7}$ & $1.6670 \times 10^{7}$ \\
\hline$d_{13}$ & $3.6246 \times 10^{7}$ & $-8.9005 \times 10^{6}$ & $-2.5646 \times 10^{6}$ \\
\hline$d_{14}$ & $-5.1781 \times 10^{6}$ & $1.2715 \times 10^{6}$ & -6.1223 \\
\hline & & \multicolumn{2}{|}{}
\end{tabular}


Constants $d_{i}(i=0,1,2, \ldots, 14)$ of Eq. (9) for specimen FTG-wet-1-10

\begin{tabular}{|c|c|c|c|}
\hline Constant & \multicolumn{2}{|c|}{$\mathrm{MPa} \sqrt{\mathrm{mm}}(\mathrm{mm})^{-i \varepsilon}$} & $\begin{array}{c}K_{\mathrm{III}}^{(\mathrm{r})}, \\
\mathrm{MPa} \sqrt{\mathrm{mm}}\end{array}$ \\
\hline$d_{0}$ & -5.4504 & 0.4254 & 9.0570 \\
\hline$d_{1}$ & 254.7753 & -49.2489 & -340.5976 \\
\hline$d_{2}$ & $-6.1407 \times 10^{3}$ & $1.3819 \times 10^{3}$ & $7.4863 \times 10^{3}$ \\
\hline$d_{3}$ & $8.8522 \times 10^{4}$ & $-2.0493 \times 10^{4}$ & $-9.5620 \times 10^{4}$ \\
\hline$d_{4}$ & $-8.1152 \times 10^{5}$ & $1.9071 \times 10^{5}$ & $7.6903 \times 10^{5}$ \\
\hline$d_{5}$ & $5.0028 \times 10^{6}$ & $-1.1894 \times 10^{6}$ & $-4.1199 \times 10^{6}$ \\
\hline$d_{6}$ & $-2.1535 \times 10^{7}$ & $5.1668 \times 10^{6}$ & $1.5227 \times 10^{7}$ \\
\hline$d_{7}$ & $6.6245 \times 10^{7}$ & $-1.6008 \times 10^{7}$ & $-3.9605 \times 10^{7}$ \\
\hline$d_{8}$ & $-1.4736 \times 10^{8}$ & $3.5802 \times 10^{7}$ & $7.2996 \times 10^{7}$ \\
\hline$d_{9}$ & $2.3732 \times 10^{8}$ & $-5.7891 \times 10^{7}$ & $-9.4745 \times 10^{7}$ \\
\hline$d_{10}$ & $-2.7382 \times 10^{8}$ & $6.6988 \times 10^{7}$ & $8.4627 \times 10^{7}$ \\
\hline$d_{11}$ & $2.2049 \times 10^{8}$ & $-5.4047 \times 10^{7}$ & $-4.9489 \times 10^{7}$ \\
\hline$d_{12}$ & $-1.1761 \times 10^{8}$ & $2.8861 \times 10^{7}$ & $1.7051 \times 10^{7}$ \\
\hline$d_{13}$ & $3.7318 \times 10^{8}$ & $-9.1628 \times 10^{6}$ & $-2.6230 \times 10^{6}$ \\
\hline$d_{14}$ & $-5.3312 \times 10^{8}$ & $1.3090 \times 10^{6}$ & -60.8341 \\
\hline
\end{tabular}

load occurred at a displacement value of about $9 \mathrm{~mm}$, except for specimen FT-wet-1-04. In that case, it occurred at more than $11 \mathrm{~mm}$. For a given value of displacement, dur-

Table S35

Constants $d_{i}(i=0,1,2, \ldots, 14)$ of Eq. (9) for specimen FTG-wet-1-12

\begin{tabular}{c|c|c|c}
\hline Constant & \multicolumn{2}{|c|}{$\begin{array}{c}(\mathrm{r}) \\
\mathrm{MPa} \sqrt{\mathrm{mm}}(\mathrm{mm})^{-i \varepsilon}\end{array}$} & $\begin{array}{c}K_{\mathrm{III}}^{(\mathrm{r})}, \\
\mathrm{MPa} \sqrt{\mathrm{mm}}\end{array}$ \\
\hline$d_{0}$ & -5.3256 & 0.4049 & 8.7896 \\
\hline$d_{1}$ & 247.0653 & -47.9206 & -329.6842 \\
\hline$d_{2}$ & $-5.9457 \times 10^{3}$ & $1.3452 \times 10^{3}$ & $7.2518 \times 10^{3}$ \\
\hline$d_{3}$ & $8.5720 \times 10^{4}$ & $-1.9934 \times 10^{4}$ & $-9.2673 \times 10^{4}$ \\
\hline$d_{4}$ & $-7.8606 \times 10^{5}$ & $1.8540 \times 10^{5}$ & $7.4554 \times 10^{5}$ \\
\hline$d_{5}$ & $4.8470 \times 10^{6}$ & $-1.1558 \times 10^{6}$ & $-3.9948 \times 10^{6}$ \\
\hline$d_{6}$ & $-2.0867 \times 10^{7}$ & $5.0195 \times 10^{6}$ & $1.4766 \times 10^{7}$ \\
\hline$d_{7}$ & $6.4199 \times 10^{7}$ & $-1.5549 \times 10^{7}$ & $-3.8410 \times 10^{7}$ \\
\hline$d_{8}$ & $-1.4282 \times 10^{8}$ & $3.4771 \times 10^{7}$ & $7.0800 \times 10^{7}$ \\
\hline$d_{9}$ & $2.3001 \times 10^{8}$ & $-5.6218 \times 10^{7}$ & $-9.1899 \times 10^{7}$ \\
\hline$d_{10}$ & $-2.6540 \times 10^{8}$ & $6.5049 \times 10^{7}$ & $8.2090 \times 10^{7}$ \\
\hline$d_{11}$ & $2.1372 \times 10^{8}$ & $-5.2481 \times 10^{7}$ & $-4.8009 \times 10^{7}$ \\
\hline$d_{12}$ & $-1.1399 \times 10^{8}$ & $2.8024 \times 10^{7}$ & $1.6543 \times 10^{7}$ \\
\hline$d_{13}$ & $3.6172 \times 10^{7}$ & $-8.8973 \times 10^{6}$ & $-2.5457 \times 10^{6}$ \\
\hline$d_{14}$ & $-5.1675 \times 10^{6}$ & $1.2710 \times 10^{6}$ & 183.7385 \\
\hline & & &
\end{tabular}

Constants $d_{i}(i=0,1,2, \ldots, 14)$ of Eq. (9) for specimen FTG-wet-1-11

\begin{tabular}{c|c|c|c}
\hline \multirow{2}{*}{ Constant } & \multicolumn{2}{|c|}{$K_{1}^{(\mathrm{r})}}$, & $K_{2}^{(\mathrm{r})}$, \\
& \multicolumn{2}{|c|}{$\mathrm{MPa} \sqrt{\mathrm{mm}}(\mathrm{mm})^{-i \varepsilon}$} & $\begin{array}{c}K_{\mathrm{III}}^{(\mathrm{r})}, \\
\mathrm{MPa} \sqrt{\mathrm{mm}}\end{array}$ \\
\hline$d_{0}$ & -5.3021 & 0.4094 & 8.7764 \\
\hline$d_{1}$ & 247.1880 & -47.8327 & -329.4974 \\
\hline$d_{2}$ & $-5.9554 \times 10^{3}$ & $1.3428 \times 10^{3}$ & $7.2421 \times 10^{3}$ \\
\hline$d_{3}$ & $8.5861 \times 10^{4}$ & $-1.9913 \times 10^{4}$ & $-9.2503 \times 10^{4}$ \\
\hline$d_{4}$ & $-7.8725 \times 10^{5}$ & $1.8531 \times 10^{5}$ & $7.4396 \times 10^{5}$ \\
\hline$d_{5}$ & $4.8538 \times 10^{6}$ & $-1.1557 \times 10^{6}$ & $-3.9856 \times 10^{6}$ \\
\hline$d_{6}$ & $-2.0895 \times 10^{7}$ & $5.0204 \times 10^{6}$ & $1.4731 \times 10^{7}$ \\
\hline$d_{7}$ & $6.4280 \times 10^{7}$ & $-1.5554 \times 10^{7}$ & $-3.8314 \times 10^{7}$ \\
\hline$d_{8}$ & $-1.4299 \times 10^{8}$ & $3.4788 \times 10^{7}$ & $7.0617 \times 10^{7}$ \\
\hline$d_{9}$ & $2.3029 \times 10^{8}$ & $-5.6250 \times 10^{7}$ & $-9.1657 \times 10^{7}$ \\
\hline$d_{10}$ & $-2.6572 \times 10^{8}$ & $6.5089 \times 10^{7}$ & $8.1870 \times 10^{7}$ \\
\hline$d_{11}$ & $2.1397 \times 10^{8}$ & $-5.2515 \times 10^{7}$ & $-4.7878 \times 10^{7}$ \\
\hline$d_{12}$ & $-1.1413 \times 10^{8}$ & $2.8042 \times 10^{7}$ & $1.6497 \times 10^{7}$ \\
\hline$d_{13}$ & $3.6215 \times 10^{7}$ & $-8.9030 \times 10^{6}$ & $-2.5382 \times 10^{6}$ \\
\hline$d_{14}$ & $-5.1735 \times 10^{6}$ & $1.2718 \times 10^{6}$ & 61.8230 \\
\hline & & &
\end{tabular}

ing the stable delamination propagation phase, it appears that the delamination of specimen FT-wet-1-07 propagated at lower loads than the remainder of the specimens; whereas,

Table S36

Constants $d_{i}(i=0,1,2, \ldots, 14)$ of Eq. (9) for specimen FTG-wet-1-13

\begin{tabular}{c|c|c|c}
\hline Constant & \multicolumn{2}{|c|}{$\begin{array}{c}K_{1}^{(\mathrm{r})}, \\
\mathrm{MPa} \sqrt{\mathrm{mm}}(\mathrm{mm})^{-i \varepsilon}\end{array}$} & $\begin{array}{c}K_{\mathrm{III}}^{(\mathrm{r})}, \\
\mathrm{MPa} \sqrt{\mathrm{mm}}\end{array}$ \\
\hline$d_{0}$ & -5.4302 & 0.4176 & 8.9996 \\
\hline$d_{1}$ & 252.5470 & -48.9442 & -338.1650 \\
\hline$d_{2}$ & $-6.0797 \times 10^{3}$ & $1.3734 \times 10^{3}$ & $7.4392 \times 10^{3}$ \\
\hline$d_{3}$ & $8.7638 \times 10^{4}$ & $-2.0353 \times 10^{4}$ & $-9.5070 \times 10^{4}$ \\
\hline$d_{4}$ & $-8.0349 \times 10^{5}$ & $1.8932 \times 10^{5}$ & $7.6485 \times 10^{5}$ \\
\hline$d_{5}$ & $4.9538 \times 10^{6}$ & $-1.1803 \times 10^{6}$ & $-4.0983 \times 10^{6}$ \\
\hline$d_{6}$ & $-2.1325 \times 10^{7}$ & $5.1262 \times 10^{6}$ & $1.5149 \times 10^{7}$ \\
\hline$d_{7}$ & $6.5603 \times 10^{7}$ & $-1.5880 \times 10^{7}$ & $-3.9406 \times 10^{7}$ \\
\hline$d_{8}$ & $-1.4593 \times 10^{8}$ & $3.5513 \times 10^{7}$ & $7.2636 \times 10^{7}$ \\
\hline$d_{9}$ & $2.3502 \times 10^{8}$ & $-5.7419 \times 10^{7}$ & $-9.4281 \times 10^{7}$ \\
\hline$d_{10}$ & $-2.7117 \times 10^{8}$ & $6.6439 \times 10^{7}$ & $8.4216 \times 10^{7}$ \\
\hline$d_{11}$ & $2.1837 \times 10^{8}$ & $-5.3603 \times 10^{7}$ & $-4.9250 \times 10^{7}$ \\
\hline$d_{12}$ & $-1.1647 \times 10^{8}$ & $2.8624 \times 10^{7}$ & $1.6969 \times 10^{7}$ \\
\hline$d_{13}$ & $3.6958 \times 10^{7}$ & $-9.0876 \times 10^{6}$ & $-2.6106 \times 10^{6}$ \\
\hline$d_{14}$ & $-5.2798 \times 10^{6}$ & $1.2982 \times 10^{6}$ & 0.0312 \\
\hline & & &
\end{tabular}


Constants $d_{i}(i=0,1,2, \ldots, 14)$ of Eq. (9) for specimen FTG-wet-1-14

\begin{tabular}{c|c|c|c}
\hline Constant & \multicolumn{2}{|c|}{$\begin{array}{c}K_{1}^{(\mathrm{r})}, \\
\mathrm{MPa} \sqrt{\mathrm{mm}}(\mathrm{mm})^{-i \varepsilon}\end{array}$} & $\begin{array}{c}K_{\mathrm{III}}^{(\mathrm{r})}, \\
\mathrm{MPa} \sqrt{\mathrm{mm}}\end{array}$ \\
\hline$d_{0}$ & -5.5793 & 0.4299 & 9.2321 \\
\hline$d_{1}$ & 260.0183 & -50.3048 & -346.5374 \\
\hline$d_{2}$ & $-6.2642 \times 10^{3}$ & $1.4125 \times 10^{3}$ & $7.6168 \times 10^{3}$ \\
\hline$d_{3}$ & $9.0316 \times 10^{4}$ & $-2.0947 \times 10^{4}$ & $-9.7291 \times 10^{4}$ \\
\hline$d_{4}$ & $-8.2812 \times 10^{5}$ & $1.9493 \times 10^{5}$ & $7.8248 \times 10^{5}$ \\
\hline$d_{5}$ & $5.1059 \times 10^{6}$ & $-1.2156 \times 10^{6}$ & $-4.1919 \times 10^{6}$ \\
\hline$d_{6}$ & $-2.1980 \times 10^{7}$ & $5.2808 \times 10^{6}$ & $1.5493 \times 10^{7}$ \\
\hline$d_{7}$ & $6.7621 \times 10^{7}$ & $-1.6361 \times 10^{7}$ & $-4.0297 \times 10^{7}$ \\
\hline$d_{8}$ & $-1.5042 \times 10^{8}$ & $3.6592 \times 10^{7}$ & $7.4273 \times 10^{7}$ \\
\hline$d_{9}$ & $2.4226 \times 10^{8}$ & $-5.9167 \times 10^{7}$ & $-9.6401 \times 10^{7}$ \\
\hline$d_{10}$ & $-2.7953 \times 10^{8}$ & $6.8464 \times 10^{7}$ & $8.6106 \times 10^{7}$ \\
\hline$d_{11}$ & $2.2509 \times 10^{8}$ & $-5.5238 \times 10^{7}$ & $-5.0354 \times 10^{7}$ \\
\hline$d_{12}$ & $-1.2006 \times 10^{8}$ & $2.9497 \times 10^{7}$ & $1.7349 \times 10^{7}$ \\
\hline$d_{13}$ & $3.8097 \times 10^{7}$ & $-9.3648 \times 10^{6}$ & $-2.6688 \times 10^{6}$ \\
\hline$d_{14}$ & $-5.4424 \times 10^{6}$ & $1.3378 \times 10^{6}$ & -58.4536 \\
\hline
\end{tabular}

for specimen FT-wet-1-05, propagation occurred for higher loads than those of the other specimens.

During the tests, values of temperature and relative humidity (RH) were recorded. In Table S41, the temperature

Constants $d_{i}(i=0,1,2, \ldots, 14)$ of Eq. (9)

Table S39 for specimen FTG-wet-1-16

\begin{tabular}{|c|c|c|c|}
\hline Constant & \multicolumn{2}{|c|}{$\mathrm{MPa} \sqrt{\mathrm{mm}}(\mathrm{mm})^{-i \varepsilon}$} & $\begin{array}{c}K_{\mathrm{III}}^{(\mathrm{r})}, \\
\mathrm{MPa} \sqrt{\mathrm{mm}}\end{array}$ \\
\hline$d_{0}$ & -5.4714 & 0.4259 & 9.1018 \\
\hline$d_{1}$ & 255.3895 & -49.3939 & -342.4768 \\
\hline$d_{2}$ & $-6.1528 \times 10^{3}$ & $1.3859 \times 10^{3}$ & $7.5320 \times 10^{3}$ \\
\hline$d_{3}$ & $8.8687 \times 10^{4}$ & $-2.0546 \times 10^{4}$ & $-9.6239 \times 10^{4}$ \\
\hline$d_{4}$ & $-8.1301 \times 10^{5}$ & $1.9116 \times 10^{5}$ & $7.7418 \times 10^{5}$ \\
\hline$d_{5}$ & $5.0120 \times 10^{6}$ & $-1.1920 \times 10^{6}$ & $-4.1481 \times 10^{6}$ \\
\hline$d_{6}$ & $-2.1574 \times 10^{7}$ & $5.1776 \times 10^{6}$ & $1.5333 \times 10^{7}$ \\
\hline$d_{7}$ & $6.6365 \times 10^{7}$ & $-1.6040 \times 10^{7}$ & $-3.9883 \times 10^{7}$ \\
\hline$d_{8}$ & $-1.4763 \times 10^{8}$ & $3.5874 \times 10^{7}$ & $7.3513 \times 10^{7}$ \\
\hline$d_{9}$ & $2.3774 \times 10^{8}$ & $-5.8005 \times 10^{7}$ & $-9.5419 \times 10^{7}$ \\
\hline$d_{10}$ & $-2.7431 \times 10^{8}$ & $6.7118 \times 10^{7}$ & $8.5231 \times 10^{7}$ \\
\hline$d_{11}$ & $2.2089 \times 10^{8}$ & $-5.4152 \times 10^{7}$ & $-4.9844 \times 10^{7}$ \\
\hline$d_{12}$ & $-1.1782 \times 10^{8}$ & $2.8917 \times 10^{7}$ & $1.7174 \times 10^{7}$ \\
\hline$d_{13}$ & $3.7385 \times 10^{7}$ & $-9.1807 \times 10^{6}$ & $-2.6421 \times 10^{6}$ \\
\hline$d_{14}$ & $-5.3408 \times 10^{6}$ & $1.3115 \times 10^{6}$ & -0.0156 \\
\hline
\end{tabular}

Constants $d_{i}(i=0,1,2, \ldots, 14)$ of Eq. (9) for specimen FTG-wet-1-15

\begin{tabular}{|c|c|c|c|}
\hline Constant & $\begin{array}{l}K_{1}^{(\mathrm{r})}, \\
\mathrm{MPa} \sqrt{ }\end{array}$ & $\mathrm{MPa} \sqrt{\mathrm{mm}}(\mathrm{mm})^{-i \varepsilon}$ & $\begin{array}{c}K_{\mathrm{III}}^{(\mathrm{r})}, \\
\mathrm{MPa} \sqrt{\mathrm{mm}}\end{array}$ \\
\hline$d_{0}$ & -5.3034 & 0.4115 & 8.8226 \\
\hline$d_{1}$ & 247.1732 & -47.8483 & -332.0231 \\
\hline$d_{2}$ & $-5.9522 \times 10^{3}$ & $1.3422 \times 10^{3}$ & $7.3051 \times 10^{3}$ \\
\hline$d_{3}$ & $8.5789 \times 10^{4}$ & $-1.9893 \times 10^{4}$ & $-9.3361 \times 10^{4}$ \\
\hline$d_{4}$ & $-7.8643 \times 10^{5}$ & $1.8504 \times 10^{5}$ & $7.5114 \times 10^{5}$ \\
\hline$d_{5}$ & $4.8481 \times 10^{6}$ & $-1.1537 \times 10^{6}$ & $-4.0250 \times 10^{6}$ \\
\hline$d_{6}$ & $-2.0868 \times 10^{7}$ & $5.0106 \times 10^{6}$ & $1.4879 \times 10^{7}$ \\
\hline$d_{7}$ & $6.4194 \times 10^{7}$ & $-1.5522 \times 10^{7}$ & $-3.8704 \times 10^{7}$ \\
\hline$d_{8}$ & $-1.4279 \times 10^{8}$ & $3.4712 \times 10^{7}$ & $7.1342 \times 10^{7}$ \\
\hline$d_{9}$ & $2.2996 \times 10^{8}$ & $-5.6125 \times 10^{7}$ & $-9.2603 \times 10^{7}$ \\
\hline$d_{10}$ & $-2.6533 \times 10^{8}$ & $6.4941 \times 10^{7}$ & $8.2717 \times 10^{7}$ \\
\hline$d_{11}$ & $2.1366 \times 10^{8}$ & $-5.2395 \times 10^{7}$ & $-4.8374 \times 10^{7}$ \\
\hline$d_{12}$ & $-1.1396 \times 10^{8}$ & $2.7978 \times 10^{7}$ & $1.6667 \times 10^{7}$ \\
\hline$d_{13}$ & $3.6161 \times 10^{7}$ & $-8.8827 \times 10^{6}$ & $-2.5642 \times 10^{6}$ \\
\hline$d_{14}$ & $-5.1659 \times 10^{6}$ & $1.2690 \times 10^{6}$ & 0.1980 \\
\hline
\end{tabular}

and RH values at the beginning, middle and end of the tests are presented. The ASTM standard prescribes $\vartheta=23 \pm 3^{\circ} \mathrm{C}$ and $\mathrm{RH}=50 \pm 10 \%$. The temperature values in the middle of the test were not recorded for specimens FT-wet-1-07

Table S40

Constants $d_{i}(i=0,1,2, \ldots, 14)$ of Eq. (9) for specimen FTG-wet-1-17

\begin{tabular}{c|c|c|c}
\hline Constant & \multicolumn{2}{|c|}{$\begin{array}{c}K_{1}^{(\mathrm{r})}, \\
\mathrm{MPa} \sqrt{\mathrm{mm}}(\mathrm{mm})^{-i \varepsilon}\end{array}$} & $\begin{array}{c}K_{\mathrm{III}}^{(\mathrm{r})}, \\
\mathrm{MPa} \sqrt{\mathrm{mm}}\end{array}$ \\
\hline$d_{0}$ & -5.4937 & 0.4225 & 9.1157 \\
\hline$d_{1}$ & 255.3185 & -49.5157 & -342.7493 \\
\hline$d_{2}$ & $-6.1447 \times 10^{3}$ & $1.3891 \times 10^{3}$ & $7.5431 \times 10^{3}$ \\
\hline$d_{3}$ & $8.8565 \times 10^{4}$ & $-2.0582 \times 10^{4}$ & $-9.6422 \times 10^{4}$ \\
\hline$d_{4}$ & $-8.1196 \times 10^{5}$ & $1.9141 \times 10^{5}$ & $7.7584 \times 10^{5}$ \\
\hline$d_{5}$ & $5.0059 \times 10^{6}$ & $-1.1932 \times 10^{6}$ & $-4.1576 \times 10^{6}$ \\
\hline$d_{6}$ & $-2.1548 \times 10^{7}$ & $5.1818 \times 10^{6}$ & $1.5370 \times 10^{7}$ \\
\hline$d_{7}$ & $6.6289 \times 10^{7}$ & $-1.6051 \times 10^{7}$ & $-3.9981 \times 10^{7}$ \\
\hline$d_{8}$ & $-1.4746 \times 10^{8}$ & $3.5894 \times 10^{7}$ & $7.3698 \times 10^{7}$ \\
\hline$d_{9}$ & $2.3748 \times 10^{8}$ & $-5.8034 \times 10^{7}$ & $-9.5662 \times 10^{7}$ \\
\hline$d_{10}$ & $-2.7400 \times 10^{8}$ & $6.7149 \times 10^{7}$ & $8.5451 \times 10^{7}$ \\
\hline$d_{11}$ & $2.2064 \times 10^{8}$ & $-5.4175 \times 10^{7}$ & $-4.9973 \times 10^{7}$ \\
\hline$d_{12}$ & $-1.1768 \times 10^{8}$ & $2.8928 \times 10^{7}$ & $1.7218 \times 10^{7}$ \\
\hline$d_{13}$ & $3.7344 \times 10^{7}$ & $-9.1843 \times 10^{6}$ & $-2.6489 \times 10^{6}$ \\
\hline$d_{14}$ & $-5.3348 \times 10^{6}$ & $1.3120 \times 10^{6}$ & 0.2844 \\
\hline & \multicolumn{2}{|c}{}
\end{tabular}


Table S41

Temperature and relative humidity during fracture toughness tests

\begin{tabular}{c|c|c|c|c|c|c}
\hline Specimen & $\vartheta_{\text {init }},{ }^{\circ} \mathrm{C}$ & $\vartheta_{\text {mid-test }},{ }^{\circ} \mathrm{C}$ & $\vartheta_{\text {fin }},{ }^{\circ} \mathrm{C}$ & $\mathrm{RH}_{\text {init }}, \%$ & $\mathrm{RH}_{\text {mid-test }}, \%$ & $\mathrm{RH}_{\text {fin }}, \%$ \\
\hline FT-wet-1-04 & 21.6 & 22.2 & 22.4 & 60.4 & 59.8 & 60.1 \\
\hline FT-wet-1-05 & 22.2 & 22.7 & 22.4 & 57.8 & 56.8 & 57.6 \\
\hline FT-wet-1-06 & 22.6 & 22.7 & 22.6 & 56.9 & 57.0 & 57.4 \\
\hline FT-wet-1-07 & 24.8 & - & 24.6 & - & - & - \\
\hline FT-wet-1-08 & 24.6 & - & 24.2 & - & - & - \\
\hline
\end{tabular}

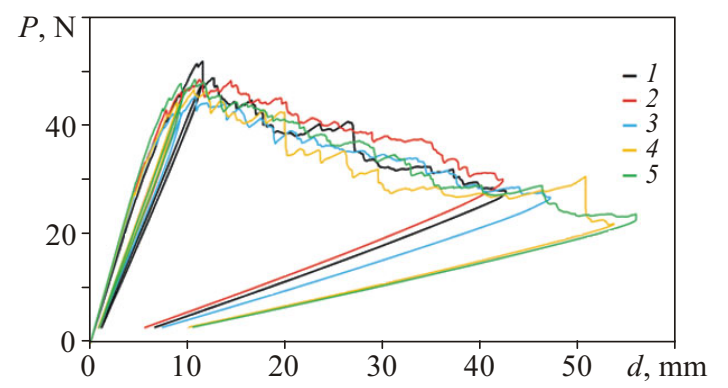

Fig. S9. Fracture toughness tests; load-displacement curves: FTwet-1-04 (1), FT-wet-1-05 (2), FT-wet-1-06 (3), FT-wet-1-07 (4), FT-wet-1-08 (5) (color online)

and FT-wet-1-08; there were also no values for RH recorded for these two specimens. All the temperature values are in the range specified in the ASTM standard. The RH values are also in the required range except for $\mathrm{RH}_{\text {init }}$ and $\mathrm{RH}_{\text {fin }}$ for specimen FT-wet-1-04. After the tests were carried out, using the optical mode of the Olympus confocal microscope, the delamination length was measured on both sides of each specimen. Those values are presented in Table S42, as $a_{\mathrm{f}}^{(\mathrm{f})}$ and $a_{\mathrm{f}}^{(\mathrm{b})}$, respectively, as well as their difference $\Delta_{\mathrm{f}}$. It may be observed that $\Delta_{\mathrm{f}}<2 \mathrm{~mm}$ for all specimens as required in the standards. For specimen FT-wet-1-04, the delamination length was not measured after the test using the confocal microscope. Based on these tests, a $G_{\mathrm{IR}}$-curve is presented in Fig. 9.

\section{S6. Fatigue delamination propagation tests}

Fatigue delamination propagation tests were carried out on five specimens at a cyclic displacement ratio $R_{\mathrm{d}}=0.1$

Fracture toughness tests; final delamination length

\begin{tabular}{c|c|c|c}
\hline Specimen & $a_{\mathrm{f}}^{(\mathrm{f})}, \mathrm{mm}$ & $a_{\mathrm{f}}^{(\mathrm{b})}, \mathrm{mm}$ & $\Delta_{\mathrm{f}}, \mathrm{mm}$ \\
\hline FT-wet-1-04 & - & - & - \\
\hline FT-wet-1-05 & 114.60 & 113.35 & 1.25 \\
\hline FT-wet-1-06 & 121.79 & 121.91 & 0.12 \\
\hline FT-wet-1-07 & 134.23 & 135.06 & 0.83 \\
\hline FT-wet-1-08 & 135.26 & 134.48 & 0.78 \\
\hline
\end{tabular}

$C, \mathrm{~mm} / \mathrm{N}$

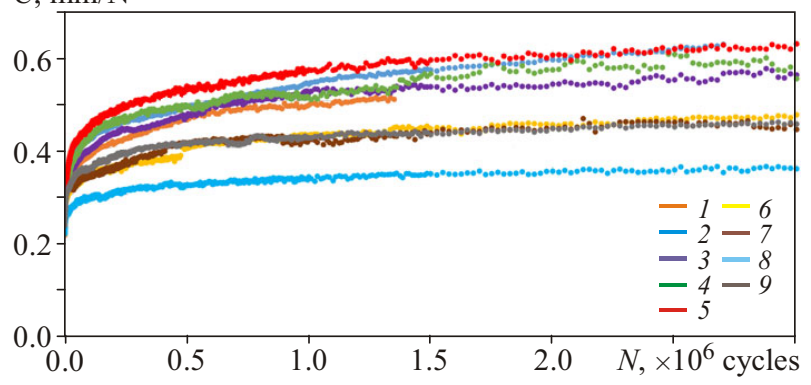

Fig. S10. Compliance values calculated by Eq. (13) for fatigue delamination tests: FTG-wet-1-09 (1), FTG-wet-1-10 (2), FTGwet-1-11 (3), FTG-wet-1-12 (4), FTG-wet-1-13 (5), FTG-wet-114 (6), FTG-wet-1-15 (7), FTG-wet-1-16 (8), FTG-wet-1-17 (9). $R_{\mathrm{d}}=0.10(1-5), 0.48(6-9)$ (color online)

and four specimens at $R_{\mathrm{d}}=0.48$. For all specimens, the compliance values calculated during the test are illustrated in Fig. S10 as a function of the cycle number $N$. It may be observed that there is scatter in the compliance values between specimens with the same displacement ratio $R_{\mathrm{d}}$. Note that for specimen FTG-wet-1-14, all compliance values are shown in the graph. As discussed in the paper, only those obtained for $N \leq 475000$ were taken into account in the calculations (see Table 1).

In Table S43, the constants $g$ and $n$ and the coefficient of determination $R^{2}$ for Eq. (14), found for each speci-

Table S43

For each specimen, fitting constants and coefficient of determination for Eq. (14)

\begin{tabular}{c|c|c|c}
\hline Specimen & $g$ & $n$ & $R^{2}$ \\
\hline FTG-wet-1-09 & 98.97 & 0.3386 & 0.9949 \\
\hline FTG-wet-1-10 & 98.82 & 0.3368 & 0.9955 \\
\hline FTG-wet-1-11 & 100.24 & 0.3575 & 0.9953 \\
\hline FTG-wet-1-12 & 100.84 & 0.3585 & 0.9955 \\
\hline FTG-wet-1-13 & 101.01 & 0.3730 & 0.9971 \\
\hline FTG-wet-1-14 & 106.70 & 0.4125 & 0.9926 \\
\hline FTG-wet-1-15 & 100.71 & 0.3403 & 0.9779 \\
\hline FTG-wet-1-16 & 109.08 & 0.4134 & 0.9946 \\
\hline FTG-wet-1-17 & 103.01 & 0.3745 & 0.9942 \\
\hline
\end{tabular}


For each specimen, fitting constants and coefficient of determination for Eq. (15) and number of sampling points

\begin{tabular}{c|c|c|c|c|c|c}
\hline Specimen & $A_{1}, \mathrm{~mm}$ & $A_{2}, \mathrm{~mm}$ & $B_{1}$ & $B_{2}$ & $R^{2}$ & Sample points \\
\hline FTG-wet-1-09 & 5.74 & 50.42 & -62.36 & 0.114 & 0.9975 & 734 \\
\hline FTG-wet-1-10 & 14.84 & 38.99 & 1.02 & 0.074 & 0.9965 & 794 \\
\hline FTG-wet-1-11 & 26.09 & 23.75 & 361.63 & 0.053 & 0.9963 & 806 \\
\hline FTG-wet-1-12 & 245.42 & -201.65 & 933.13 & 0.010 & 0.9946 & 806 \\
\hline FTG-wet-1-13 & 163.55 & -119.12 & 392.39 & 0.015 & 0.9985 & 806 \\
\hline FTG-wet-1-14 & 5.37 & -50.92 & 0.01 & 0.103 & 0.9964 & 601 \\
\hline FTG-wet-1-15 & 687.71 & -642.30 & 0.01 & 0.003 & 0.9700 & 541 \\
\hline FTG-wet-1-16 & 4.59 & 51.05 & 0.01 & 0.010 & 0.9918 & 806 \\
\hline FTG-wet-1-17 & 32.88 & 20.30 & 0.01 & 0.036 & 0.9944 & 806 \\
\hline
\end{tabular}

men, are presented. Using the compliance values obtained during each cycle, the delamination length was calculated by means of Eq. (14). In Table S43 for all specimens, it may be observed that $R^{2}$ is very high. Note that for specimen FTG-wet-1-15, there were 15 delamination length values used to determine $g$ and $n$; while for the other specimens, there were between 19 to 28 .

In Sect. 3.3, a method for obtaining a relation between the delamination length $a$ and the cycle number $N$ was described with a relation given in Eq. (15). For each specimen, in Table S44, the fitting constants $A_{1}, A_{2}, B_{1}$ and $B_{2}$ and the coefficient of determination $R^{2}$ of Eq. (15) are presented. The number of sampling points is also given in Table S44. It may be observed that $R^{2}$ is very high for all specimens; for specimen FTG-wet-1-15, it is slightly lower than the others. Here there is a lower number of sampling points. When data from all cycles for this specimen were used, a higher value of $R^{2}$, like those for other specimens was achieved. Nevertheless, $R^{2}$ for this specimen is still excellent. It may be concluded from the high $R^{2}$ values that the method for obtaining Eq. (15) is an effective tool for determining a relation between $a$ and $N$. In addition, from Fig. 7, for specimen FTG-wet-1-09, it may be seen that the visually measured delamination lengths, from the images taken during the test, fit well to the curve described by Eq. (15). Moreover, it may be observed in Table S44 that the values of the fitting constants of Eq. (15) are quite variable. For each specimen, different fitting constants were obtained which led to the best value of $R^{2}$.

In Table $\mathrm{S} 45$, the average cyclic loading ratios $R_{\mathrm{p}}$ for each specimen during the first 10000 cycles, are shown. For specimen FTG-wet-1-15, $R_{\mathrm{p}}$ is an average for the first 30000 to 40000 cycles. It may be observed that the cyclic load ratios differ somewhat from the cyclic displacement ratios. For values of $N>10000, R_{\mathrm{p}}$ does not change significantly. In addition, in Table $\mathrm{S} 45$, the delamination length at the end of the tests for all specimens, $a_{\mathrm{f}}^{(\mathrm{f})}$ and $a_{\mathrm{f}}^{(\mathrm{b})}$, at the front and back sides of the specimen, respectively, are shown. The difference between these lengths is denoted as $\Delta_{\mathrm{f}}$ and is also presented in Table S45. The values of $\Delta_{\mathrm{f}}$,

Cyclic load ratio for the first 10000 cycles in fatigue delamination propagation tests, final delamination lengths, their difference and initial temperature in the tests

\begin{tabular}{c|c|c|c|c|c}
\hline Specimen & $R_{\mathrm{p}}$, first 10k cycles & $a_{\mathrm{f}}^{(\mathrm{f})}, \mathrm{mm}$ & $a_{\mathrm{f}}^{(\mathrm{b})}, \mathrm{mm}$ & $\Delta_{\mathrm{f}}, \mathrm{mm}$ & $\vartheta_{\mathrm{i}},{ }^{\circ} \mathrm{C}$ \\
\hline FTG-wet-1-09 & 0.095 & 81.35 & 82.11 & 0.76 & 23.8 \\
\hline FTG-wet-1-10 & 0.092 & 82.81 & 83.79 & 0.98 & 22.3 \\
\hline FTG-wet-1-11 & 0.103 & 81.54 & 80.42 & 0.88 & 22.5 \\
\hline FTG-wet-1-12 & 0.087 & 83.31 & 83.20 & 0.11 & 24.3 \\
\hline FTG-wet-1-13 & 0.086 & 83.93 & 84.84 & 0.91 & 22.6 \\
\hline FTG-wet-1-14 & 0.444 & 74.08 & 75.23 & 1.15 & 22.3 \\
\hline FTG-wet-1-15 & $0.437(30 \mathrm{k}$ to 40k) & 77.14 & 77.46 & 0.32 & 23.8 \\
\hline FTG-wet-1-16 & 0.455 & 71.65 & 71.83 & 0.18 & 21.8 \\
\hline FTG-wet-1-17 & 0.452 & 76.67 & 77.47 & 0.80 & 22.6 \\
\hline
\end{tabular}


Table S46

Coefficient of determination for Eqs. (S9) and (S10)

\begin{tabular}{c|c}
\hline Equation No. & $R^{2}$ value \\
\hline$(\mathrm{S} 9)$ & 0.9529 \\
\hline$(\mathrm{S} 10)$ & 0.8478 \\
\hline
\end{tabular}

are less than $2 \mathrm{~mm}$ as required by the two fracture toughness test standards $[1,2]$. In addition, the initial temperature in the tests is also shown in Table S45 and is denoted as $\vartheta_{i}$. This temperature value was used in the thermal analyses described in Sect. 3.1 in the body of the paper. It should be noted that during the fatigue tests, the temperature may change by as much as $1.5^{\circ} \mathrm{C}$ from its initial value. It does not appear that this difference affects the calculated results of $G_{\text {Imax }}$ or $G_{\text {Imin }}$ in each cycle. To examine this point, a thermal analysis was carried out on specimen FTG-wet-1-17 with $\vartheta_{i}=25^{\circ} \mathrm{C}$. The greatest difference in $G_{\text {Imin }}$ in each cycle between this analysis and that when $\vartheta_{i}=22.6^{\circ} \mathrm{C}$ was $0.3 \%$. This calculation was carried out for $G_{\text {Imin }}$ rather than $G_{\text {Imax }}$, since the former is more sensitive to temperature changes.

Values of $G_{\text {Ithr }}$ and $\hat{G}_{\text {Ithr }}$ from Eqs. (19) and (20), respectively, were determined. As described in Sect. 4.3, these values may be found from Eqs. (25) and (26), respectively, once $\Delta G_{\text {Ieff thr }}$ and $\Delta \hat{G}_{\text {Ieff thr }}$ are known. To obtain $\Delta \hat{G}_{\text {Ieff thr }}$, all of the test results are plotted versus the cycle number $N$ on a log-log scale as illustrated in Fig. 13 for $\Delta \hat{G}_{\text {Ieff }}$. For each value of $R_{\mathrm{d}}$, a straight line was fit through each group of results. The intersection of the lines yields an initial value $\Delta \hat{G}_{\text {Ieff thr. }}^{(\mathrm{i})}$ This value of $\Delta \hat{G}_{\text {Ieff }}$ is the initial value used to obtain a final value $\Delta \hat{G}_{\text {Ieff thr }}^{(\mathrm{f})}$ when determining the master-curve. The expressions for the fitting lines are given as

$$
\Delta \hat{G}_{\text {Ieff }}=1.6671 N^{-0.1581},
$$

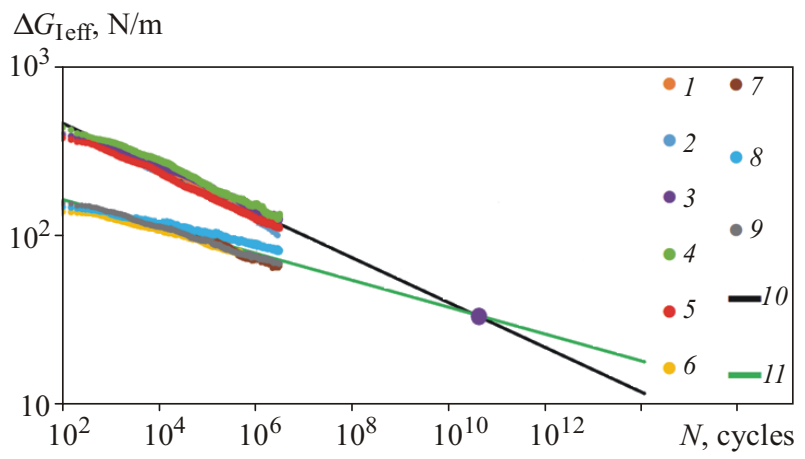

Fig. S11. Plot of $\Delta G_{\text {Ieff }}$ versus the cycle number $N$, for all fatigue specimens: FTG-wet-1-09 (1); FTG-wet-1-10 (2); FTG-wet1-11 (3); FTG-wet-1-12 (4); FTG-wet-1-13 (5); FTG-wet-1-14 (6); FTG-wet-1-15 (7); FTG-wet-1-16 (8); FTG-wet-1-17 (9); fit, $R_{\mathrm{d}}=0.10(10) ;$ fit, $R_{\mathrm{d}}=0.48(11)$ (color online)
Table S47

Final threshold values $\hat{G}_{\mathrm{Ithr}}^{(\mathrm{f})}$ and $G_{\mathrm{Ithr}}^{(\mathrm{f})}$ for $\Delta K_{1}$ or $\Delta \bar{K}_{2}$ as $f\left(G_{\mathrm{I}}\right)$ in Eq. (1)

\begin{tabular}{c|c|c|c|c}
\hline \multirow{2}{*}{ Specimen } & \multicolumn{2}{|c|}{$\Delta K_{1}$} & \multicolumn{2}{c}{$\Delta \bar{K}_{2}$} \\
\cline { 2 - 5 } & $\hat{G}_{\text {Ithr }}^{(\mathrm{f})}$ & $G_{\text {Ithr }}^{(\mathrm{f})}, \mathrm{N} / \mathrm{m}$ & $\hat{G}_{\text {Ithr }}^{(\mathrm{f})}$ & $G_{\text {Ithr }}^{(\mathrm{f})}, \mathrm{N} / \mathrm{m}$ \\
\hline FTG-wet-1-09 & 0.0548 & 39.9 & 0.0715 & 52.0 \\
\hline FTG-wet-1-10 & 0.0546 & 39.7 & 0.0711 & 51.7 \\
\hline FTG-wet-1-11 & 0.0559 & 40.7 & 0.0729 & 53.0 \\
\hline FTG-wet-1-12 & 0.0540 & 39.3 & 0.0704 & 51.2 \\
\hline FTG-wet-1-13 & 0.0537 & 39.1 & 0.0701 & 51.0 \\
\hline FTG-wet-1-14 & 0.1455 & 105.9 & 0.1898 & 138.1 \\
\hline FTG-wet-1-15 & 0.1417 & 103.1 & 0.1847 & 134.4 \\
\hline FTG-wet-1-16 & 0.1513 & 110.1 & 0.1973 & 143.6 \\
\hline FTG-wet-1-17 & 0.1496 & 108.9 & 0.1952 & 142.0 \\
\hline
\end{tabular}

$$
\Delta \hat{G}_{\text {Ieff }}=0.4616 N^{-0.1004}
$$

for $R_{\mathrm{d}}=0.1$ and $R_{\mathrm{d}}=0.48$, respectively. The coefficient of determination for Eqs. (S9) and (S10) is given in Table S46. The difference in $R^{2}$ for the two equations results from the difference between the behavior of specimen FTG-wet-116 for $R_{\mathrm{d}}=0.48$ and that of the other specimens for the same displacement ratio. Note that the initial threshold values are used to obtain the master-curves. This value is changed until a best fit is obtained between the fatigue data and the master-curve.

The same procedure for obtaining $\Delta \hat{G}_{\text {Ieff thr }}^{(\mathrm{i})}$, as explained in Sect. 4.3, may be carried out to determine an initial value $\Delta G_{\text {Ieff thr }}^{(\mathrm{i})}$. In may be noted that

$$
\Delta G_{\text {Ieff }}=\left(\sqrt{G_{\text {Imax }}}-\sqrt{G_{\text {Imin }}}\right)^{2} \text {. }
$$

With a plot of $\Delta G_{\text {Ieff }}$ versus $N$ as shown in Fig. S11, a value of $\Delta G_{\text {Ieff thr }}^{(\mathrm{i})}=33.98 \mathrm{~N} / \mathrm{m}$ was found. This value of $\Delta G_{\text {Ieff }}$ was used as an initial value in the master curve calculation for determining a final value $\Delta G_{\text {Ieff thr }}^{(\mathrm{f})}$. In Table S47, the final values of $G_{\text {Ithr }}$ and $\hat{G}_{\text {Ithr }}$ as calculated from Eqs. (25) and (26), respectively, are presented for all specimens. The dimensional results in Table S47 are reasonable. Perhaps they may be used in an industrial setting to prevent failure. Finally, it may be observed that there is a difference between the values of $G_{\mathrm{Ithr}}^{(\mathrm{f})}$ when calculated by means of the two master curves for $\Delta K_{1}$ and $\Delta \bar{K}_{2}$. This is to be expected since the curves are different as seen in Table 3.

\section{References}

1. ASTM D5528-13. Standard Test Method for Mode I Interlaminar Fracture Toughness of Unidirectional Fiber-Reinforced Polymer Matrix Composites. - West Conshohocken, PA: ASTM International, 2013.

2. ISO 15024. Fiber Reinforced Plastic Composites-Determination of Mode I Interlaminar Fracture Toughness, $G_{\text {Ic }}$, for Unidirectional Reinforced Materials. - Switzerland: ISO, 2001. 
3. ASTM D6115-97. Standard Test Method for Mode I Fatigue Delamination Growth Onset of Unidirectional Fiber-Reinforced Polymer Matrix Composites. - West Conshohocken, PA: ASTM International, 2011.

4. Miyagawa H., Sato C., Mase T., Drown E., Drzal L.T., Ikegami K. Transverse elastic modulus of carbon fibers measured by Raman spectroscopy // Mat. Sci. Eng. A. - 2005. - V. 412. - P. 88-92.

5. Torayca T300 data sheet. - Toray Carbon Fibers America, Inc. - http: //www.toraycfa.com/pdfs/T300DataSheet.pdf(Accessed 22.11.2015).

6. Bowles D.E., Tompkins S.S. Prediction of coefficients of thermal expansion for unidirectional composites // J. Compos. Mater. - 1989. V. 23. - P. 370-388.

7. Matweb - Material Property Data. - http://www.matweb.com/search/ DataSheet.aspx?MatGUID=3dbc779c2f034329b2836b02b9483629 (Accessed 09.04.2017).
8. Aboudi J. The generalized method of cells and high-fidelity generalized method of cells micromechanical models - A review // Mech. Adv. Mater. Struct. - 2004. - V. 11. - P. 329-366.

9. Mega M., Banks-Sills L. Mixed Mode Interface Fracture Toughness of a Multi-Directional Composite - UD/woven pair. - 2018 (in preparation).

10. Ting T.C.T. Anisotropic Elasticity: Theory and Applications. - New York: Oxford University Press, 1996.

11. DaVis. Version 8.3. - Göttingen, Germany: LaVision, 2015.

12. ABAQUS. Version 6.17. - Providence, RI: Dassault Systfiemes Simulia Corp., 2017.

13. Banks-Sills L. Interface Fracture and Delaminations in Composite Materials. - Cham, Switzerland: Springer, 2018
Received November 02, 2018, revised November 02,2018 , accepted November 09, 2018 